Florida International University FIU Digital Commons

\title{
Development of Micro Immunosensors to Study Genomic and Proteomic Biomarkers Related to Cancer and Alzheimer's Disease
}

Shradha V. Prabhulkar

Florida International University, sprab001@fiu.edu

DOI: $10.25148 /$ etd.FI1 1081601

Follow this and additional works at: https://digitalcommons.fiu.edu/etd

\section{Recommended Citation}

Prabhulkar, Shradha V., "Development of Micro Immunosensors to Study Genomic and Proteomic Biomarkers Related to Cancer and Alzheimer's Disease" (2011). FIU Electronic Theses and Dissertations. 467.

https://digitalcommons.fiu.edu/etd/467 


\section{FLORIDA INTERNATIONAL UNIVERSITY}

Miami, Florida

\section{DEVELOPMENT OF MICRO IMMUNOSENSORS TO STUDY GENOMIC AND PROTEOMIC BIOMARKERS RELATED TO CANCER AND ALZHEIMER'S DISEASE}

A dissertation submitted in partial fulfillment of the requirements for the degree of DOCTOR OF PHILOSOPHY

in

BIOMEDICAL ENGINEERING

by

Shradha Prabhulkar

2011 
To: Dean Amir Mirmiran

College of Engineering and Computing

This dissertation, written by Shradha Prabhulkar, and entitled Development of Micro Immunosensors to Study Genomic and Proteomic biomarkers related to Cancer and Alzheimer's disease, having been approved in respect to style and intellectual content, is referred to you for judgment.

We have read this dissertation and recommend that it be approved.

Anthony McGoron

Wei-Chiang Lin

$\begin{array}{r}\hline \text { Wei-Chiang Lin } \\ \hline \text { Helen Tempest }\end{array}$

Chenzhong Li, Major Professor

Date of Defense: July 14, 2011

The dissertation of Shradha Prabhulkar is approved.

\begin{tabular}{r} 
Dean Amir Mirmiran \\
College of Engineering and Computing \\
\\
\hline Interim Dean Kevin O'Shea \\
University Graduate School
\end{tabular}

Florida International University, 2011 


\section{DEDICATION}

I would like to dedicate this dissertation to my mother whose love and support has been the driving force of my life. 


\section{ACKNOWLEDGMENTS}

This dissertation has been made possible by the collective support of my family, friends and mentors. I would like to thank my parents and my sister who are my greatest support system in life. Their unconditional love and support have kept me going through the hard times. My mentor Dr. Chenzhong Li has taught me a great deal and will be a father-figure for life. He has always had my best interest at heart and has provided me with every opportunity to grow. I am grateful for all the kindness and patience that he has shown me over the years. I would also like to thank our collaborators Dr. John Cirrito and Dr. Melodie Naja for their invaluable advice in steering me towards the right direction. My lab members Dr. Subbiah Alwarappan, Chang Liu, Lia Hondrulis, Pratik Shah and Dr. Jennifer Mckenzie have been great friends as well as colleagues and have helped me not just with academics but to grow as a person. I would also like to thank the undergraduate students Rudolph Piatyszek, Gainie Cesar and David Neuman whose invaluable help has enabled me to finish my experiments on schedule. It was a privilege to mentor them and I feel that I have learned a great deal from them.

The friends I made in Miami have been my surrogate family and have helped me every step of the way. They have come and gone but each one of them has touched my

life in a special way and taught me to live life to the fullest. Their support and good wishes have been the driving force in helping me successfully finish my dissertation.

I truly thank all of them from the bottom of my heart. 


\title{
ABSTRACT OF THE DISSERTATION \\ DEVELOPMENT OF MICRO IMMUNOSENSORS TO STUDY GENOMIC AND \\ PROTEOMIC BIOMARKERS RELATED TO CANCER AND ALZHEIMER'S
}

DISEASE

by

\author{
Shradha Prabhulkar \\ Florida International University, 2011 \\ Miami, Florida \\ Professor Chenzhong Li, Major Professor
}

A report from the National Institutes of Health defines a disease biomarker as a "characteristic that is objectively measured and evaluated as an indicator of normal biologic processes, pathogenic processes, or pharmacologic responses to a therapeutic intervention." Early diagnosis is a crucial factor for incurable disease such as cancer and Alzheimer's disease (AD). During the last decade researchers have discovered that biochemical changes caused by a disease can be detected considerably earlier as compared to physical manifestations/symptoms. In this dissertation electrochemical detection was utilized as the detection strategy as it offers high sensitivity/specificity, ease of operation, and capability of miniaturization and multiplexed detection. Electrochemical detection of biological analytes is an established field, and has matured at a rapid pace during the last 50 years and adapted itself to advances in micro/nanofabrication procedures. Carbon fiber microelectrodes were utilized as the platform sensor due to their high signal to noise ratio, ease and low-cost of fabrication, 
biocompatibility, and active carbon surface which allows conjugation with biorecognition moieties.

This dissertation specifically focuses on the detection of 3 extensively validated biomarkers for cancer and AD. Firstly, vascular endothelial growth factor (VEGF) a cancer biomarker was detected using a one-step, reagentless immunosensing strategy. The immunosensing strategy allowed a rapid and sensitive means of VEGF detection with a detection limit of about $38 \mathrm{pg} / \mathrm{mL}$ with a linear dynamic range of $0-100 \mathrm{pg} / \mathrm{mL}$. Direct detection of AD-related biomarker amyloid beta $(\mathrm{A} \beta)$ was achieved by exploiting its inherent electroactivity. The quantification of the ratio of $A \beta 1-40 / 42$ (or $A \beta$ ratio) has been established as a reliable test to diagnose AD through human clinical trials. Triple barrel carbon fiber microelectrodes were used to simultaneously detect $\mathrm{A} \beta 1-40$ and $\mathrm{A} \beta 1$ 42 in cerebrospinal fluid from rats within a detection range of $100 \mathrm{nM}$ to $1.2 \mu \mathrm{M}$ and $400 \mathrm{nM}$ to $1 \mu \mathrm{M}$ respectively.

In addition, the release of DNA damage/repair biomarker 8-hydroxydeoxyguanine (8-OHdG) under the influence of reactive oxidative stress from single lung endothelial cell was monitored using an activated carbon fiber microelectrode. The sensor was used to test the influence of nicotine, which is one of the most biologically active chemicals present in cigarette smoke and smokeless tobacco. 


\section{TABLE OF CONTENTS}

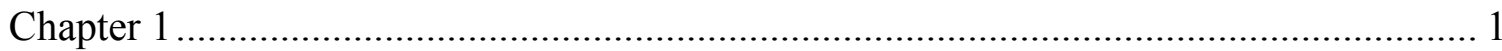

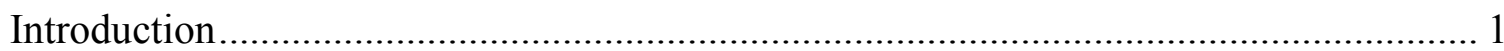

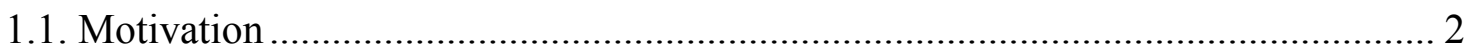

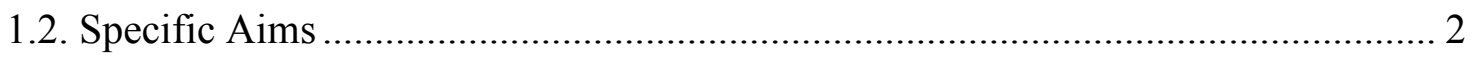

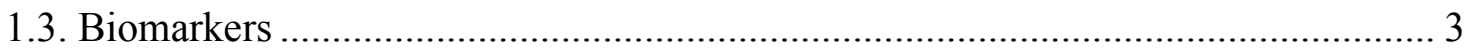

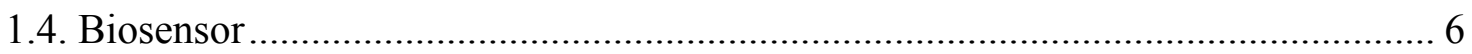

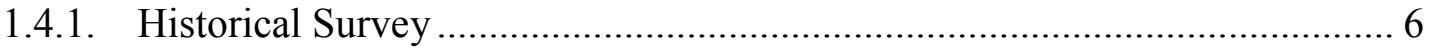

1.4.2. Definition and classification of biosensor ...................................................... 7

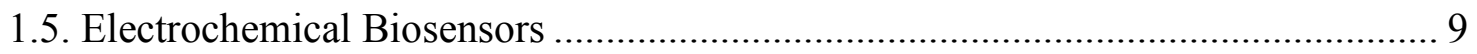

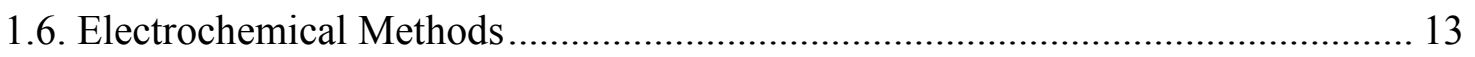

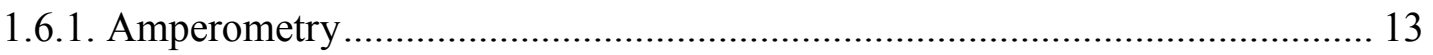

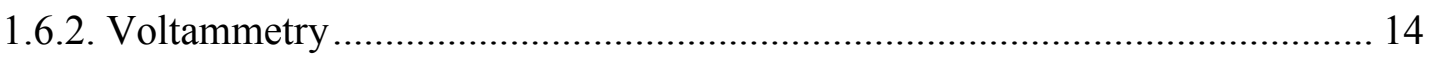

1.6.3 Linear sweep voltammetry / Cyclic voltammetry ………………………….... 15

1.6.4. Square wave voltammetry (SWV) ........................................................... 18

1.6.5. Constant potential amperometry (CPA) ………………………………....... 20

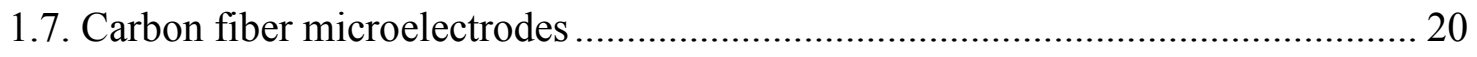

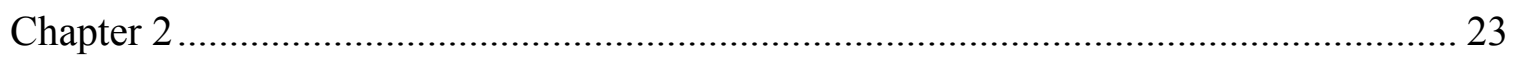

Amperometric micro-immunosensor for the detection of tumor biomarker ……............. 23

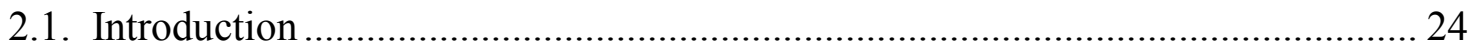

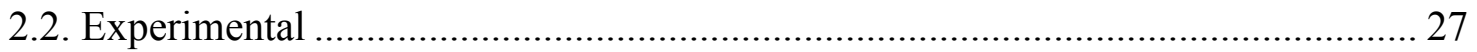

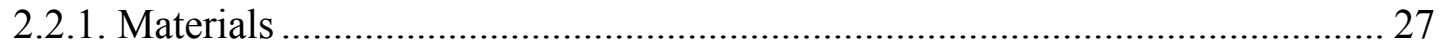

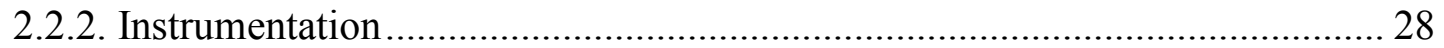

2.2.3. Preparation of micro immunosensor............................................................. 28 
2.2.3.1. Fabrication of disk-shaped carbon fiber microelectrodes ....................... 28

2.2.3.2. Insulation of carbon fiber microelectrodes ........................................ 29

2.2.3.3. Preparation of the ferrocene linked anti-VEGF (Fc-anti-VEGF) ............ 29

2.2.3.4. Modification of carbon fiber microelectrode surface ............................ 30

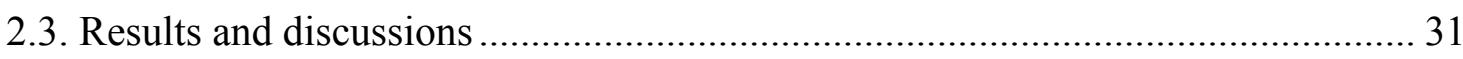

2.3.1. Characterization of disk shaped Carbon fiber microelectrodes .................... 31

2.3.1.1 Surface characterization using SEM................................................ 31

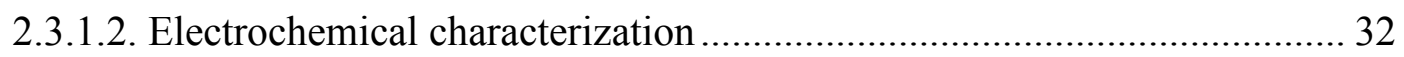

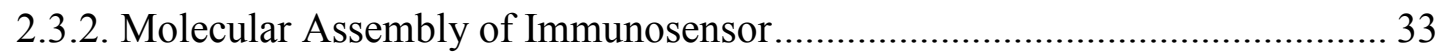

2.3.3. Optimization of immobilization conditions........................................... 35

2.3.3.1. Effect of incubation time ................................................................. 35

2.3.3.2. Amount of anti-VEGF immobilized carbon fiber microelectrode surface 36

2.3.4. Electrochemical Characterization of Fc-anti-VEGF modified Carbon fiber

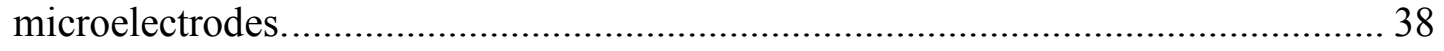

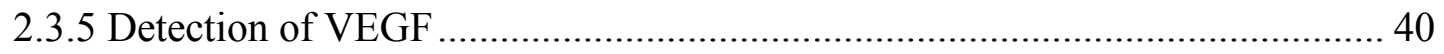

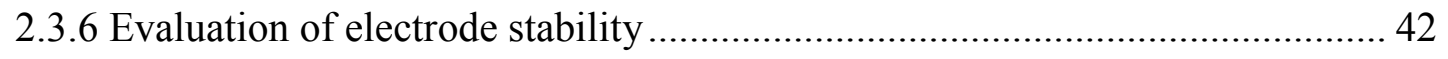

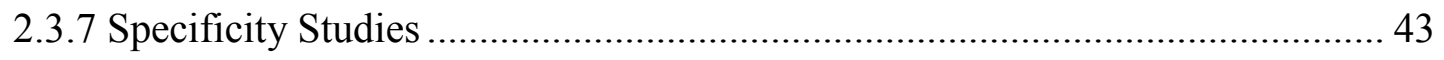

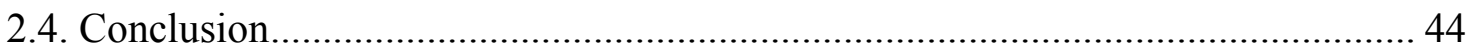

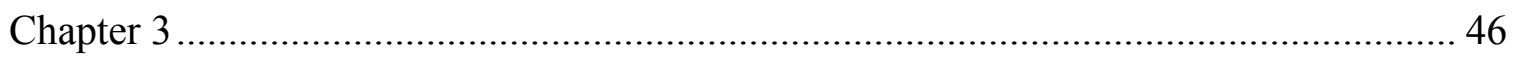

Electrochemical Sensor for Multiplex detection of Amyloid Beta 40 and 42 for

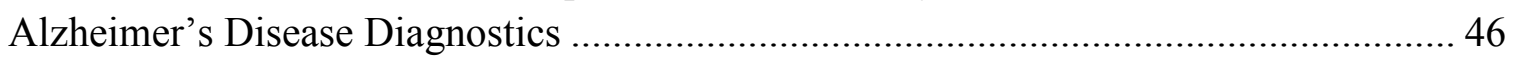

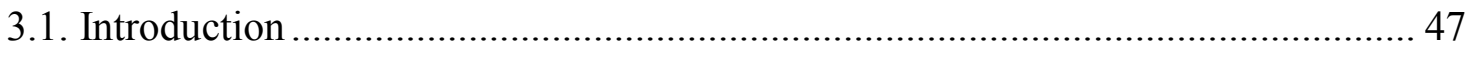

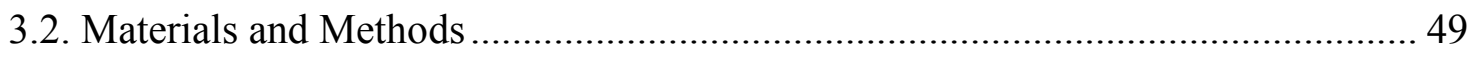

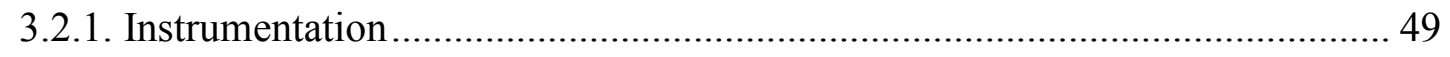

3.2.2. Fabrication of Triple Barrel $A \beta 1-40 / A \beta 1-42$ Sensor .................................... 50 
3.2.3. Measurement of $A \beta 1-40$ and $A \beta 1-42$ in cerebrospinal fluid (CSF) solutions 51

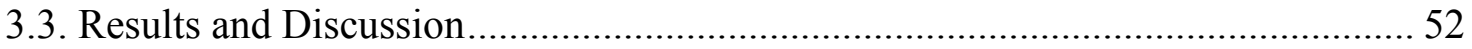

3.3.1. Molecular architecture of the immunosensor ............................................ 52

3.3.2. Characterization of fabricated triple-barrel carbon fiber microelectrodes ...... 53

3.3.3. Optimization of antibody immobilization parameters ................................ 55

3.3.4. Immunosensor Performance ................................................................... 59

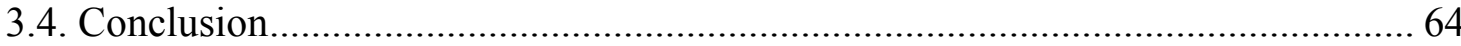

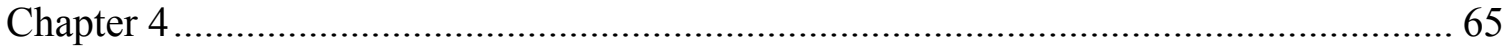

Assessment of oxidative DNA damage and repair at single cellular level via real-time

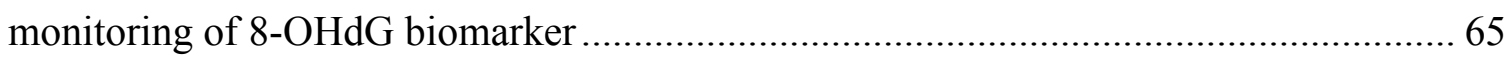

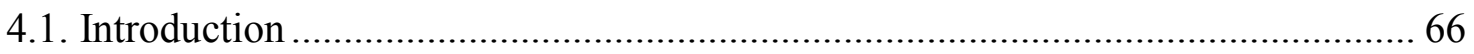

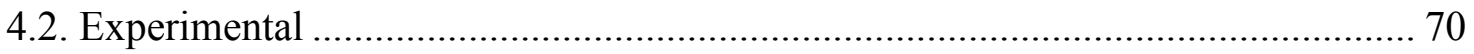

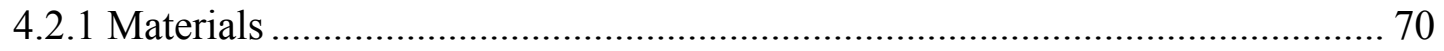

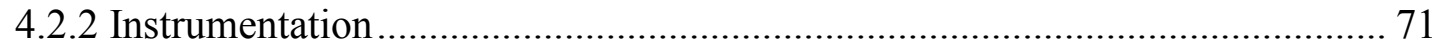

4.2.3. Preparation and activation of carbon fiber microelectrodes ......................... 71

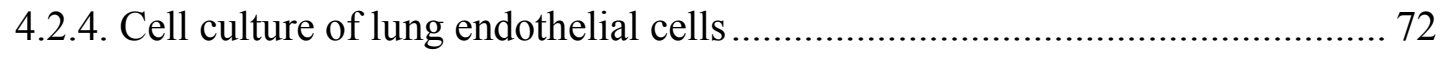

4.2.5. Calibration of microelectrode for 8-OHdG measurements ........................... 72

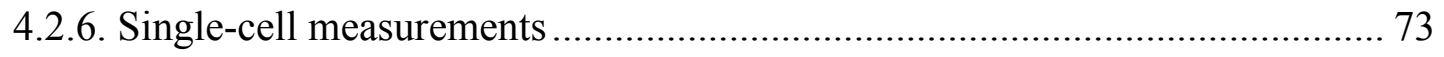

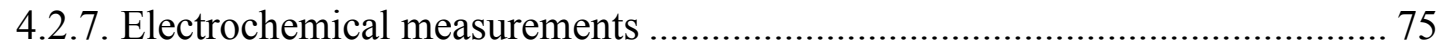

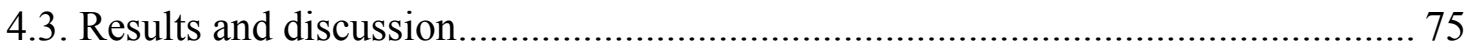

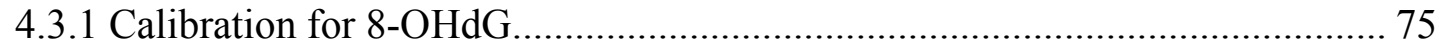

4.3.2. Detection of $8-\mathrm{OHdG}$ secretion from single lung epithelial cells ................... 77

4.3.3. Test effects of nicotine on oxidative DNA damage and repair / Test effects of

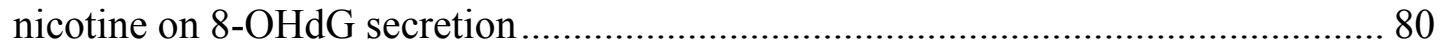

4.3.3.1. Concentration effects of nicotine .................................................. 81 
4.3.3.2. Time effects of 8-OHdG nicotine induced measurements.

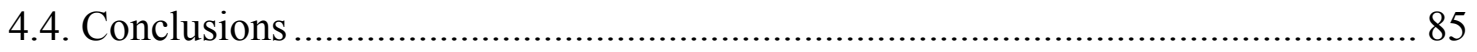

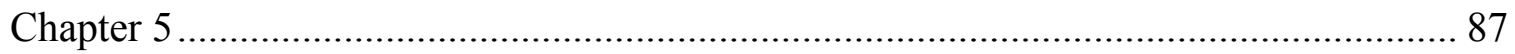

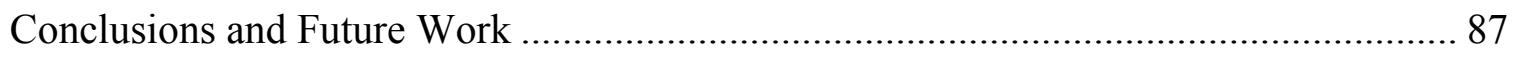

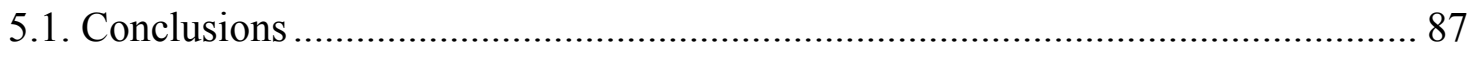

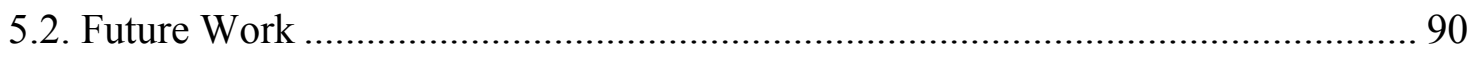

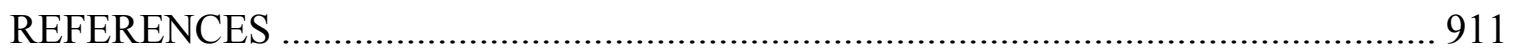

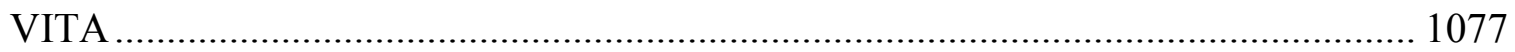




\section{LIST OF FIGURES}

Figure 1.1. A schematic illustration of the functional components of a biosensor..... 8

Figure 1.2. Voltage applied between working and counter electrode with respect to time and the current response measured at the working electrode during LSV. 18

Figure 1.3. Voltage applied between the working and counter electrodes and current response measured at the working electrode during $\mathrm{CV}$. 18

Figure 1.4. Square wave voltammetry potential sweep.

Figure 1.5. Schematic representation of carbon fiber microelectrode components 22

Figure 1.6. Actual photograph of carbon fiber microelectrode to appreciate size. 22

Figure 2.1. SEM images of phenol-allylphenol copolymer insulated disk shaped carbon fiber microelectrodes.

Figure 2.2.A. Cyclic voltammograms of 3 non-insulated carbon fiber microelectrodes. Measurements were taken in $0.03 \mathrm{~mol} / \mathrm{L}$ potassium ferricyanide solution. Scan rate was $0.1 \mathrm{~V} / \mathrm{s}$ and potential limits were from $-1.0 \mathrm{~V}$ to $+0.4 \mathrm{~V} \mathrm{vs}$. $\mathrm{Ag} / \mathrm{AgCl}$ reference electrode 33

Figure 2.2.B. Cyclic voltammograms of phenol-allylphenol insulated (disk shaped) carbon fiber microelectrodes. Measurements were taken in $0.03 \mathrm{~mol} / \mathrm{L}$ potassium ferricyanide solution. Scan rate was $0.1 \mathrm{~V} / \mathrm{s}$ and potential limits were from $-0.4 \mathrm{~V}$ to $+0.4 \mathrm{~V}$ vs. $\mathrm{Ag} / \mathrm{AgCl}$ reference electrode

Figure 2.3. A schematic representing the molecular architecture and working of a micro immunosensor.

Figure 2.4. Fc-anti-VEGF modified carbon fiber microelectrode incubated with a 200 $\mathrm{pg} / \mathrm{ml}$ VEGF solution. Linear Sweep Voltammetry was performed in $0.5 \mathrm{M} \mathrm{NaClO}_{4}$ solution (vs. $\mathrm{Ag} / \mathrm{AgCl}$ ) every 10 minutes. Oxidation peak current is plotted versus responding incubation time.

Figure 2.5. Activated Carbon fiber microelectrodes were incubated with $5 \mu \mathrm{L}$ of PBS buffer, 50, 150, 300, 400, 750, 800, 850, 1000, $1100 \mathrm{pg} / \mathrm{ml}$ solutions of Fc-anti-VEGF solutions. Cyclic voltammetry was performed in $0.5 \mathrm{M} \mathrm{NaClO}_{4}$ solution (vs. $\mathrm{Ag} / \mathrm{AgCl}$ ) after 5 hours. Oxidation peak current obtained for each CFME is plotted versus the concentration of the antibody solution. 
Figure 2.6. Cyclic Voltammograms of Fc-anti-VEFG modified Carbon fiber microelectrode measured in $0.5 \mathrm{M} \mathrm{NaClO}_{4}$, with scan rates of $0.1,0.2,0.3,0.4,0.5$, and $0.75 \mathrm{~V} / \mathrm{s} . \quad 39$

Figure 2.7. Anodic and Cathodic peak current of Fc-anti-VEGF modified carbon fiber microelectrode in $0.5 \mathrm{M} \mathrm{NaClO}_{4}$ electrolyte.

Figure 2.8. Linear sweep voltammetry responses of Fc-anti-VEGF modified CFME to VEGF at different concentrations. All measurements were performed in $0.5 \mathrm{M} \mathrm{NaClO}_{4}$ versus $\mathrm{Ag} / \mathrm{AgCl}$.

Figure 2.9. Calibration Curve: The linear relationship between change of current response and VEGF concentration.

Figure 2.10. Drop in peak current of $4 \mathrm{Fc}$-anti-VEGF modified carbon fiber microelectrodes after being incubated with $50 \mathrm{pg} / \mathrm{ml}$ VEGF, $50 \mathrm{pg} / \mathrm{ml} \mathrm{IgG,} 25 \mathrm{pg} / \mathrm{ml}$ $\mathrm{VEGF}+25 \mathrm{pg} / \mathrm{ml} \mathrm{IgG}$, and $10 \mu \mathrm{g} / \mathrm{ml}$ BSA in $10 \mathrm{mM}$ PBS respectively. Measurements were performed in $0.5 \mathrm{M} \mathrm{NaClO}_{4}$ versus $\mathrm{Ag} / \mathrm{AgCl}$.

Figure 3.1. Schematic illustration of the microbioelectronic detection system for Alzheimer's disease related $A \beta 1-40$ and $A \beta 1-42$ peptides. 53

Figure 3.2. SEM image triple barrel carbon fiber microelectrode. 54

Figure 3.3. Cyclic voltammograms of the three barrels of a microelectrode. Measurements were taken in $0.03 \mathrm{~mol} / \mathrm{L}$ potassium ferricyanide solution. Scan rate was $0.1 \mathrm{~V} / \mathrm{s}$ and potential limits were from 0.0 to $+0.8 \mathrm{~V}$ versus $\mathrm{Ag} / \mathrm{AgCl}$ reference electrode. 55

Figure 3.4. DPV response obtained from HRP labeled antibodies immobilized using PBS and MES buffer solutions.

Figure 3.5. Bare triple barrel carbon fiber microelectrode incubated with a $1.5 \mu \mathrm{g} / \mathrm{ml}$ solution of HRP labeled anti-A $\beta$ antibody (mHJ5.1) solution. DPV was every 1 minute performed using $10 \mathrm{mM}$ PBS buffer and $1 \mathrm{mM} \mathrm{KCl}$ as supporting electrolyte. Oxidation peak current is plotted versus responding incubation time.

Figure 3.6. Effects of driving potential on the amount of antibody immobilized on electrode surface using $1000 \mu \mathrm{g} / \mathrm{ml}$ antibody solution and incubation time of 7 minutes. 58

Figure 3.7. HRP signal generated by electrode following the application of an increasing load of HRP labeled antibody. 
Figure 3.8. Square wave voltammetricresponses of 3 barrel of the immunosensorobtained in rat (A) cerebrospinal fluid solution, spiked with (B) $100 \mathrm{nM} \mathrm{A} \beta 1-40$ and $100 \mathrm{nM} A \beta 1$ 42 (C) $500 \mathrm{nM} \mathrm{A} \beta 1-40$ and $500 \mathrm{nM} \mathrm{A} \beta 1-42$ (D) $1 \mu \mathrm{M} A \beta 1-40$ and $1 \mu \mathrm{M} A \beta 1-42$

solutions. Square wave voltammetry parameters: Init $\mathrm{E}(\mathrm{V})=1$; Final $\mathrm{E}(\mathrm{V})=0$; Incr E $(V)=0.004 ;$ Amplitude $(\mathrm{V})=0.04 ;$ Frequency $(\mathrm{Hz})=500$.

Figure 3.9. (A) Calibration curve: the linear relationship between peak oxidation current and $A \beta 1-40$ concentration. (B) Calibration curve: the linear relationship between peak oxidation current and $\mathrm{A} \beta 1-42$ concentration.

Figure 3.10. Oxidation peak current obtained from three anti-A $\beta$ modified carbon fiber microelectrodes after being incubated with $1 \mu \mathrm{M}$ of $\mathrm{A} \beta 1-40,1 \mu \mathrm{M}$ of $\mathrm{A} \beta 1-42$ and $500 \mathrm{nM}$ of $A \beta 1-40+500 \mathrm{nM}$ of $\mathrm{A} \beta 1-42$ spiked into rat cerebrospinal fluid solutions respectively. Measurements were performed in $10 \mathrm{mM}$ PBS buffer and $1 \mathrm{mM} \mathrm{KCl}$ versus $\mathrm{Ag} / \mathrm{AgCl}$. 63

Figure 4.1. Schematic showing the electroactive behavior of 8-OHdG. 68

Figure 4.2. View of calibration system to measure 8-OHdG response at the surface of an activated carbon fiber microelectrode.

Figure 4.3. View of the detection system in single cell experiments. A carbon fiber microelectrode was placed at a fixed distance of $0.5 \mu \mathrm{m}$ away from the surface of a cell.74 Figure 4.4. Typical amperometric response to the injection of $10 \mathrm{pM}, 20 \mathrm{pM}, 30 \mathrm{pM}$, $40 \mathrm{pM}, 50 \mathrm{pM}$, and 60pM 8-OHdG by using the calibration system. 76

Figure 4.5. The calibration curve for microelectrode response towards 8-OHdG solution over the concentration range of $10-60 \mathrm{pM}$. 76

Figure 4.6. Current recordings made at a single lung endothelial cell in saline buffer with the electrode potential was held at $+0.42 \mathrm{~V}$. The bars indicate calcium ionophore injection via microcapillary placed $1 \mathrm{~cm}$ from cell surface. 78

Figure 4.7. Current recordings made at single lung endothelial cell with $10 \mathrm{mM}$ hydrogen peroxide exposure. The bars indicate calcium ionophore injection via microcapillary placed $1 \mathrm{~cm}$ from cell surface.

Figure 4.8. Background subtracted fast scan cyclic voltammogram at the surface of single lung epithelial cell incubated with $10 \mathrm{mM}$ hydrogen peroxide. The potential sweep was carried out from 0.2 to $0.8 \mathrm{~V}$, at a scan rate of $200 \mathrm{~V} / \mathrm{s}$. 80

Figure 4.9. Image of single lung epithelial cell in saline buffer solution, recorded $2 \mathrm{~h}$ after the petri dish was placed on the microincubator. 81 
Figure 4.10. Current recordings made at a single lung endothelial cell in saline buffer with the electrode potential was held at $+0.42 \mathrm{~V}$. The bars indicate calcium ionophore injection via microcapillary placed $1 \mathrm{~cm}$ from cell surface.

Figure 4.11. Average peak currents obtained from 3 individual isolated cells after $1 \mathrm{~h}$ of incubation with $0.025,0.05,0.1,0.5,1,2,4,6$, and $8 \mathrm{mM}$ nicotine solution respectively. Average background peak current of $0.85 \mathrm{pA}$ is represented as dashed line.

Figure 4.12. Image of detached and unhealthy lung epithelial cells, recorded after the addition of $9 \mathrm{mM}$ nicotine solution.

Figure 4.13. Average current recordings made at the surface of 20 single isolated lung epithelial cells with $4 \mathrm{mM}$ nicotine exposure for a period of $2 \mathrm{~h}$. Average background peak current of $0.85 \mathrm{pA}$ is represented as dashed line. 
8-OHdG: 8-hydroxydeoxyguanine

8-OxoG : 8-hydroxyguanine

$\mathrm{AD}$ : Alzheimer's disease

$\mathrm{A} \beta$ : Amyloid beta

BER : Base excision repair mechanism

BSA : Bovine serum albumin

CPA : Constant potential amperometry

CSF : Cerebrospinal fluid

CSW: Cyclic square-wave

CV : Cyclic Voltammetry

DPV : Differential pulse voltammetry

EDC : 1-ethyl-3-[3-dimethylaminopropyl] carbodiimide hydrochloride

ELISA : Enzyme linked immunosorbent assay

Fc : Ferrocene

Fc-anti-VEGF : Ferrocene linked anti-VEGF

FSCV : Fast scan cyclic voltammetry

HRP : Horse radish peroxide

LSV : Linear sweep voltammetry

NHSS : $N$-hydroxysulfosuccinimide

PBS : Phosphate buffer saline

ROS : Reactive oxygen species

SEM : Scanning electron microscopy

SWV : Square wave voltammetry 
Trp : Trytophan

Tyr : Tyrosine

VEGF : Vascular endothelial growth factor 
Chapter 1

Introduction 


\subsection{Motivation}

The motivation of the dissertation was to develop sensors to detect disease biomarkers in patient body fluids and at the surface of single cells. Monitoring disease biomarkers allow early disease diagnosis as biomolecular changes occur earlier as compared to any physical symptoms. Disease progression and response to therapy can also be monitored by measuring biomarkers in patient fluid samples. Electrochemical sensors were used as the platform technology as they provide several key advantages such as miniaturization, high sensitivity, and fast response time. The goal of the dissertation was to develop direct, one-step immunosensors to measure all types of disease biomarkers. Biomarkers can be broadly classified as electroactive and the non-electroactive biomarkers, as the platform technology used was electrochemistry.

\subsection{Specific Aims}

Specific Aim 1: Development of amperometric immunosensor for detection of nonelectroactive biomarkers in patient fluid samples.

More than $90 \%$ of the bio-molecules present in the human body are non-electroactive. Any of these bio-molecules may act biomarkers towards a specific disease. Thus the first aim of the dissertation research was to develop a highly sensitive, one-step detection strategy to measure non-electroactive bio-molecules in patient fluid samples. Vascular endothelial growth factor was used a model non-electroactive analyte as it is highly overexpressed by tumor tissue. 
Specific Aim 2: Development of amperometric immunosensor for multiplex detection of electroactive biomarkers in patient fluid samples.

Many interesting biomolecules such as neurotransmitters, prostrate specific antigen, hemoglobin etc. are electroactive due to the presence of metallic co-factors or active amino acids such as tyrosine, trytophan, cysteine, and glycine. The second aim deals with the development of a direct sensing strategy to detect these electroactive biomolecules. Multiplex detection allows simultaneous detection two or three different biomarkers which enables earlier disease diagnosis with better accuracy. Electroactive protein biomarkers - Amyloid beta 40 and 42 related to Alzheimer's disease were used as model analytes.

Specific Aim 3: Development of a sensing strategy to detect biomarkers at the surface of single cells.

Monitoring biomarker release at the surface of a single cell enables the study of the underlying cause of disease and factors influencing disease progression. Single cells maintain all their physiological activities and can be monitored without the interference of other biological components and mechanisms present in the body. In order to study biomarkers at the surface of single cells, an electroactive DNA damage biomarker known as 8-hydroxydeoxyguanine was used as the model analyte.

\subsection{Biomarkers}

Biomarkers comprise of cellular molecules such as proteins or nucleic acids that can be detected in cells, blood, urine, or other body fluids and are over-expressed due to the 
onset of disease. To date a wide range of biomarkers have been identified for different types of diseases and have made their way into translational medicine. These include DNA modifications, RNA, proteins (enzymes and glycoproteins), hormones and related molecules, molecules of the immune system, oncogenes and other modified molecules. The DNA-based markers include single nucleotide polymorphisms (Aly et al., 2011), chromosomal aberrations (Rossner et al., 2011), changes in DNA copy number (Nakao et al., 2011), microsatellite instability (Kloor et al., 2005), and differential promoter-region methylation (Das and Singal, 2004). The RNA-based biomarkers include overexpressed or underexpressed transcripts, and regulatory RNAs (Sunde, 2010). The protein markers include cell-surface receptors such as CD20 (Dorner et al., 2010), tumour antigens such as prostate-specific antigen (Tosoian and Loeb, 2010), phosphorylation states (Moran et al., 2006), carbohydrate determinants, and peptides released by tumors into serum, urine, sputum, nipple aspirates or other body fluids. New developments in the fields of proteomics and genomics research are resulting in the rapid identification of novel biomarkers. High throughput detection strategies and toxicology studies are enabling the identification of antigens towards disease diagnosis. Protein micro-arrays, serological analysis of recombinant cDNA expression libraries (SEREX), and serological proteome analysis (SERPA) technologies have been successfully used towards the detection of biomarkers related to cancer and AD. FDA officials are collaborating with researchers from drug companies, government agencies and academic institutes to develop a list of validated biomarkers that signal disease progression and drug safety and efficacy.

According to FDA's draft guidance, there are four different types of biomarkers: 
- Prognostic biomarkers are used to determine the disease progression in a patient.

- Predictive biomarkers are a baseline characteristic that indicate the likelihood a specific patient will respond to a given treatment.

- Pharmocodynamic biomarkers test the biological response that occurred in a patient after receiving a particular drug, such as a change in blood pressure or cholesterol. Drug companies usually test these biomarkers in phase II clinical trials and submit the results to the FDA; however, actual drug approval is generally based on harder clinical endpoints.

- Surrogate endpoints are biomarkers that are intended to be used as a substitute for a clinical efficacy endpoint.

Numerous biomarkers are still going through evaluation to improve their specificity and sensitivity in the context of their clinical use. The field of biomarker discovery is based on a close collaboration between clinicians, analytical scientists and chemometritians/statisticians. Defining the final purpose of a biomarker or biomarker pattern at the onset of a study enables appropriate selection case and control samples, design of experiments, sample collection, storage and separation protocols, choice and validation of the quantitative profiting platform followed by data processing, statistical analysis and validation workflows. Biomarker candidates that result after statistical validation need be submitted for further validation. Preferably another clinical center should be assigned to assess the specificity and sensitivity of a given biomarker-based assay in a larger set of independent samples (Horvatovich and Bischoff, 2010). In order to make the process of disease biomarker discovery transparent, accessible, and easily 
understood in the context of its conclusions, stringent guidelines have been established (McShane et al., 2005).

\subsection{Biosensor}

\subsubsection{Historical Survey}

Research efforts have focused for the last several decades on improving the "quality of human life". Control of disease, quality of food/water and environmental safety are closely linked to these efforts. The development of biosensors which incorporates the well established chemical sensing techniques with a bio-recognition element has drawn the interest of the food-industry, bio-industry, medical, and environmental control industries. The capabilities of biosensors to combine continuous, selective, high sensitivity, and fast monitoring make them indispensable (Newman and Setford, 2006).

Clark et al. and others first introduced biosensors in the 1950's combining physically entrapped enzymes to an electrochemical transducer (Leland C. Clark Jr, 1962; Sharmat and Rogers, 1994). During the last several decades the field of biosensors has grown exponentially with research teams involving researchers with different backgrounds such as physicists, chemists, medical researchers and engineers. In a recently published comprehensive report by Global Industry Analysts, the global market for biosensors is predicted to reach US $\$ 12$ billion by the year 2015 , with point-of-care testing devices such as the glucose sensor representing the largest segment (Global Industry Analysts, 2011). Growth in population and the increase in the number of people suffering from lifestyle related issues such as obesity and diabetes is driving this market growth due to the need for periodic medical testing. R\&D activities related to healthcare are also rising 
with biosensors required for applications such as drug discovery, drug analysis, and for in-vivo testing of pharmacodynamic effects of new drug candidates.

\subsubsection{Definition and classification of biosensor}

A biosensor can be broadly defined as an analytical device that converts a biological response, based on the composition, structure or function of a biological system, into an electrical signal. Biosensors are often used to determine the concentration of substances or to monitor a biological system. (Leland C. Clark Jr, 1962).

Biosensor broadly consists of 3 parts:

- The biological recognition element, which can be, but are not limited to tissue, microorganisms, organelles, cell receptors, enzymes, antibodies, nucleic acids, etc.

- The transducer or the detector element (optical, piezoelectric, electrochemical, thermal, magnetic etc.) that transforms the signal resulting from the interaction of the analyte of interest with the bio-recognition element into a signal that can be measured and quantified.

- The detector, which consists of associated electronics or signal processors that are primarily responsible for the display of the results in a user-friendly way. The detector often accounts for the most expensive and bulky part of the biosensor 
device.

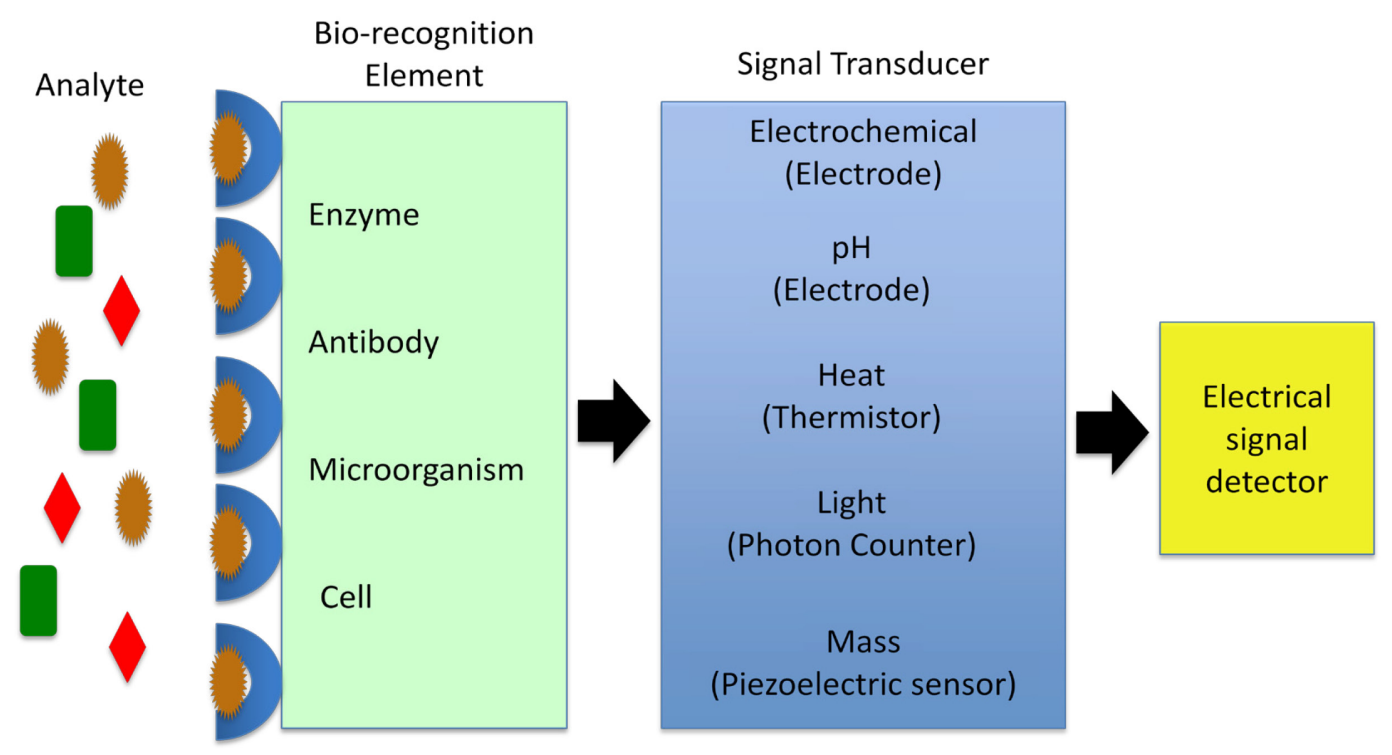

Figure 1.1. A schematic illustration of the functional components of a biosensor.

A successful biosensor must possess most of the following beneficial features:

1. The bio-recognition element must be highly specific for the purpose of the analysis, and be stable under normal storage conditions.

2. The reaction between the bio-recognition element and analyte of interest should be as independent of physical parameters such as stirring, $\mathrm{pH}$ and temperature. This would allow the analysis of samples to be conducted with minimal pretreatment.

3. The response of the biosensor should be accurate, precise, reproducible and linear over a relevant analytical range, without dilution or concentration. The signal to noise ratio of the biosensor should be high.

4. If the biosensor is to be used for in-vivo monitoring in clinical situations, the probe must be tiny and biocompatible, having no toxic or antigenic effects. If the 
sensor is reusable then it should be able to withstand standard sterilization procedures.

5. The complete biosensor should be cheap, small, portable and capable of being used by semi-skilled operators.

6. There should be a market for the biosensor. There is no benefit to developing a biosensor if other factors (e.g. government subsidies, the continued employment of skilled analysts, or poor customer perception) encourage the use of traditional methods and discourage the decentralization of laboratory testing.

\subsection{Electrochemical Biosensors}

Electrochemical sensors have been favored over optical sensors mainly due to numerous factors such as 1) they are low cost, 2) they can be miniaturized for in-vivo applications or can be made portable for in-field applications 3) they can be mass-produced using standard micro/nano fabrication cleanroom facilities. Based on the electrochemical property to be measured the electrochemical sensors can be classified as potentiometric, amperometric or conductimetric.

Potentiometric biosensors make use of ion-selective electrodes such as in order to transduce the biological reaction into an electrical signal. In the simplest terms this consists of an immobilized enzyme membrane surrounding the probe from a $\mathrm{pH}$-meter, where the catalyzed reaction generates or absorbs hydrogen ions. The reaction occurring next to the thin sensing glass membrane causes a change in $\mathrm{pH}$, which may be read 
directly from the pH-meter's display. Typical of the use of such electrodes is that the electrical potential is determined at very high impedance allowing effectively zero current flow and causing no interference with the reaction. The basis of this type of biosensor is the Nerst equation that relates the electrode potential (E) to the concentration of the electroactive species present in buffer solution.

For the reaction: $\mathrm{aA}+\mathrm{ne}^{-} \leftrightarrow \mathrm{bB}$, the Nerst equation is described as follows:

$$
E=E^{0}+\frac{R T}{n F}\left\{\frac{C_{A}^{a}}{C_{B}^{b}}\right\}
$$

Where $\mathrm{E}^{0}$ is the standard redox potential, $\mathrm{R}$ is the gas constant, $\mathrm{T}$ is the absolute temperature, $\mathrm{F}$ is the Faraday constant, $\mathrm{n}$ is the number of electrons exchanged in the reaction, and $\mathrm{C}_{\mathrm{A}}$ and $\mathrm{C}_{\mathrm{B}}$ are the concentrations of the oxidized and reduced species. $\mathrm{A}$ typical application of potentiometric sensors was developed to measure glucose (Kuffmann and Guibault 1991). Glucose has minimal effect on $\mathrm{pH}$, however the enzymatically formed product of glucose and glucose oxidase immobilized on the sensor outer surface of a pH electrodes causes acidification and thus results in a signal change. Semiconductor based physio-chemical transducers are commonly used in ISFETs (ionselective field effect transistors) and LAPS (light addressable potentiometric sensor) (Yuqing et al. 2003 and 2005; Yoshinobu et al. 2005). The working principle of the ISFET sensor is related to a local potential generated at the surface of the sensor by ions from solution. Potentiometric sensors using semiconductor sensors have been successfully developed for the detection of herbicide atrazine (D' Agostino et al., 2006), neurotransmitter serotonin (Kitade et al., 2004), creatinine (Karakus et al., 2006), 
glycoalkaloids (Korpan et al., 2006), and organophosphate pesticides (Timur and Telefoncu 2004). The LAPS biosensor has been used for the detection of as low as 10 cells $/ \mathrm{ml}$ of Escherichia coli and has been commercialized for an automated 8-channel device for detection of biological agents (Ercole et al., 2002).

Amperometric sensors are based on the measurement of the current resulting from the electrochemical oxidation or reduction of an electroactive species in solution or at the surface of the electrode. Amperometric sensors are more sensitive and suitable for mass production as compared to potentiometric sensors. The working electrode in an amperometric sensor usually consists of a noble metal such as $\mathrm{Pt}, \mathrm{Au}$ or a carbonaceous material such as glassy carbon, carbon paste, screen printed carbon-ink etc. Amperometric sensors can work in a two- or three-electrode configuration based on the application. The first case consists of the working (contains bio-recognition element) and reference electrodes. The main shortcoming of the two-electrode configuration is the short linear range obtained due to limited control of the potential on the working electrode surface with higher currents. A third auxillary electrode is employed to solve this problem. Therefore, in the three-electrode configuration voltage is applied between the reference and the working electrodes, and current flows between the working and the auxillary electrodes. Using amperometric sensors in the 3-electrode configuration currents as low as $10^{-9}$ to $10^{-6} \mathrm{~A}$ can be easily measured. The resulting current is directly correlated to the bulk concentration of the electroactive species or its production or consumption rate within the adjacent biocatalytic layer. As biocatalytic reaction rates are often chosen to be first order dependent on the bulk analyte concentration, such steady- 
state currents are usually proportional to the bulk analyte concentration. Amperometric sensors have often been used on a large scale for detection of analytes such as glucose, lactate (Ohnuki et al., 2007) and salicylic acid (Marzouk et al., 2007). Biosensors utilizing enzymes such as acetylcholinesterase and butyrylcholinesterase have been employed for the rapid detection of organophosphates and carbamates. Detection of cancer marker genes such as BRAC1 and BRAC2 from breast tissue has been accomplished using the catalytic oxidation of guanine nucleobase (Tansil et al., 2005).

Amperometric and potentiometric transducers have been used commonly for biosensor development, but much attention in recent years has been devoted towards impedance based transducers as they can accomplish label-free analysis. Conductimetric biosensors follow the changes in conductance or impedance of a solution as a result of the biorecognition component using a noble element working electrode. Thus the expression of impedance or its inverse conductance is as follows, where $\mathrm{Z}$ is impedance, $\mathrm{R}$ is component resistance, $\mathrm{C}$ is component capacitance:

$$
Z^{2}=R^{2}+\frac{1}{(2 f C)^{2}}
$$

Conductimetric biosensors include two electrodes with applied alternating voltage, amplitudes from a few to $100 \mathrm{mV}$ can be used. Biosensors based on the conductimetric principle present a number of advantages: a) thin-film electrodes are suitable for miniaturization and large scale production using inexpensive technology, b) they do not require any reference electrode, c) transducers are not light sensitive, d) the driving voltage can be sufficiently low to decrease significantly the power consumption, e) large 
spectrum of compounds of different nature can be determined on the basis of various reactions and mechanisms.

\subsection{Electrochemical Methods}

Electrochemical methods have been commonly used towards the development of numerous biosensors, the most famous of which is the glucose biosensor. Electrochemical analysis involves the measurement of current, potential or charge. The concentration and properties of the analyte, or the properties of the material used to make the electrode can be reflected by these measurements. Basic electrochemical methods involve: voltammetry and amperometry. Variations of these methods such as cyclic voltammetry, linear sweep voltammetry, square wave voltammetry and constant potential amperometry are selected to suit the specific application.

\subsubsection{Amperometry}

Amperometry can be defined as the measurement of a steady-state current in an electrolytic cell which is due to the oxidation or reduction of the analyte species. There may be no applied potential (galvanic cell) or there may be an applied potential. In this later case, a limiting current is established which is proportional to the concentration of the analyte.

Consider a solution containing the analyte, $\mathrm{A}$, in the presence of some conductive buffer. If an electrolytic potential is applied to the solution through a working electrode, then the measured current depends (in part) on the concentration of the analyte. Measurement of this current can be used to determine the concentration of the analyte directly; this is a 
form of amperometry. However, the difficulty is that the measured current depends on several other variables, and it is not always possible to control all of them adequately. This limits the precision of direct amperometry. If the potential applied to the working electrode is sufficient to reduce the analyte, then the concentration of analyte close to the working electrode will decrease. More of the analyte will slowly diffuse into the volume of solution close to the working electrode, restoring the concentration. If the potential applied to the working electrode is great enough (an overpotential), then the concentration of analyte next to the working electrode will depend entirely on the rate of diffusion. In such a case, the current is said to be diffusion limited. As the analyte is reduced at the working electrode, the concentration of the analyte in the whole solution will very slowly decrease; this depends on the size of the working electrode compared to the volume of the solution.

\subsubsection{Voltammetry}

The common characteristic of all voltammetric techniques is that they involve the application of a potential $(E)$ to an electrode and the monitoring of the resulting current (i) flowing through the electrochemical cell. In many cases the applied potential is varied or the current is monitored over a period of time $(t)$. Thus, all voltammetric techniques can be described as some function of $E, i$, and $t$. They are considered active techniques (as opposed to passive techniques such as potentiometry) because the applied potential forces a change in the concentration of an electroactive species at the electrode surface by electrochemically reducing or oxidizing it. The analytical advantages of the various voltammetric techniques include excellent sensitivity with a very large useful linear 
concentration range for both inorganic and organic species $\left(10^{-12}\right.$ to $\left.10^{-1} \mathrm{M}\right)$, a large number of useful solvents and electrolytes, a wide range of temperatures, rapid analysis times (seconds), simultaneous determination of several analytes, the ability to determine kinetic and mechanistic parameters, a well-developed theory and thus the ability to reasonably estimate the values of unknown parameters, and the ease with which different potential waveforms can be generated and small currents measured.

\subsubsection{Linear sweep voltammetry / Cyclic voltammetry}

In linear sweep voltammetry (LSV) a fixed potential range is employed much like potential step measurements. However in LSV the voltage is scanned from a lower limit to an upper limit as shown below. The characteristics of the linear sweep voltammogram depend on a number of factors including:

- The rate of the electron transfer reaction(s)

- The chemical reactivity of the electroactive species

- The voltage scan rate

In LSV measurements the current response is plotted as a function of voltage rather than time, unlike potential step measurements. The scan begins from the left hand side of the current/voltage plot where no current flows. As the voltage is swept further to the right (to more reductive values) a current begins to flow and eventually reaches a peak before dropping. To rationalize this behavior we need to consider the influence of voltage on the equilibrium established at the electrode surface. Here the rate of electron transfer is fast in comparison to the voltage sweep rate. Therefore at the electrode surface equilibrium is established identical to that predicted by thermodynamics. The exact form of the 
voltammogram can be rationalized by considering the voltage and mass transport effects. As the voltage is initially swept from $V_{1}$ the equilibrium at the surface begins to alter and the current begins to flow. The current rises as the voltage is swept further from its initial value as the equilibrium position is shifted further to the right hand side, thus converting more reactant. The peak occurs, since at some point the diffusion layer has grown sufficiently above the electrode so that the flux of reactant to the electrode is not fast enough to satisfy that required by the Nernst equation. In this situation the current begins to drop just as it did in the potential step measurements. In fact the drop in current follows the same behavior as that predicted by the Cottrell equation. The above voltammogram was recorded at a single scan rate. If the scan rate is altered the current response also changes. Each curve has the same form but it is apparent that the total current increases with increasing scan rate. This again can be rationalized by considering the size of the diffusion layer and the time taken to record the scan. Clearly the linear sweep voltammogram will take longer to record as the scan rate is decreased. Therefore the size of the diffusion layer above the electrode surface will be different depending upon the voltage scan rate used. In a slow voltage scan the diffusion layer will grow much further from the electrode in comparison to a fast scan. Consequently the flux to the electrode surface is considerably smaller at slow scan rates than it is at faster rates. As the current is proportional to the flux towards the electrode the magnitude of the current will be lower at slow scan rates and higher at high rates.

Cyclic voltammetry (CV) is very similar to LSV. In this case the voltage is swept between two values at a fixed rate, however now when the voltage reaches V2 the scan is reversed and the voltage is swept back to V1. A typical cyclic voltammogram recorded 
for a reversible single electrode transfer reaction is shown in below. Again the solution contains only a single electrochemical reactant. The forward sweep produces an identical response to that seen for the LSV experiment. When the scan is reversed we simply move back through the equilibrium positions gradually converting electrolysis product $\left(\mathrm{Fe}^{2+}\right.$ back to reactant $\mathrm{Fe}^{3+}$ ). The current flow is now from the solution species back to the electrode and so occurs in the opposite sense to the forward seep but otherwise the behavior can be explained in an identical manner. For a reversible electrochemical reaction the $\mathrm{CV}$ recorded has certain well defined characteristics such as:

1. The voltage separation between the current peaks is $\pm 59 \mathrm{mV}$.

2. The positions of peak voltage do not alter as a function of voltage scan rate.

3. The ratio of the peak currents is equal to one

4. The peak currents are proportional to the square root of the scan rate

The Randles-Sevcik equation can be used to predict the peak current obtained from a reversible redox reaction:

$i_{\mathrm{p}}=\left(2.69 \times 10^{5}\right) n^{3 / 2} \mathrm{ACD}^{1 / 2} v^{1 / 2}$

where $i_{\mathrm{p}}$ is current maximum in amperes, $n=$ number of electrons transferred in the redox event, $\mathrm{A}=$ electrode area in $\mathrm{cm}^{2}, \mathrm{~F}=$ Faraday's Constant in $\mathrm{C} \mathrm{mol}^{-1}, \mathrm{D}=$ diffusion coefficient in $\mathrm{cm}^{2} / \mathrm{s}, \mathrm{C}=$ concentration in $\mathrm{mol} / \mathrm{cm}^{3}, v=$ scan rate in $\mathrm{V} / \mathrm{s}$. 

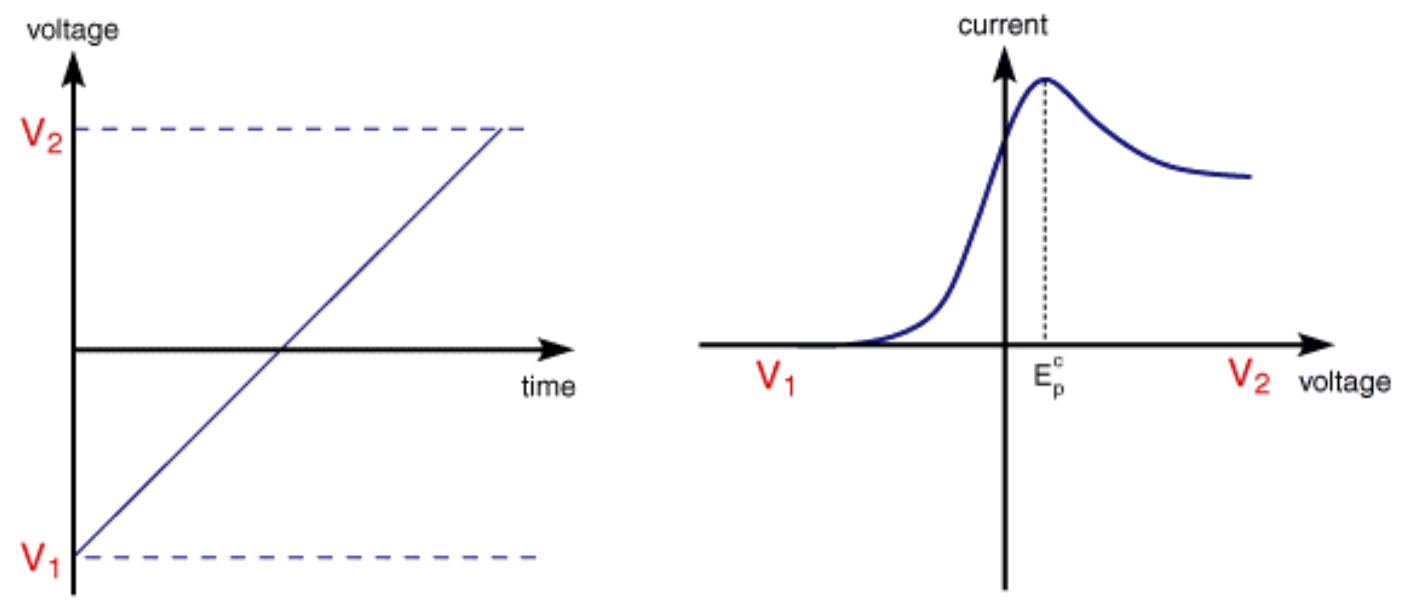

Figure 1.2. Voltage applied between working and counter electrode with respect to time and the current response measured at the working electrode during LSV.
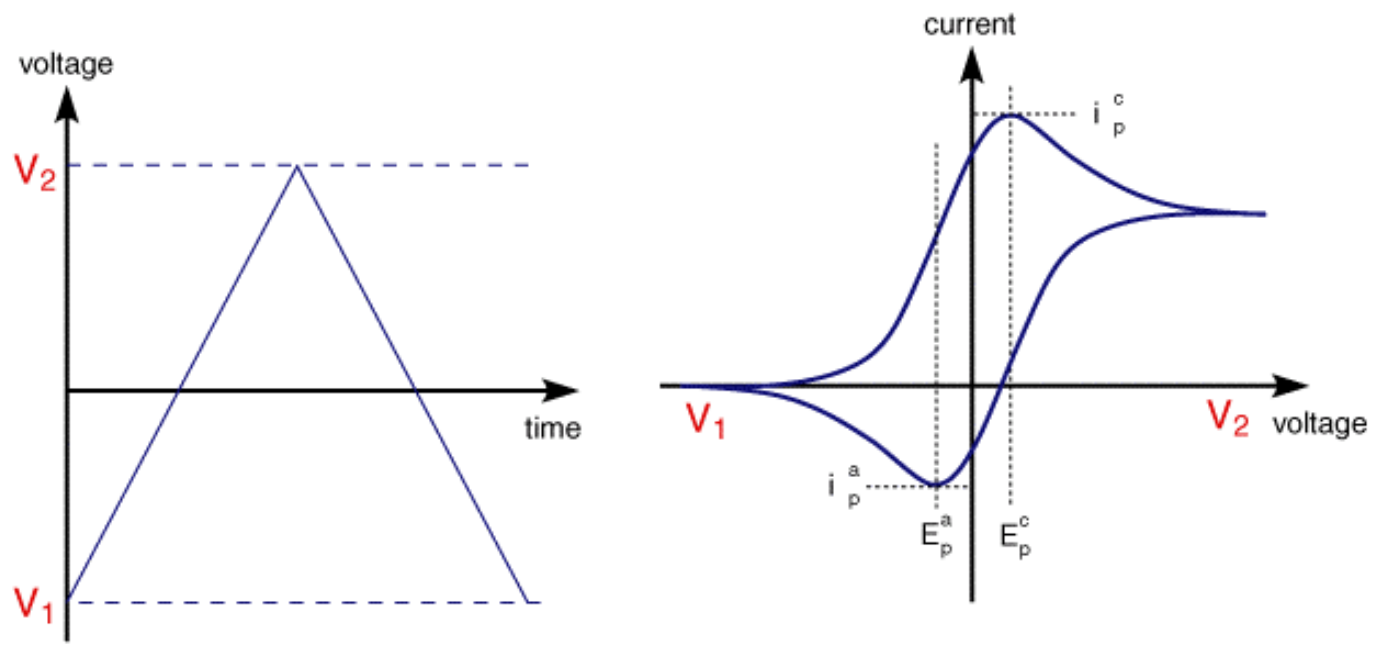

Figure 1.3. Voltage applied between the working and counter electrodes and current response measured at the working electrode during $\mathrm{CV}$.

\subsubsection{Square wave voltammetry (SWV)}

The excitation signal in SWV consists of a symmetrical square-wave pulse superimposed on a staircase waveform of step height $\mathrm{E}$, where the forward pulse of the square wave 
coincides with the staircase step. The net current is obtained by taking the difference between the forward and reverse currents and is centered on the redox potential. The peak height is directly proportional to the concentration of the electroactive species and direct detection limits as low as $10^{-8} \mathrm{M}$ are possible. SWV has several advantages. Among these are its excellent sensitivity, rejection of background currents and speed of analysis. This speed, coupled with computer control and signal averaging, allows for experiments to be performed repetitively and increases the signal to noise ratio. Applications of SWV include the study of electrode kinetics with regard to preceding, following, or catalytic homogeneous chemical reactions, determination of some species at trace levels, and its use with electrochemical detection in HPLC.

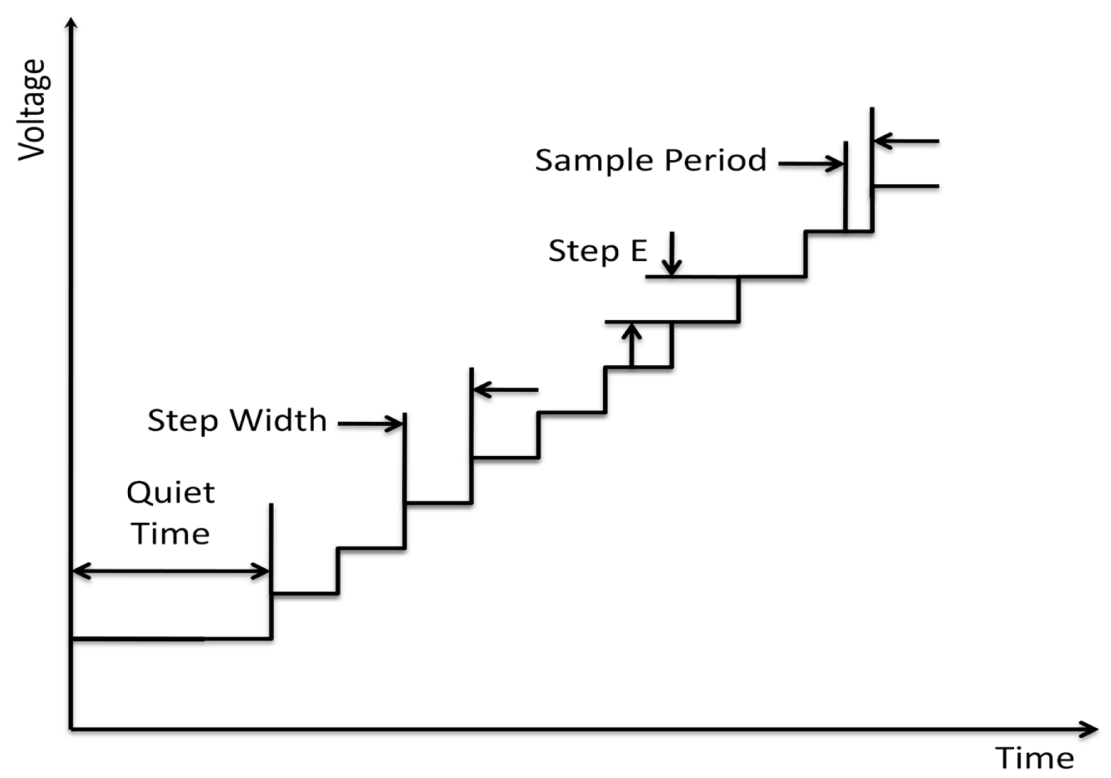

Figure 1.4. Square wave voltammetry potential sweep. 


\subsubsection{Constant potential amperometry (CPA)}

CPA is an electrochemical technique where a constant potential is applied to a sensor (working electrode) and the faradaic current is measured. This current is generated by the reduction or oxidation of a chemical substance the electrode surface. The advantage of this technique is that the time resolution is limited only by the data collection frequency of the instrument. On the other hand, the primary disadvantage is the low chemical selectivity. For example, all species with oxidation potentials below the applied voltage will be oxidized and contribute to the current.

\subsection{Carbon fiber microelectrodes}

Carbonaceous electrodes have been used for several decades to detect various biological analytes due to their high electric conductivity, stable background currents, high signal to noise ratio and signal reproducibility (Kinoshita, 1998). Carbonaceous materials such as glassy carbon, carbon paste, carbon fibers, graphite and porous carbon have been employed for several years as electrochemical transducers. Recently, novel materials such as carbon nanotubes, graphene, carbon nanospheres are have been garnering attention due to unique electrochemical and mechanical properties (Qureshi et al., 2009). Carbon fiber microelectrodes were introduced by Pujol et al. nearly 30 years ago, who used them with normal pulse polarography to measure the oxidation of several neurotransmitters, including dopamine, norepinephrine and serotonin (Ponchon et al., 1979). Since then, the most popular applications for carbon fiber electrodes have been as sensors for in-vivo detection of neurotransmitters. Carbon fiber microelectrodes have been used for biological applications due to advantages such as: 
- Excellent biocompatibility and non-toxicity towards cells.

- Good electrochemical properties which have been extensively studied and characterized.

- Miniature size $(<10 \mu \mathrm{m}$ in diameter $)$ of electrodes makes them ideal for implantation with minimal damage.

- Carbon fiber microelectrodes enable rapid measurements when used with fast electrochemical techniques such as amperometry, chronoamperometry and fast scan cyclic voltammetry.

Carbon fiber microelectrodes and electrochemistry have been established as a standard technique to monitor numerous neurotransmitters such as dopamine, serotonin, epinephrine, norepinephrine, etc (Troyer et al., 2002; Heien et al., 2004). Thus carbon fiber microelectrodes have enabled scientists to map the neurochemical activity of the brain related to disorders such as epilepsy, Huntington' s disease, Parkinson' s disease, Tourette syndrome, depression, etc (Pacia et al., 2001; Sidlo et al., 2008). Carbon fiber microelectrodes have also been used to test the pharmacodynamics of drugs in in-vivo models. Another interesting application of carbon fiber microelectrodes was developed by Wightman and his colleagues by placing a carbon fiber microelectrode with a $5 \mu \mathrm{m}$ diameter at micrometer distances from a living adrenal chromaffin cell; they were able to monitor exocytosis in real time (Leszczyszyn et al., 1990; Wightman et al., 1991). Although estranged from their indigenous surroundings, individual isolated or cultured cells can sustain their characteristic metabolic and neuro(physiological) processes. Thus single cells can act as good experimental models for examining complex biological processes and functions in a controlled straightforward manner. Thus single and array 
microelectrodes have been used to measure neurotransmitter, nitric oxide, reactive oxygen species release from single cells (Schulte and Schuhmann, 2007).

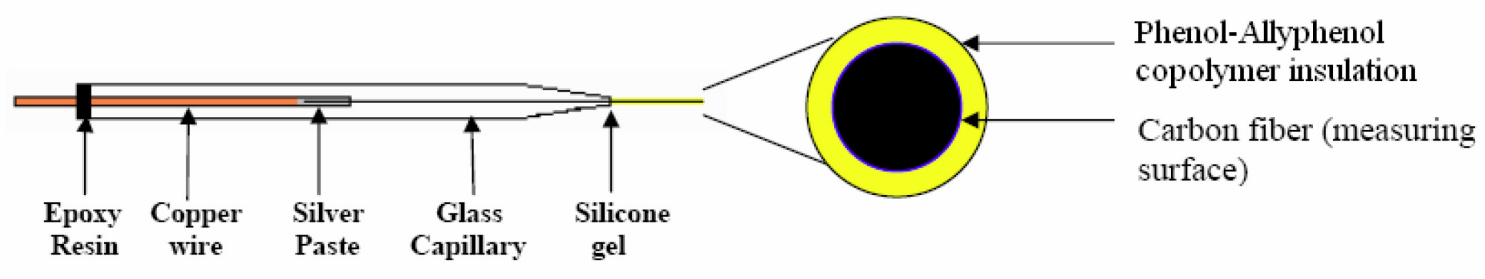

Figure 1.5. Schematic representation of carbon fiber microelectrode components.

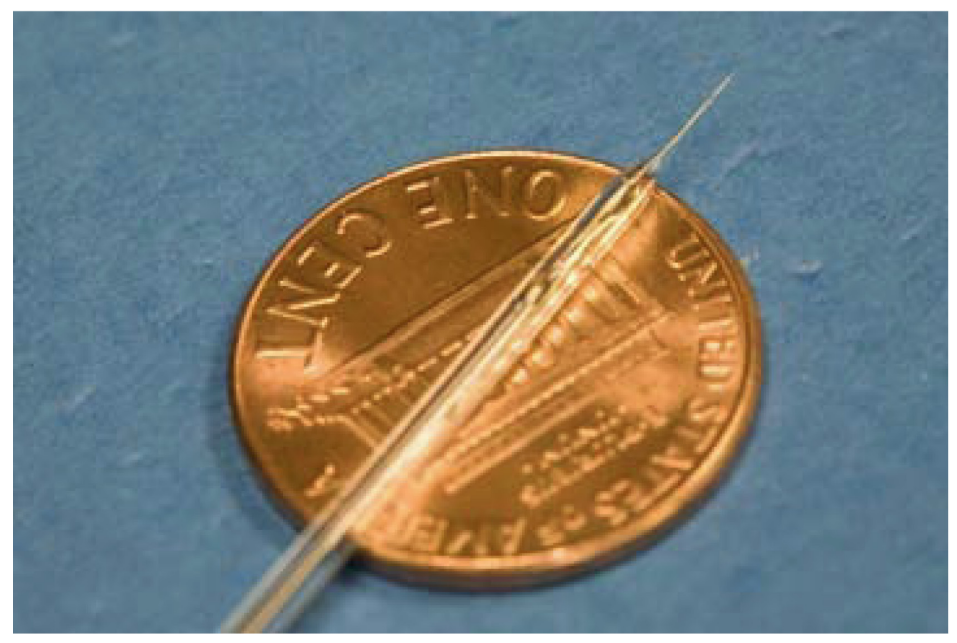

Figure 1.6. Actual photograph of carbon fiber microelectrode to appreciate size. 


\section{Chapter 2}

Amperometric micro-immunosensor for the detection of tumor biomarker 


\subsection{Introduction}

VEGF is an important angiogenic factor that plays a crucial role in tumor growth and metastasis. It is a homodimeric glycoprotein produced by endothelial cells and binds to a protein receptor in the endothelium vessels, initiating a signaling cascade that ultimately results in angiogenesis (Kranz et al., 1999) (Kurebayashi et al., 1999) (Ruohola et al., 1999) (Zhai et al., 1999). VEGF production is increased by tumor cells in response to stimuli such as hypoxia, abnormal gene activity and activation of other receptors and pathways in tumor cells. VEGF is overexpressed in a vast majority of human tumors including lung, thyroid, breast, gastrointestinal tract, kidney, bladder, ovary, etc. Tumor secreted VEGF initially accumulates on the tumor endothelium (Ferrara and DavisSmyth, 1997). VEGF levels on cell surface and in serum can thus be used as a predictive factor for malignancy. Furthermore, patients with VEGF-positive tumors have been shown to have a worse prognosis and early relapse compared to those with VEGFnegative tumors (Masakazu Toi, 1994) (Maeda et al., 1996).

The current techniques used for VEGF quantification include

immunohistochemistry, enzyme linked immunosorbent assays (ELISA), radioimmunoassay, Western blot, etc. However all these techniques are labor-intensive, time consuming, require highly trained personnel or expensive equipment. Therefore, there is a need to develop a suitable detection strategy to carry out real-time, direct, sensitive analysis of VEGF. The development of a direct, real time detection protocol for VEGF would enable monitoring serum VEGF levels in patients during therapy to determine efficacy. 
Detection of biomolecules has been of significant interest in areas such as genomics, proteomics, medical diagnostics and environmental monitoring. Optical, mechanical, magnetic and electrochemical sensors have been at the forefront of biomolecular detection. Electrochemical biosensors have attracted substantial research efforts due to their high sensitivity, selectivity, miniaturization, low cost, and ease of operation. They have been used for detecting small amounts of hormones, enzymes, viruses, tumor antigens, DNA mutants and bacterial antigens (Privett et al., 2008). All electrochemical biosensors are based on a two component system, which include a biological recognition element and a signal conversion unit (Leland C. Clark Jr, 1962). Electrochemical immunosensors use antibodies as their biorecognition elements. Antibodies offer numerous advantages such as high specificity, versatility, and good stability. Electrochemical immunosensors operate by measuring either current (amperometric), potential difference (potentiometric) or capacitance. The measurement of current is the most common and convenient method used to detect biomolecules. Amperometric immunosensors can be classified into two different types, as direct and indirect. Direct immunosensors can be used to detect proteins exhibiting electroactive amino acids such as tyrosine (Tyr) and tryptophan (Trp) or a metal center with reversible redox-activity (metalloproteins) (Reynaud et al., 1980, Brabec and Schindlerova, 1981, Okuno et al., 2007, Armstrong, 1990). However most biomolecules are not electroactive, hence redox tags are required to enhance their detection. For the detection of nonelectroactive VEGF, ferrocene was chosen as an electrochemical tag due to its special properties such good stability, and easy chemical modification, (Zhang et al., 2008). When an appropriate potential is applied ferrocene is easily detectable using voltammetry 
as it rapidly oxidizes without the formation of intermediate products. Zhang et al., developed a highly sensitive immunoassay strategy based on the combination of ferrocene label and poly(o-phenylenediamine) film/gold nanoparticle amplification using IgG (Immunoglobulin) as the model analyte (Zhang et al., 2008). Akram et al,(Akram et al., 2006) quantified human chorionic gonadotrophin in clinical samples by measuring the oxidation of ferrocene linked to a secondary antibody. Ferrocene was used for the detection of hemoglobin $A_{1 c}$ and human chorionic gonadotrophin using flow immunoassay systems (Tanaka et al., 2007, Lim and Matsunaga, 2001). Ferrocene linked oligonucleotide conjugates have also been used for the electrochemical study of DNA and detection of DNA mutants (Ihara et al., 1996) (Nakayama et al., 2002).

The sensing platform employed in the presented work is composed of carbon fiber microelectrodes which offer advantages such as extremely high sensitivity due to high signal-noise ratio, enhanced mass transport, and reduced ohmic drop. In addition, the use of microelectrodes opens up the possibility of in vivo electrical sensing of various biological compounds in living cells and tissue cultures. Furthermore, the miniaturized size of the electrode allows the careful selection of the cell or matrix to be investigated with negligible physical damage to the implanted region. In this regard, the use of a micro sized electrode also offers a non-destructive way of highly sensitive analysis.

In the present work, we describe a reagentless, electrochemical immunosensing strategy for an enhanced detection of immunospecies based on the direct oxidation of ferrocene label. We describe the fabrication of disk shaped carbon fiber microelectrodes which are immobilized with ferrocene labeled anti-VEGF antibody using a Jeffamine cross-linker. Upon incubation of these electrodes with VEGF solution, the formation of 
immunocomplexes, leads to a decrease in the electrochemical response of ferrocene due to increased spatial blocking. This alteration in the electrode response induced by interfacial immunoreactions was employed to quantify the amount of VEGF. Using the proposed immunosensing strategy, VEGF could be detected specifically with a low detection limit and a wide linear dynamic range. The experimental conditions were optimized, and the performance features such as stability and specificity were also evaluated. Thus we describe a one-step immunosensing format for the direct detection of target analytes.

\subsection{Experimental}

\subsubsection{Materials}

Carbon fibers $(5 \mu \mathrm{m}$ in dia.) were donated by World Precision Instruments (Sarasota, FL). Anti-Vascular Endothelial Growth Factor, Vascular Endothelial Growth Factor, 2Allylphenol, liquefied phenol (90\%), and butyl cellosolve (2-butoxyethanol), reagent grade methanol, Jeffamine ${ }^{\circledR}$ ED-600, potassium ferrocyanide, potassium ferricyanide, were purchased from Sigma Aldrich (St. Louis, MO). Borosilicate glass capillaries (outer dia. $0.5 \mathrm{~mm}$, inner dia $0.3 \mathrm{~mm}$ ) were obtained from Sutter Instrument Company (Novato, CA). Ferrocene monocarboxylic acid min. 97\%, EDC (1-ethyl-3-[3dimethylaminopropyl] carbodiimide hydrochloride) $98 \%$, sodium perchlorate $\left(\mathrm{NaClO}_{4}\right)$ (anhydrous) and Na-HEPES [sodium 4-(2-hydroxyethyl)-1-piperazineethanesulfonate] were purchased from Fisher Scientific (Pittsburgh, PA). Sylgard 184 was obtained from Dow Corning Corporation (Midland, MI). 


\subsubsection{Instrumentation}

Carbon fiber microelectrodes were prepared using P-97 micropipette Puller (Sutter Instrument Company, Novato, CA). Ferrocene monocarboxylic acid solution filtration was carried using the Millex-GS (Syringe driven filtration unit, $0.22 \mu \mathrm{m}$ ). Anti-VEGF was concentrated using the Microcon (Ultracel YM-50, $50 \mathrm{kDa}$ ) purchased from Millpore Corporation (Bedford, MA). Scanning electron microscopy (SEM) was carried out on the JEOL JSM 5900LV. Electrochemical measurements were carried out using CHI-630A electrochemical analyzer ( $\mathrm{CH}$ Instruments, Inc., Austin, TX). A conventional three electrode cell consisting of an $\mathrm{Ag} / \mathrm{AgCl}$ reference electrode $(3 \mathrm{M} \mathrm{KCl})$ (Bioanalytical Systems, IN, USA), and a platinum wire as an auxiliary electrode was employed.

\subsubsection{Preparation of micro immunosensor}

\subsubsection{Fabrication of disk-shaped carbon fiber microelectrodes}

Carbon fiber microelectrodes were fabricated by following the method described by Ates et al. (Ates et al., 2008). Briefly, a single carbon fiber of diameter $5 \mu \mathrm{m}$ was attached to the stripped end of an insulated copper wire (dia. $0.2 \mathrm{~mm}$ ) using a silver conductive paste. The silver paste was allowed to dry, after which the free end of the copper wire was cannulated into a borosilicate glass capillary. The copper wire was fixed to the capillary using a fast drying epoxy resin. The capillary was then pulled using a micropipette puller. This pulling procedure results in two glass pipettes, one of which is discarded, and the other which holds the carbon fiber protruding from its tip. The junction between the carbon fiber and capillary is sealed with a drop of the Sylgard silicone preparation and 
allowed to cure until it becomes firm. The protruding fiber was trimmed to a length of $2 \mathrm{~mm}$.

\subsubsection{Insulation of carbon fiber microelectrodes}

Carbon fiber microelectrodes were insulated according to the procedure described by Strein and Ewing (Strein and Ewing, 1992). Briefly, Carbon fibers were insulated using electropolymerisation of allylphenol in a solution containing $90 \mathrm{mM}$ 2-allylphenol and $60 \mathrm{mM}$ phenol. A constant potential of $4.0 \mathrm{~V}$ was applied to the carbon fiber microelectrode vs. a platinum wire counter/reference for a period 14 to 16 minutes. The polymer coating was then cured by placing the electrodes in an oven at $150{ }^{\circ} \mathrm{C}$ for 30 minutes.

\subsubsection{Preparation of the ferrocene linked anti-VEGF (Fc-anti-VEGF)}

The conjugation of ferrocene monocarboxylic to anti-VEGF is carried out as described by Lim and Matsunaga (Lim and Matsunaga, 2001). Briefly, $4 \mathrm{mg}$ of ferrocene monocarboxylic acid was dissolved in $800 \mu 1$ of Na-HEPES buffer $(0.15 \mathrm{M}, \mathrm{pH} 7.3)$ and filtered through a $0.22 \mu \mathrm{m}$ pore filter. $10 \mathrm{mg}$ of EDC and $90 \mu \mathrm{lof} 500 \mu \mathrm{g} / \mathrm{mL}$ anti-VEGF were then added to this filtered solution and incubated for 4 hours at room temperature. Removal of unlabeled ferrocene was carried out using ultrafiltration with a Centricon YM-30 filtration device. After each filtration step the filtrate was collected and analyzed using UV-Vis spectroscopy. Ultrafiltration was conducted until the peak corresponding to ferrocene disappeared from the spectra of the filtrate solution (Mina Okochi, 2005). 


\subsubsection{Modification of carbon fiber microelectrode surface}

Fc-anti-VEGF immobilization was carried out by coupling the carboxylic acid (-COOH) groups found on the carbon fiber to the $\mathrm{C}$ terminal of the antibody via a bifunctional linker molecule (Jeffamine ${ }^{\circledR}$ ED-600). This modification resulted in a stable monolayer of Fc-anti-VEGF on the carbon fiber surface.

\subsection{Activation of carbon fiber surface}

Carboxyl groups on the carbon fiber surface were activated by reacting with $4 \mathrm{mg} / \mathrm{mL}$ of EDC in phosphate buffer ( $\left.0.15 \mathrm{M} \mathrm{NaCI}, 0.10 \mathrm{M} \mathrm{Na}_{2} \mathrm{HPO}_{4}, \mathrm{pH} 7.4\right)$ for 12 hours.

\subsection{Attachment of $F c$-anti-VEGF to carbon fiber surface}

The electrodes were then dipped into a $0.4 \mathrm{mM}$ solution of Jeffamine ED-600 in aqueous buffer for 30 minutes. This attaches the hydrophilic spacer arm of Jeffamine to the electrode surface via an amide bond. Following a buffer wash, the electrodes were then placed in Fc-anti-VEGF solution for 5 hours at $4{ }^{\circ} \mathrm{C}$. The carboxylic groups present on the anti-VEGF antibody form amide bonds with the free terminal amines on the surfacebound Jeffamine molecules (Pantano et al., 1991). Thus two amide bonds formed on each end of the linker molecule assist in the immobilization of anti-VEGF on the carbon fiber microelectrode surface. Covalent coupling is always preferred as it provides a more stable and permanent binding of biological materials to the substrate. In the process of immobilized antibody-antigen molecular recognition, the orientation of the immobilized antibody and the accessibility of the antigen dictate the interaction between antibody and antigen. The use of a linker molecule for immobilization has been shown to considerably 
improve both these factors. Jeffamine ED-600 was found to have an optimal length that resulted in the highest binding efficiency and increase in bio-affinity of immobilized antibodies (Cao et al., 2007).

\subsection{Results and discussions}

\subsubsection{Characterization of disk shaped Carbon fiber microelectrodes}

\subsubsection{Surface characterization using SEM}

Controlling the electroactive surface area of the microelectrodes was a crucial parameter to achieve reliability and reproducibility. Uncoated cylindrical carbon fibers could not be used as it is difficult to control the area of the fiber in contact with the electrolyte during each measurement. Disk shaped microelectrodes fulfilled this requirement as they are fully insulated and only a uniform circular area corresponding to their diameter is electroactive. Carbon fiber microelectrodes were fabricated and properly sealed prior to being insulated by electropolymerisation using a phenol-allylphenol copolymer. The insulated carbon fibers were then transected using a scalpel blade under a dissecting microscope to reveal a disk shaped electroactive area. From the SEM images of the disk shaped microelectrode shown in figure 2.1. it is evident that the insulating layer is well formed and only the tip of the carbon fiber is exposed. 

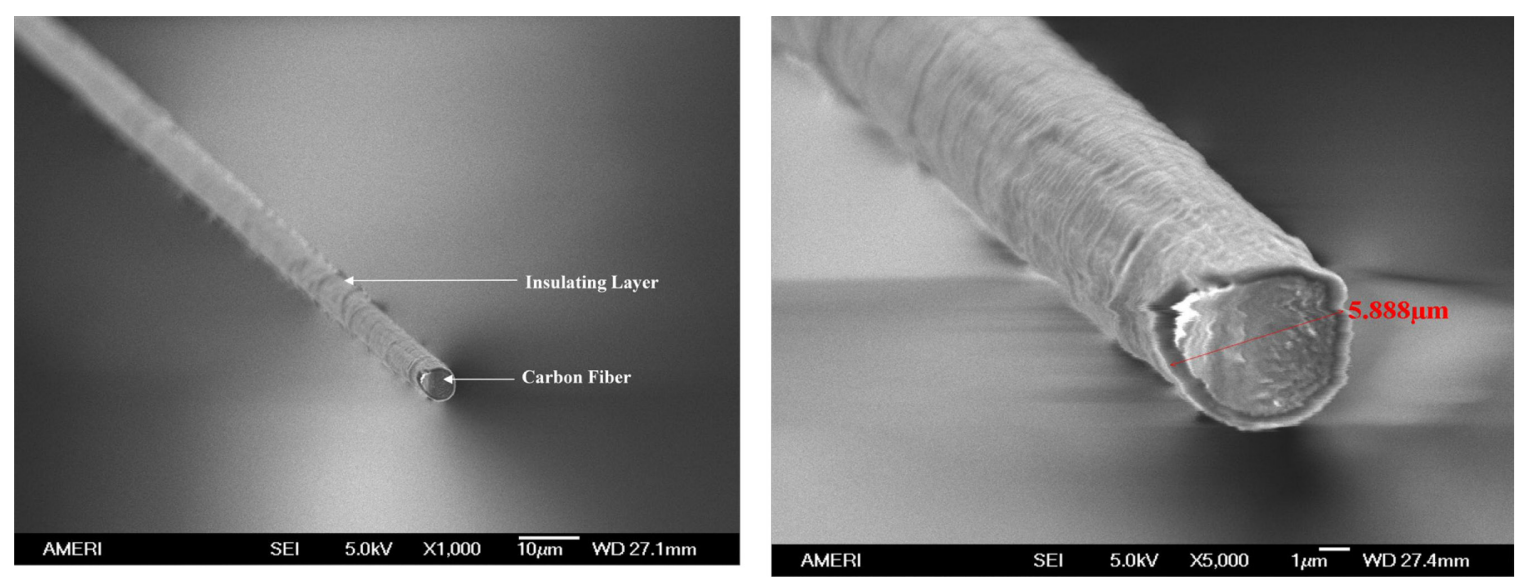

Figure 2.1. SEM images of phenol-allylphenol copolymer insulated disk shaped carbon fiber microelectrodes.

\subsubsection{Electrochemical characterization}

Cyclic voltammetry was performed in $0.03 \mathrm{M} \mathrm{Fe}(\mathrm{CN}) 6^{-3} /^{-4}$ before and after microelectrode insulation. From figure 2.2 it is evident that before insulation the electroactive area of each electrode varies however after insulation the electrodes behave in a similar pattern. The effective radii Reff of these electrodes can be determined from the limiting plateau currents $\left(\mathrm{I}_{\mathrm{lim}}\right)$ according to the following equation (Huang and Kennedy, 1995, Zhang et al., 1999).

$$
\mathrm{I}_{\text {lim }}=2 \pi \mathrm{nFDCReff}
$$

In the above equation, ' $n$ ' is the number of electrons transferred during the electrochemical process, ' $F$ ' is Faraday constant, while ' $D$ ' and ' $C$ ' are the diffusion coefficient and concentration of the electroactive species, respectively. By using the known value of the diffusion coefficient of potassium ferricyanide, $7.2 \times 10^{-6} \mathrm{~cm}^{2} / \mathrm{s}$, (Albillos et al., 1997) the average Reff for the microelectrodes was calculated to be 
approximately $5 \mu \mathrm{m}$. Carbon fiber microelectrodes with similar surface area were chosen for further work.
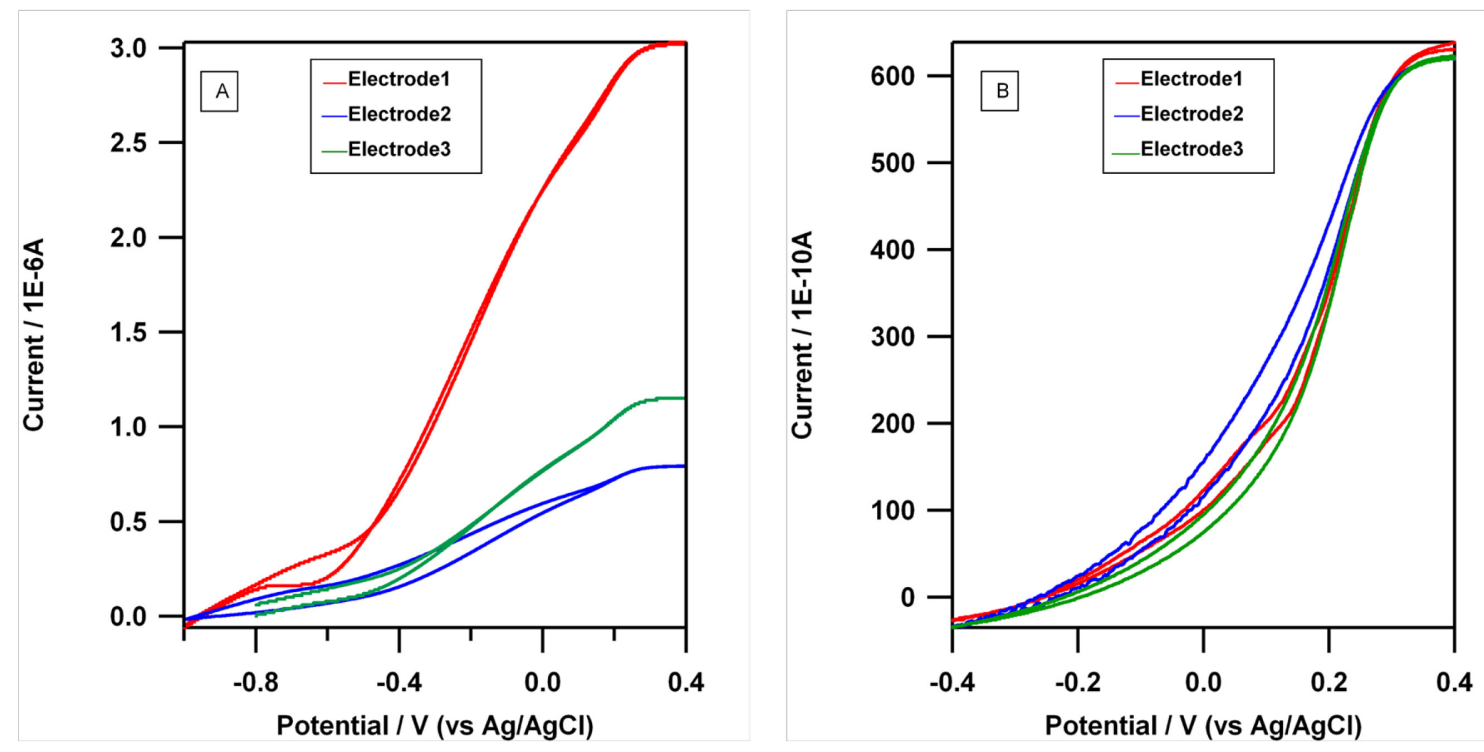

Figure 2.2.A. Cyclic voltammograms of 3 non-insulated carbon fiber microelectrodes. Measurements were taken in $0.03 \mathrm{~mol} / \mathrm{L}$ potassium ferricyanide solution. Scan rate was $0.1 \mathrm{~V} / \mathrm{s}$ and potential limits were from $-1.0 \mathrm{~V}$ to $+0.4 \mathrm{~V}$ vs. $\mathrm{Ag} / \mathrm{AgCl}$ reference electrode

Figure 2.2.B. Cyclic voltammograms of phenol-allylphenol insulated (disk shaped) carbon fiber microelectrodes. Measurements were taken in $0.03 \mathrm{~mol} / \mathrm{L}$ potassium ferricyanide solution. Scan rate was $0.1 \mathrm{~V} / \mathrm{s}$ and potential limits were from $-0.4 \mathrm{~V}$ to $+0.4 \mathrm{~V}$ vs. $\mathrm{Ag} / \mathrm{AgCl}$ reference electrode

\subsubsection{Molecular Assembly of Immunosensor}

This work has been directed towards developing a reagentless, electrochemical immunosensor for the detection of VEGF. The general molecular assembly of the immunosensor is depicted in figure 2.3. To construct the immunosensor carbon fiber microelectrodes were used as the sensing platform. Ferrocene tagged anti-VEGF antibodies were immobilized on the microelectrode surface using a Jeffamine linker. Covalent attachment of antibody using Jeffamine linker enables covalent attachment which offers higher stability than physical adsorption methods. Covalent attachment also 
enables better control of antibody orientation, which has been proven to play a key role in immunosensor performance. Direct oxidation of ferrocene tagged on anti-VEGF which is attached to the carbon fiber surface gives a measurable signal. The formation of VEGF and anti-VEGF immunocomplexes leads to spatial blocking and a drop in measured current. In our work, linear sweep voltammetry for the oxidation of ferrocene monocarboxylic acid was performed before and after incubation of VEGF with immunosensor, so that the resultant drop in oxidation peak current could be related to the amount of VEGF present in sample solution. Traditionally, sandwich formats which include two antibodies, one to capture the analyte and the other to provide a measurable signal have been used to create immunosensors. We describe a direct detection method in which a single antibody tagged using ferrocene performs both the functions of analyte capture and signaling, enabling a one-step detection platform. The voltammetric performance of the micro immunosensor is directly influenced by the parameters involved in its preparation. The incubation time and amount of anti-VEGF immobilized on the surface are two crucial parameters. Experiments were performed in order to evaluate and optimize the above mentioned parameters.

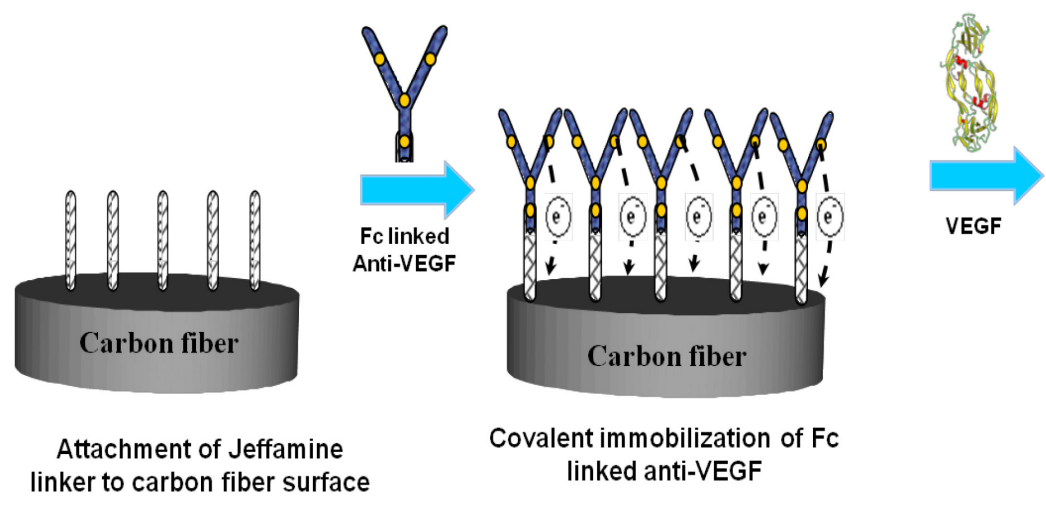

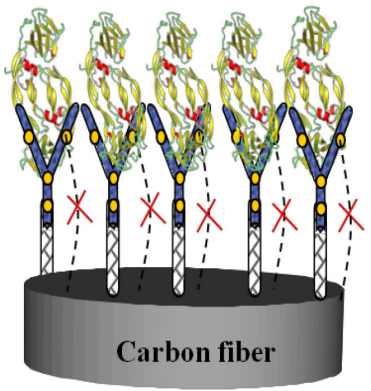

Immunocomplex formation. Increase in spatial blocking 
Figure 2.3. A schematic representing the molecular architecture and working of a micro immunosensor.

\subsubsection{Optimization of immobilization conditions}

\subsubsection{Effect of incubation time}

The incubation time required for the antigen-antibody immunoreaction is an important parameter that determines the performance of an immunosensor. Hence, we conducted experiments to optimize the incubation time. An Fc-anti-VEGF modified carbon fiber microelectrode was incubated with $5 \mu \mathrm{L}$ of $200 \mathrm{pg} / \mathrm{ml}$ VEGF solution. Linear sweep voltammetry was then performed in a $0.5 \mathrm{M} \mathrm{NaClO}_{4}$ solution at 10 minute intervals. From figure 2.4. it is evident that the oxidation peak current keeps decreasing gradually with the augment of incubation time. After about 40 minutes the peak current stabilizes, which indicates saturated formation of immunocomplex. Hence an incubation time of 40

minutes was chosen for all further experiments to allow completeness of the immunoreactions. 


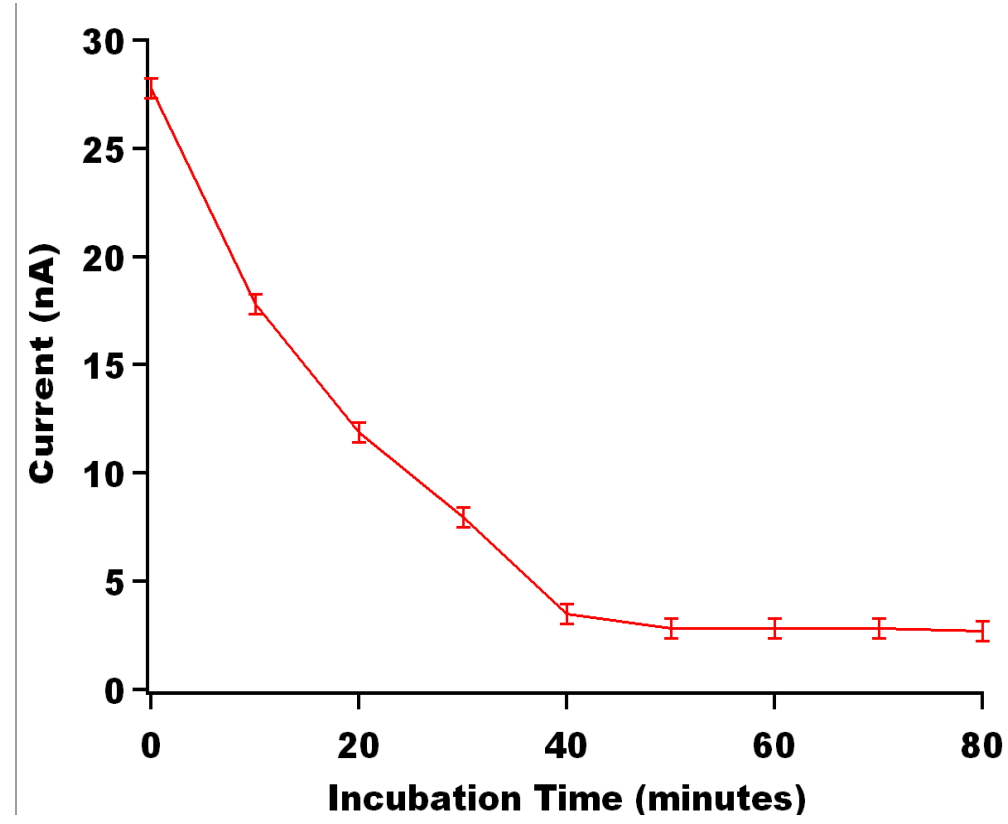

Figure 2.4. Fc-anti-VEGF modified carbon fiber microelectrode incubated with a $200 \mathrm{pg} / \mathrm{ml} \mathrm{VEGF}$ solution. Linear Sweep Voltammetry was performed in $0.5 \mathrm{M} \mathrm{NaClO}_{4}$ solution (vs. $\mathrm{Ag} / \mathrm{AgCl}$ ) every 10 minutes. Oxidation peak current is plotted versus responding incubation time.

\subsubsection{Amount of anti-VEGF immobilized carbon fiber microelectrode surface}

To evaluate the amount of ferrocene labeled antibody immobilized on the surface of carbon fiber microelectrode we rely on the resulting oxidation current from $\mathrm{Fc}$-antiVEGF modified electrode. Linear sweep voltammetry was performed in a $0.5 \mathrm{M} \mathrm{NaClO}_{4}$ solution at a scan rate of $0.75 \mathrm{~V} / \mathrm{s}$. In these experiments, 10 carbon fiber microelectrodes activated using EDC were incubated with different concentrations of $\mathrm{Fc}$-anti-VEGF solution for about 5 hours at $4{ }^{\circ} \mathrm{C}$. The oxidation current obtained for each of the electrodes were plotted against the corresponding concentration of the Fc-anti-VEGF solution with which it was incubated. We observe from figure 2.5. that enhanced binding of the antibody to the electrode surface was observed during the concentration range of $50-750 \mathrm{pg} / \mathrm{ml}$. The binding efficiency leveled off for the concentration of $800 \mathrm{pg} / \mathrm{ml}$ and 
higher. Hence, for all further immobilization experiments the ferrocene labeled antiVEGF concentration used was $800 \mathrm{pg} / \mathrm{ml}$.

To quantify the amount of ferrocene labeled anti-VEGF immobilized on carbon fiber microelectrode surface we use the following equation:

$$
\mathrm{Ip}=\mathrm{n}^{2} \mathrm{~F}^{2} \mathrm{vA \Gamma} / 4 \mathrm{RT}(2.2)
$$

where 'Ip' is the peak current, ' $n$ ' is the number of electrons transferred during the electrochemical process, ' $F$ ' is Faraday constant, ' $v$ ' is the scan rate in $V / s$, ' $I$ ' is surface coverage in $\mathrm{mol} / \mathrm{cm}^{2}$, ' $\mathrm{R}$ ' is the Universal Gas constant and ' $\mathrm{T}$ ' is temperature in ${ }^{\circ} \mathrm{K}$. Cyclic voltammetry performed in $0.5 \mathrm{M} \mathrm{NaClO}_{4}$ solution with a scan rate of $0.75 \mathrm{~V} / \mathrm{s}$, using an Fc-anti-VEGF modified Carbon fiber microelectrode revealed an oxidation peak current of $20.4 \mathrm{pA}$. Using these values in equation (2.2) we obtained surface coverage values of ferrocene to be $33.3 \times 10^{-7} \mathrm{~mol} / \mathrm{cm}^{2}$. To calculate the surface coverage of antiVEGF from that of ferrocene we have to consider that, approximately 12 ferrocene moieties are attached to each anti-VEGF molecule. Hence the surface coverage of antiVEGF is calculated to be $2.78 \times 10^{-8} \mathrm{~mol} / \mathrm{cm}^{2}$. 


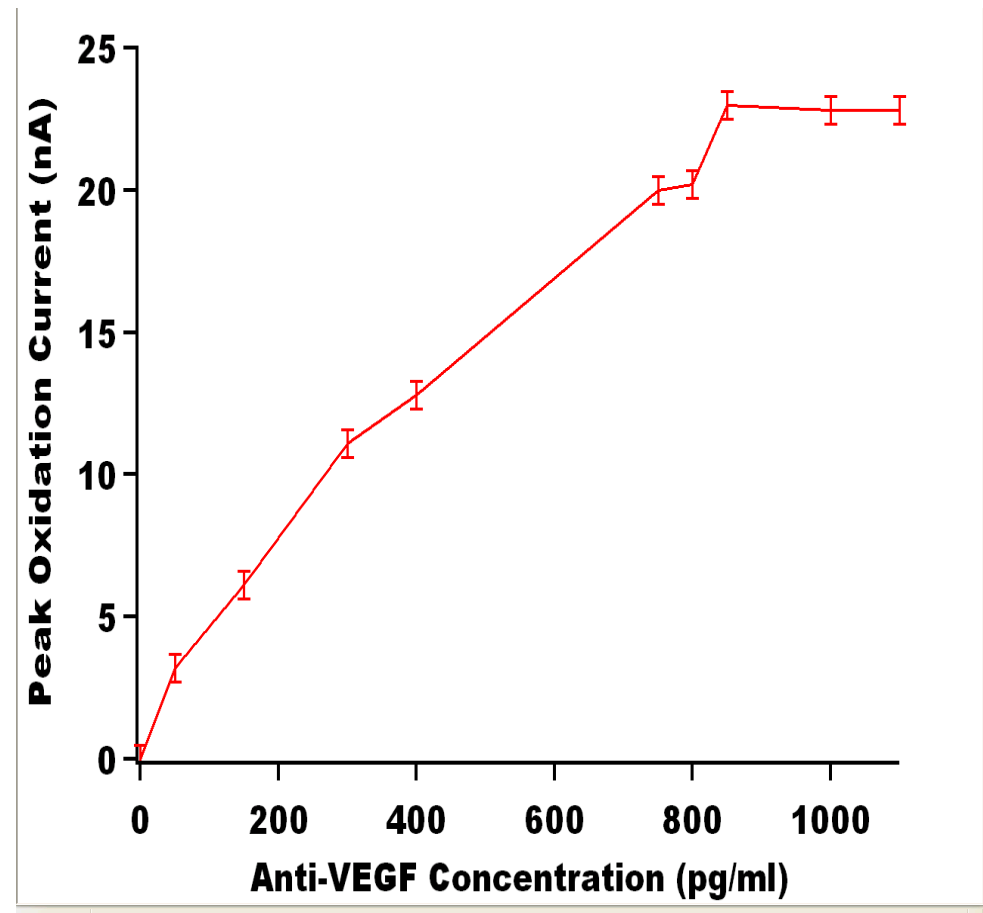

Figure 2.5. Three activated Carbon fiber microelectrodes were incubated with $5 \mu \mathrm{L}$ of PBS buffer, 50, 150, $300,400,750,800,850,1000,1100 \mathrm{pg} / \mathrm{ml}$ solutions of Fc-anti-VEGF solutions. Cyclic voltammetry was performed in $0.5 \mathrm{M} \mathrm{NaClO}_{4}$ solution (vs. Ag/AgCl) after 5 hours. The average value of peak oxidation current obtained from three microelectrodes is plotted versus the concentration of the antibody solution.

\subsubsection{Electrochemical Characterization of Fc-anti-VEGF modified Carbon fiber} microelectrodes.

The voltammetric behavior of Fc-anti-VEGF was studied at different scan rates ( 0.1 to $0.75 \mathrm{~V} / \mathrm{s}$ ) as shown in figure 2.6. All the voltammograms recorded at different scan rates exhibited well-defined, symmetrical oxidation and reduction peaks. The oxidation peak for free ferrocene monocarboxylic acid appears at $0.395 \mathrm{~V}$ versus $\mathrm{Ag} / \mathrm{AgCl}$ (Tanaka et al., 2007). In our case the anti-VEGF bound ferrocene displays an oxidation peak at 0.52 $\mathrm{V}$ versus $\mathrm{Ag} / \mathrm{AgCl}$. The shift in peak potential is due to the chemical conjugation of antiVEGF to the carboxylic acid of ferrocene. The redox potential of ferrocene derivatives depends on the functional groups present in the side chain (Padeste et al., 2000). Both the 
oxidation and reduction peak currents increased linearly with scan rates (figure 2.7.), which indicates that the $\mathrm{Fc}$ always remains on the electrode retaining its electrochemical activity. The oxidation and reduction peak currents were almost equal, and the potential difference between the peaks was constant with increase of scan rates showing that the electron transfer between the ferrocene moieties and carbon fiber microelectrode surface was relatively fast, indicating a surface controlled process (Zhang et al., 2007).

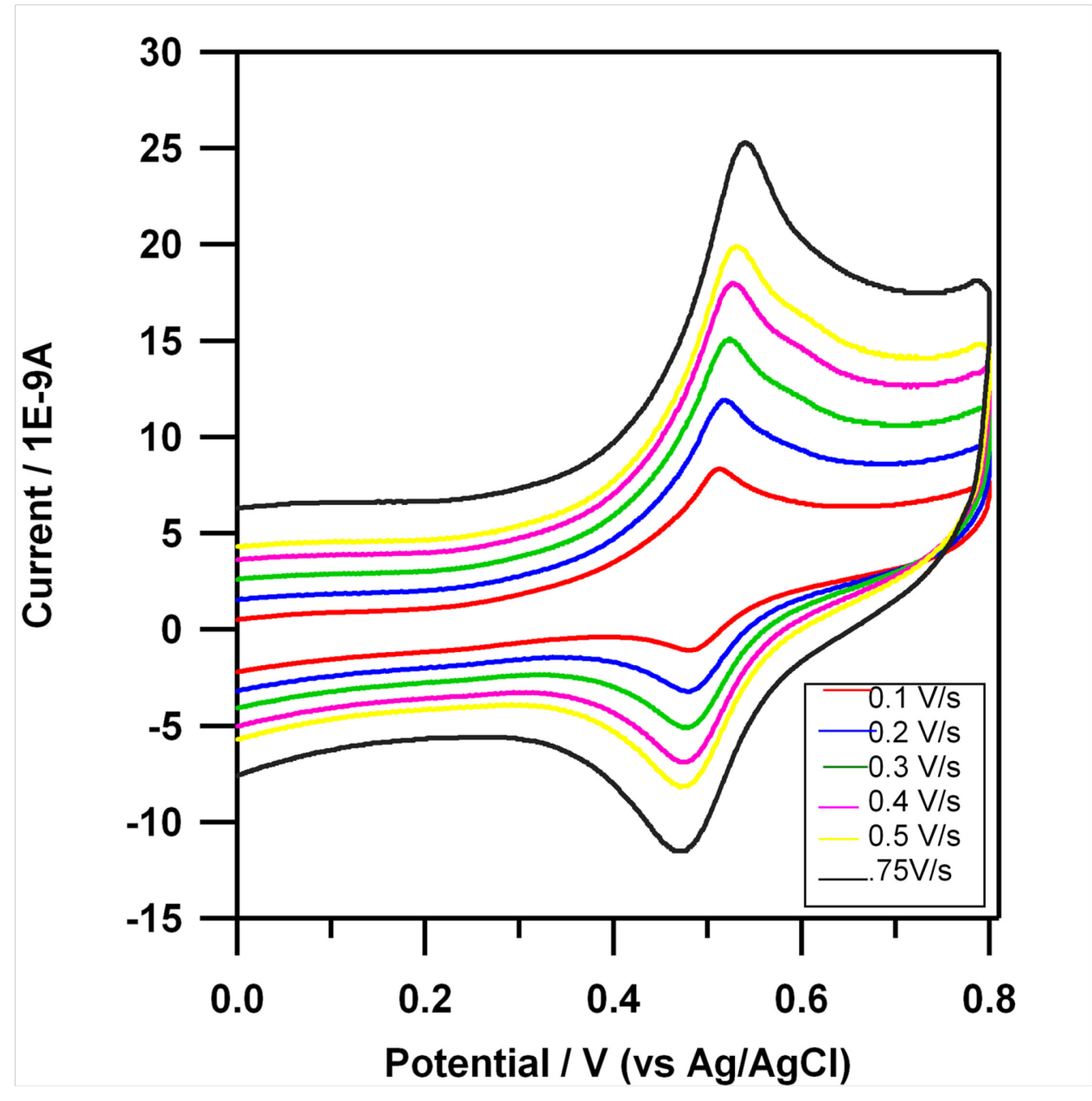

Figure 2.6. Cyclic Voltammograms of Fc-anti-VEFG modified Carbon fiber microelectrode measured in $0.5 \mathrm{M} \mathrm{NaClO}_{4}$, with scan rates of $0.1,0.2,0.3,0.4,0.5$, and $0.75 \mathrm{~V} / \mathrm{s}$. 


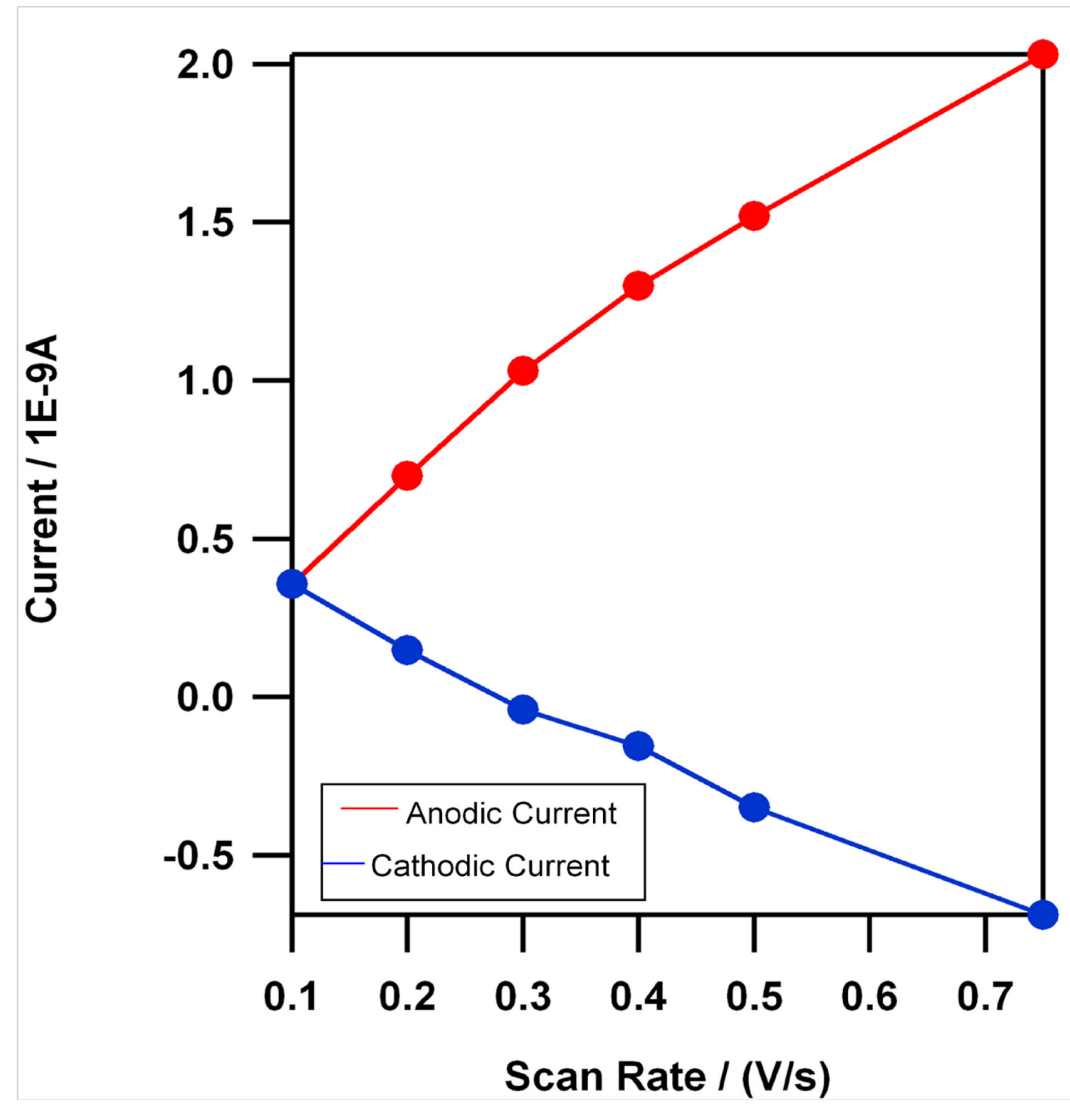

Figure 2.7. Anodic and Cathodic peak current of Fc-anti-VEGF modified carbon fiber microelectrode in 0.5 $\mathrm{M} \mathrm{NaClO}_{4}$ electrolyte.

\subsubsection{Detection of VEGF}

The micro-immunosensors designed as aforementioned were then incubated with 10 $\mathrm{pg} / \mathrm{ml}$ to $110 \mathrm{pg} / \mathrm{ml}$ solutions of VEGF at room temperature. After incubating the sensor with sample solutions for a period of 40 minutes, electrochemical measurements were carried out in a $0.5 \mathrm{M} \mathrm{NaClO}_{4}$ solution at a $0.75 \mathrm{~V} / \mathrm{s}$ scan rate. From Fig. 2.8., we observe that when we move from A-J the magnitude of the oxidation current decreases. This decrease in peak current with increase in VEGF concentration can be attributed to the increased spatial blocking caused due to the formation of immunocomplexes. The immunoreactions between VEGF and anti-VEGF causes a blockage to the flow of 
electrons coming from the ferrocene molecules attached to the antibody and traveling to the carbon fiber sensor surface (Wu et al., 2008). From this observation it is evident that a fall in peak current is inversely proportional to VEGF concentration in solution.

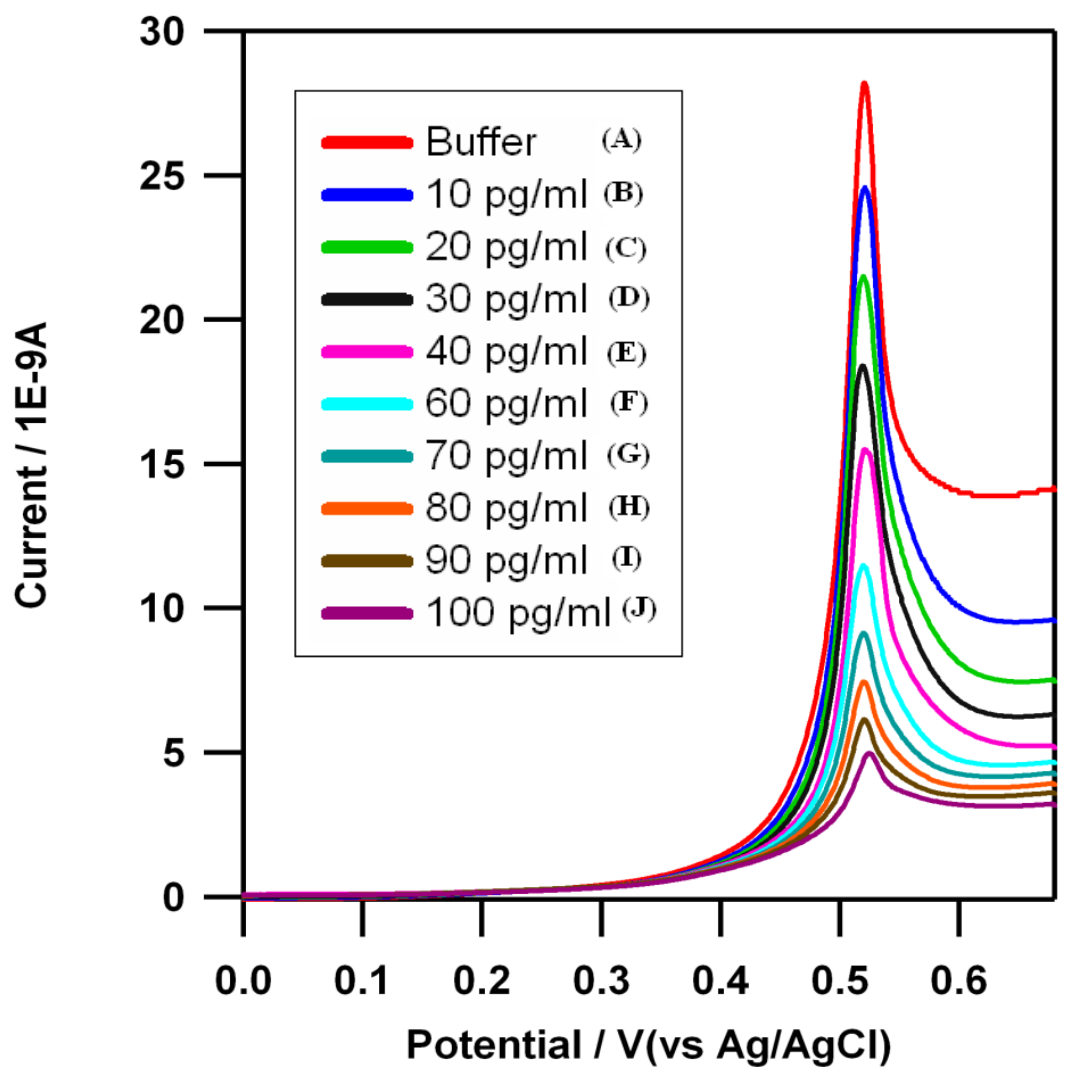

Figure 2.8. Linear sweep voltammetry responses of Fc-anti-VEGF modified carbon fiber microelectrode to VEGF at different concentrations. All measurements were performed in $0.5 \mathrm{M} \mathrm{NaClO}_{4}$ versus $\mathrm{Ag} / \mathrm{AgCl}$.

A calibration curve obtained by plotting change in peak current $\left(\Delta \mathrm{I}_{\text {peak }}\right)$ against the concentration of VEGF is shown in figure 2.9. Based on the plot the sensitivity and detection limit were found to be $2.047 \mathrm{pA} \mathrm{pg} / \mathrm{ml}$ and $38 \mathrm{pg} / \mathrm{ml}$, respectively. 


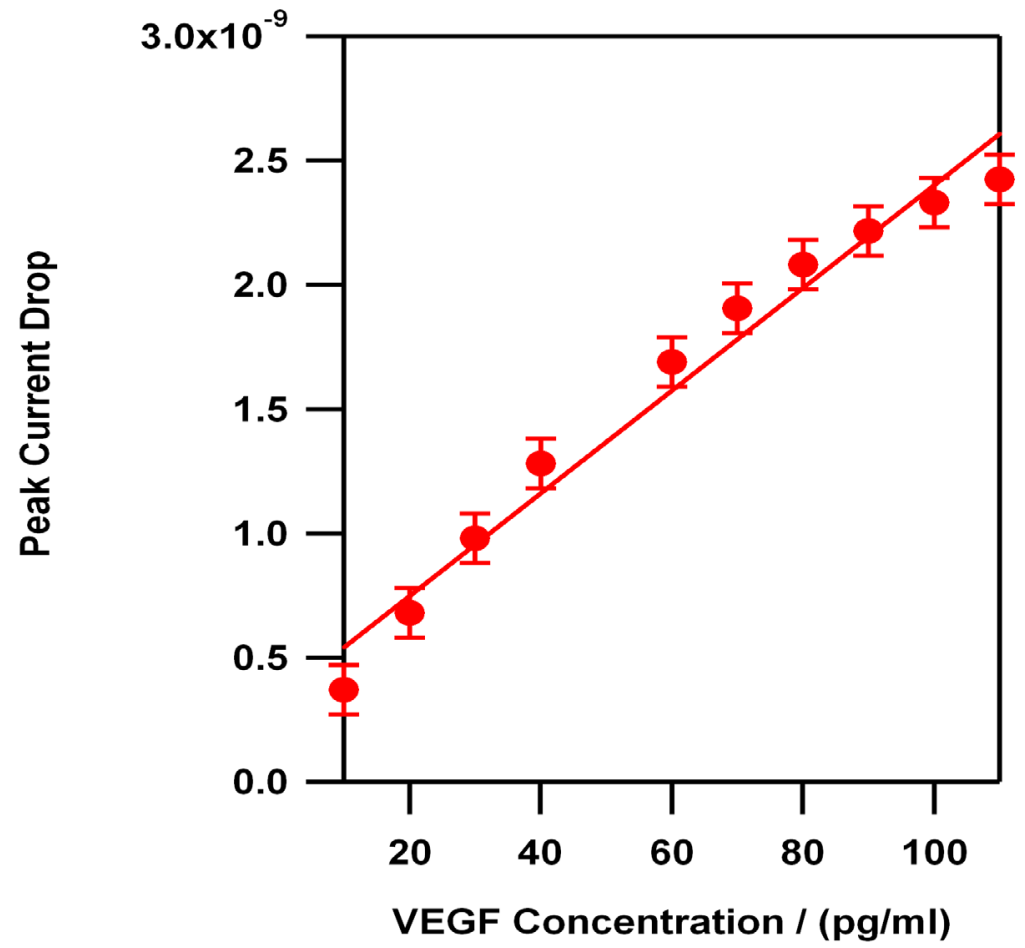

Figure 2.9. Calibration Curve: The linear relationship between change of current response and VEGF concentration.

\subsubsection{Evaluation of electrode stability}

We have evaluated the stability of the electrodes over a period of one month. The microimmunoelectrodes were stored in $0.1 \mathrm{M}$ PBS buffer solution at $4{ }^{\circ} \mathrm{C}$ after fabrication. Stability of the designed electrodes was studied by incubating them with $50 \mathrm{pg} / \mathrm{ml}$ of VEGF. Cyclic voltammetry was performed every day before and after incubation. The activity of the immunosensors was evaluated by measuring the drop in peak current after incubation. Up to the $24^{\text {th }}$ day the drop in peak current corresponded to the drop expected for $50 \mathrm{pg} / \mathrm{ml}$ of VEGF. From then onwards the activity of the immunosensors kept declining. This trend suggests that the designed electrodes are suitable for VEGF analysis up to 24 days. 


\subsubsection{Specificity Studies}

Specificity is a crucial parameter which influences the performance of an immunosensor in real matrices. We need to prove that the presented sensor responds only to the VEGF and anti-VEGF immunoreaction and not to the nonspecific adsorption of other proteins. In order to demonstrate the specificity of our immunosensor we have incubated our electrodes with IgG and bovine serum albumin (BSA). Four Fc-anti-VEGF modified carbon fiber microelectrodes were incubated for 40 minutes with 4 different sample solutions which include a) $50 \mathrm{pg} / \mathrm{ml}$ VEGF, b) $50 \mathrm{pg} / \mathrm{ml} \mathrm{IgG,} \mathrm{c)} 25 \mathrm{pg} / \mathrm{ml}$ VEGF +25 $\mathrm{pg} / \mathrm{ml} \mathrm{IgG}$, and, d) $10 \mu \mathrm{g} / \mathrm{ml}$ BSA in $10 \mathrm{mM}$ PBS, respectively. Linear sweep voltammetry was performed before and after incubation for each electrode. Figure 2.10. shows drop in peak current after incubation with the sample solutions. It is evident that there a current drop proportional to the VEGF concentration for samples a and c. However, samples b and d show no significant changes in peak currents. Hence we can conclude that the obtained current change was caused due the immunoreactions of VEGF and anti-VEGF and the presence of other proteins seemed not to interfere with the sensor performance. 


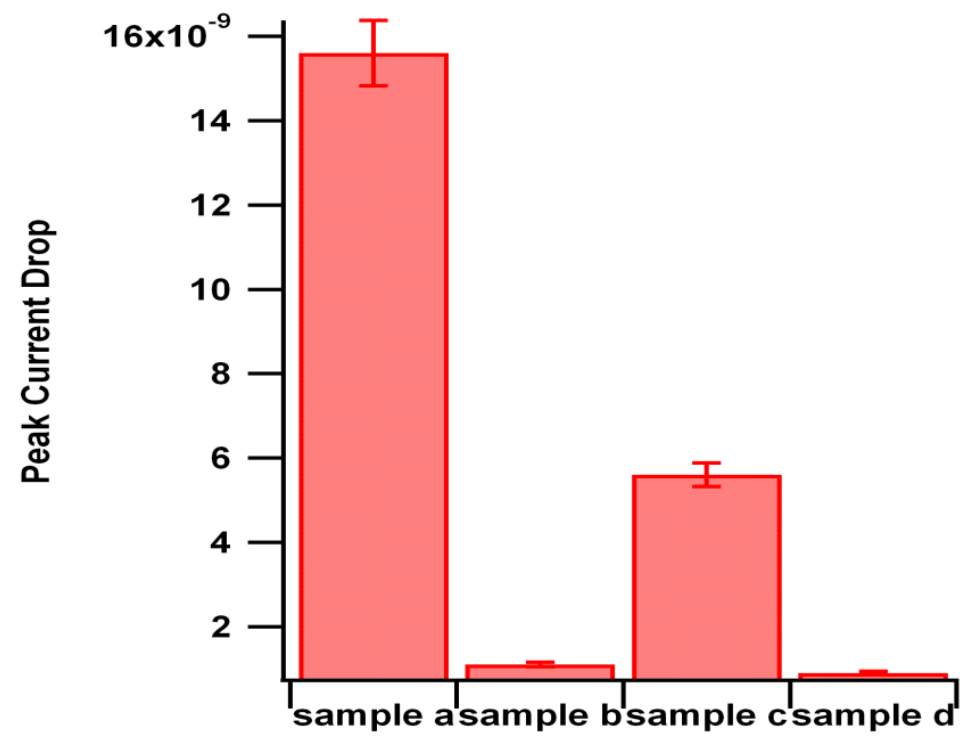

Figure 2.10. Drop in peak current of $4 \mathrm{Fc}$-anti-VEGF modified carbon fiber microelectrodes after being incubated with sample a (50 pg/ml VEGF), sample b (50 pg/ml IgG), sample c ( $25 \mathrm{pg} / \mathrm{ml}$ VEGF $+25 \mathrm{pg} / \mathrm{ml}$ $\mathrm{IgG})$, and sample d (10 $\mu \mathrm{g} / \mathrm{ml} \mathrm{BSA})$ in $10 \mathrm{mM}$ PBS respectively. Measurements were performed in $0.5 \mathrm{M}$ $\mathrm{NaClO}_{4}$ versus $\mathrm{Ag} / \mathrm{AgCl}$.

\subsection{Conclusion}

In this work we have successfully designed and characterized a reagentless, miniaturized electrochemical immunosensing system for the rapid detection of VEGF. In addition, this single use sensor requires no sample preparation for measurement of VEGF in patient fluid samples. The detection mechanism is based on the measurement of electrochemical signal changes induced by the interfacial immunoreactions of surface immobilized ferrocene linked anti-VEGF antibody probes with VEGF present in solution. A detection limit of about $38 \mathrm{pg} / \mathrm{ml}$ for VEGF is obtained in this work which is sufficient to detect VEGF in plasma of normal subject $(138 \mathrm{pg} / \mathrm{ml})$ and cancer patients (435$445 \mathrm{pg} / \mathrm{ml}$ ) (Karayiannakis et al., 2002). Further, a similar detection strategy can be applied towards the detection of any non-electroactive biomolecules by using an appropriate antibody. Therefore the detection strategy is applicable towards most 
biomolecules present in patient fluid samples and can be used to obtain diagnostic, prognostic or therapy response related information. The limitations of the detection strategy are the long response time (45 minutes), need to redox probe (ferrocene) to provide an indirect measurement of biomarker binding, and single-use capabilities. In order to resolve these disadvantages a direct detection strategy was developed as described in Chapter 3. 


\section{Chapter 3}

Electrochemical Sensor for Multiplex detection of Amyloid Beta 40 and 42 for Alzheimer's Disease Diagnostics 


\subsection{Introduction}

Alzheimer's disease (AD) is one of the most common neurodegenerative diseases currently affecting about 5.3 million people in the United States alone (Herbert et al., 2003). The national cost of caring for $\mathrm{AD}$ patients is $\sim 100$ billion each year. Despite important advances in the understanding of $\mathrm{AD}$, much is still unknown about the underlying cause of the disease. A $\beta$ peptide compries of 39-42 amino acids is the primary constituent of plaques found in the brain of patients suffering from AD. These insoluble plaques hinder the communication between neurons causing cell death, cognitive dysfunction, and behavioral abnormalities, they also initiate a host of other events including inflammation and tau aggregation as neurofibrillary tangles (Hardy and Higgins, 1992; Murphy and LeVine, 2010). However, till date there is no inexpensive, sensitive, real time detection strategy for monitoring $A \beta$ in-vivo which can ultimately answer critical questions regarding its production, accumulation and clearance under physiological and patho-physiological scenarios. The growing potential of the $A \beta$ ratio to act as a biomarker in diagnostic, prognostic, and therapeutic research studies warrants a better understanding of its biochemistry (Andreasen et al., 1999; Hampel et al., 2010; Blennow, 2004). There is still a significant amount of research required to completely understand the link between $\mathrm{A} \beta$ and the underlying cause of AD. Assessment of the interstitial and cerebrospinal pools of $A \beta$ may provide unique insights into the regulation of $A \beta$ aggregation and plaque formation (Bibl et al., 2007; Tampellini and Gunnar, 2010). Studies of this nature have been previously performed in-vitro on neuronal cell cultures and brain slices using fluorescence microscopy and ELISA (Wyss-Coray et al., 
2003). Towards in-vivo $A \beta$ measurements, microdialysis has been the most commonly utilized technique for the past 10 years (Cirrito et al., 2005).

This work has been directed towards the development of an electrochemical immunosensor capable of simultaneously detecting two $A \beta$ isoforms using the intrinsic electroactivity of $A \beta$ (Vestergaard et al., 2005). A $\beta$ contains a single Tyr residue at position 10 , bearing a phenolic group, which is easily oxidized at the electrode surface (Chikae et al., 2008). Carbon fiber microelectrodes were used as the platform sensor as they offer advantages such as high signal to noise ratio, biological compatibility, and miniature size (Armstrong-James and Millar, 1979). Carbon based electrodes have been proven to sensitively detect Tyr oxidation (Okuno et al., 2007; Kerman et al., 2006). Using SWV the voltage applied to the carbon fiber microelectrode was scanned within a window of $-0.2 \mathrm{~V}$ to $1.0 \mathrm{~V}$. The voltammogram shows increase/peak in measured current due to the oxidation of electroactive species, when the electrode attains the corresponding oxidation potential. When the electrode scans through $0.6 \mathrm{~V}$, Tyr residues present in $\mathrm{A} \beta$ oxidize which causes up to 4 electrons/molecule to be released that are detected by the electrode as increased/peak current. While $0.6 \mathrm{~V}$ can cause oxidation of a variety of molecules, including all nearby tyrosines, an antibody covalently attached to the electrode surface can provide specificity for a particular target such as $\mathrm{A} \beta$. By monitoring the intrinsic electrochemical activities of $A \beta$, direct, real-time, and reagentless detection is possible. 


\subsection{Materials and Methods}

Carbon fibers $(5 \mu \mathrm{m}$ in diameter) were donated by World Precision Instruments (Sarasota, FL). Borosilicate glass capillaries (3 barrels, inner diameter $1.0 \mathrm{~mm}$ ) were obtained from Sutter Instrument Company (Novato, CA). Sylgard 184 was obtained from Dow Corning Corporation (Midland, MI). 1-ethyl-3-[3-dimethylaminopropyl] carbodiimide hydrochloride (EDC) and $N$-hydroxysulfosuccinimide (NHSS), EZ-Link Plus Activated Peroxidase was purchased from Thermo Fisher Scientific Inc. (Rockford, IL). A $\beta$ antibodies (mHJ2, mHJ7.4, mHJ5.1) were donated by Dr. Cirrito's laboratory. A $\beta 1-40$ and A $\beta 1-42$ synthetic peptide were obtained from American Peptide Company (Sunnyvale, CA). MES buffer, 3,3'-diaminobenzidine (DAB), hydrogen peroxide $\left(\mathrm{H}_{2} \mathrm{O}_{2}\right)$, sodium chloride, and other reagents were purchased from Sigma-Aldrich (St. Louis, MO).

\subsubsection{Instrumentation}

Carbon fiber microelectrodes were prepared using P-97 Micropipette Puller and BV-10 Beveller acquired from Sutter Instrument Company (Novato, CA). Microelectrode activation and electrochemical measurements in connection with $\mathrm{CV}$, differential pulse voltammetry (DPV) and SWV were carried out using the 600C Electrochemical Analyzer attached to a Picoamp Booster from CH Instruments, Inc. (Austin, TX). SEM of the triple barrel microelectrodes was carried out on the JEOL JSM 5900LV. The cyclic square

wave E-field was applied using the Leader LFG-13005 function generator and monitored using the Lafayette-82418 oscilloscope. A conventional three electrode cell consisting of 
an $\mathrm{Ag} / \mathrm{AgCl}$ reference electrode $(3 \mathrm{M} \mathrm{KCl})$ (Bioanalytical Systems, IN, USA), and a platinum wire as an auxiliary electrode was employed.

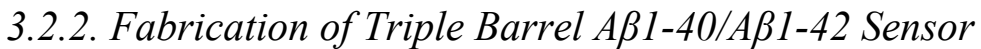

Triple barrel carbon fiber microelectrodes were fabricated using the same method as described in our previous work. Briefly, a single carbon fiber of diameter $5 \mu \mathrm{m}$ was attached to the stripped end of an insulated copper wire (diameter $0.2 \mathrm{~mm}$ ) using a silver conductive paste. Each barrel of the borosilicate glass triple barrel capillary was then cannulated with a carbon fiber attached copper wire. The three copper wires were then fixed to the capillary using a fast drying epoxy resin. The capillary was then pulled using a micropipette puller. This pulling procedure results in two glass pipettes, one of which is discarded, and the other which holds three carbon fibers protruding from its tip. The junction between the carbon fibers and capillary is sealed with a drop of the Sylgard silicone preparation and allowed to cure until it becomes firm. The microelectrodes were then beveled at $45^{\circ}$ using a diamond abrasive plate, to obtain three disk shaped electrodes which are completely isolated from each other. The surface of the electrodes was cleaned by $5 \mathrm{~s}$ sonication in acetone, $1 \mathrm{M}$ nitric acid, $1 \mathrm{M} \mathrm{KOH}$ and distilled water sequentially. To facilitate the binding of capture antibody, the microelectrodes were electroactivated using a $150 \mathrm{mM} \mathrm{NaCl}$ solution $(\mathrm{pH}=10)$ at $1.2 \mathrm{~V}(\mathrm{vs} . \mathrm{Ag} / \mathrm{AgCl})$ for 8 minutes at room temperature. $0.4 \mathrm{M}$ of EDC and 0.1 M of NHSS solutions in 0.1 M MES buffer ( $\mathrm{pH}=6)$ were then sequentially applied for 20 minutes to activate the carboxylic groups on the carbon fiber surface by forming a semi stable amine reactive NHS ester. The microelectrodes were then placed sequentially in mHJ2 (specific to A $\beta 1-40)$ (E1(40)), 
mHJ7.4 (specific to $\mathrm{A} \beta 1-42)$ (E2(42)), and mHJ5.1 (specific to all isoforms of $\mathrm{A} \beta$ ) (E3(TOT)) antibody solutions and a cyclic square wave E-field $(-0.3 \mathrm{~V}$ to $+0.3 \mathrm{~V}, 0.1$ $\mathrm{Hz}, 10$ minutes) was applied sequentially to each electrode versus a platinum wire cathode. Application of the E-field allows for the selective placement of $\mathrm{mHJ} 2$ on E1, mHJ7.4 on E2(42) and mHJ5.1 on E3(TOT). Electrodes were incubated in $0.1 \%$ ethanolamine solution to block any non-specific binding sites. In order to obtain quantitative measurements about the amount of antibody conjugated to the electrode, horseradish peroxide (HRP) labeled antibodies were utilized. Labeling of A $\beta$ antibody (mHJ5.1) to HRP was performed as per protocol specified by Thermo Scientific. DAB and $\mathrm{H}_{2} \mathrm{O}_{2}$ were used as the substrates in HRP catalysis reaction and measurements were conducted using DPV (Zhang et al., 2008). Crucial parameters related to efficient antibody immobilization such as antibody solution concentration, E-field parameters, and immobilization time were optimized based on the HRP based electrochemical results.

\subsubsection{Measurement of $A \beta 1-40$ and $A \beta 1-42$ in cerebrospinal fluid (CSF) solutions}

Aforementioned micro-immunosensors were then challenged using rat CSF solutions spiked with different combinations of $A \beta 1-40$ and $A \beta 1-42$ within a range of $10 \mathrm{nM}$ to 2 $\mu \mathrm{M}$. A cyclic square wave E-field ( +0.75 to $-0.75 \mathrm{~V}, 50 \mathrm{~Hz}, 10$ minutes) was applied simultaneously to each of the three electrodes in order to accelerate the incubation process. The electrodes were rinsed twice with PBS buffer $(\mathrm{pH}=7.2)$ to get rid of any randomly or loosely attached $\mathrm{A} \beta$ molecules. SWV was used to simultaneously evaluate the response of each of the three microelectrodes before and after the 
immunoreactions.SWV voltammetry was performed using $10 \mathrm{mM} \mathrm{PBS}$ and $1 \mathrm{mM} \mathrm{KCl}$ as the supporting electrolyte.

\subsection{Results and Discussion}

\subsubsection{Molecular architecture of the immunosensor}

Here we report the development of a real-time immunosensor which can perform highly sensitive $\mathrm{A} \beta$ measurements. The general molecular architecture and working principle of the immunosensor is shown in Fiure 3.1. To construct this immunosensor, 3 distinct antibodies were placed on each of the barrels of the carbon microelectrode. Antibodies mHJ2 placed on E1(40) and mHJ7.4 placed on E2(42) are highly specific to the detection of A $\beta 1-40$ and $A \beta 1-42$ respectively. Antibody mHJ5.1 which binds to the central region of the $A \beta$ peptide can capture all $A \beta$ isoforms and thus acts as a positive control for the immunosensor. The function of antibodies in the developed immunoensor is three-fold and needs to be explained in detail. 1) Antibodies capture/bind $A \beta$ molecules to the sensor surface which decreases the electron tunneling distance between the sensor surface and the $A \beta$ molecules. The decrease in the tunneling distance allows for electrons generated due to the oxidation of $A \beta$ to travel to the sensor surface during SWV and generate a current signal. Therefore lower quantities of $A \beta$ can also generate a measurable signal and improve sensor performance. 2) The capture/binding of $A \beta$ to the surface of the carbon fiber eliminates cross talk between the 3 microelectrodes during simultaneous measurements of $A \beta 1-40$ and $A \beta 1-42.3)$ Antibodies also enable highly specific detection of $A \beta 1-40$ and $A \beta 1-42$. 
In this work SWV for the oxidation of $A \beta$ was performed so that the magnitude of the resultant oxidation peak could be related to the amount of $A \beta 1-40 / 42$ captured by the specific antibodies onto the electrode surface. Parameters involved in the preparation of an immunosensor play a vital role on its voltammetric response. Therefore, the immunosensor was optimized for a maximum voltammetric response by optimizing key parameters such as amount of antibody immobilized on the electrode surface and incubation time. A cyclic square wave E-field was applied in order to accelerate the movement of antibodies towards the electrode surface which resulted in faster immobilization time.
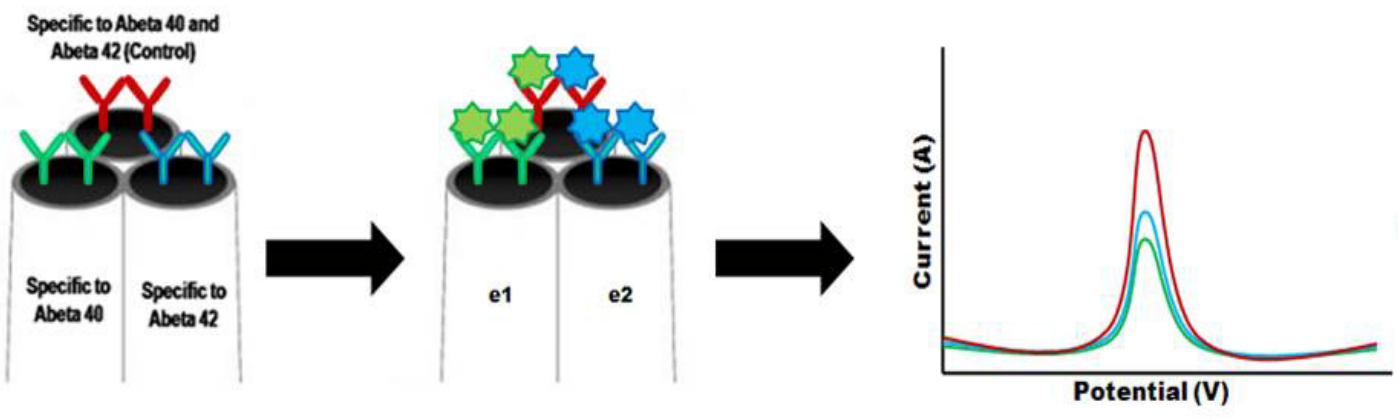

Figure 3.1. Schematic illustration of the microbioelectronic detection system for Alzheimer's disease related $\mathrm{A} \beta 1-40$ and $\mathrm{A} \beta 1-42$ peptides.

\subsubsection{Characterization of fabricated triple-barrel carbon fiber microelectrodes}

Carbon fiber microelectrodes have previously been employed for the direct electrochemical evaluation of neurotransmitters, enzymes, etc. In addition, the use of microelectrodes opens up the possibility of in-vivo application of the immunosensor. The miniaturized size of the electrode (several microns in diameter) would allow the careful 
selection of the biological matrix to be investigated with negligible physical damage to the implanted region (Huffman and Venton et al., 2008). Figure 3.2 shows the image of a triple barrel carbon fiber microelectrode obtained using SEM. The SEM image of the tip of the electrode shows three distinct disc shaped carbon fibers embedded in an epoxy matrix. From the SEM images each of the carbon fibers can be estimated to be $4-5 \mu \mathrm{m}$. In order to precisely quantify the effective working area of each electrode, cyclic voltammetry was conducted. Based on Randles-Sevcik equation $\left(\mathrm{Ipa}=\left(2.69 \times 10^{5}\right) \mathrm{n}^{3 / 2}\right.$ $\mathrm{AD}^{1 / 2} v^{1 / 2} \mathrm{C}_{\mathrm{red}}$ ), the electroactive area (A) of all electrodes was determined from the anodic peak current (Ipa) obtained in the cyclic voltammograms conducted using $0.03 \mathrm{M}$ $\mathrm{Fe}(\mathrm{CN})_{6}^{-3} /^{-4}\left(\mathrm{C}_{\mathrm{red}}\right)$ at a specific scan rate $(v)$ as shown in figure 3.3. The diffusion coefficient (D) was taken to be $6.5 \times 10^{-6} \mathrm{~cm}^{2} \mathrm{~s}^{-1}$ at $20{ }^{\circ} \mathrm{C}$ as derived by Kakuichi et al., 2002 and the average effective working area for each of the microelectrodes was calculated to be approximately $\sim 5 \mu \mathrm{m}$.

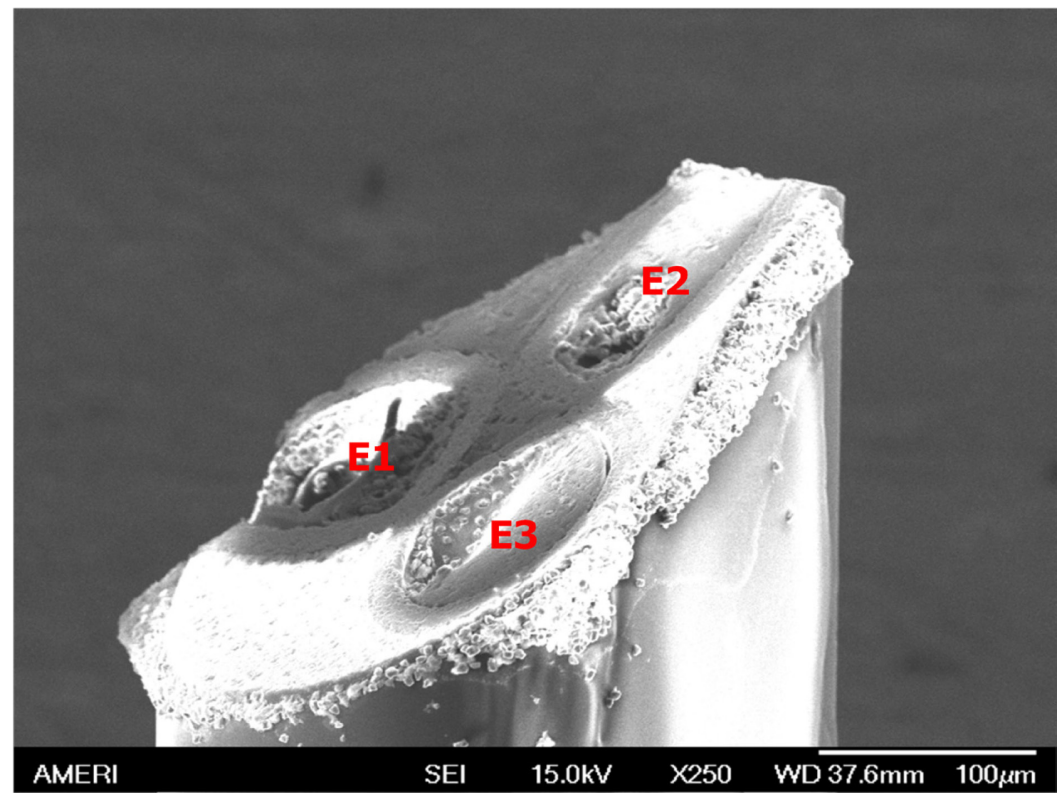

Figure 3.2. SEM image triple barrel carbon fiber microelectrode. 


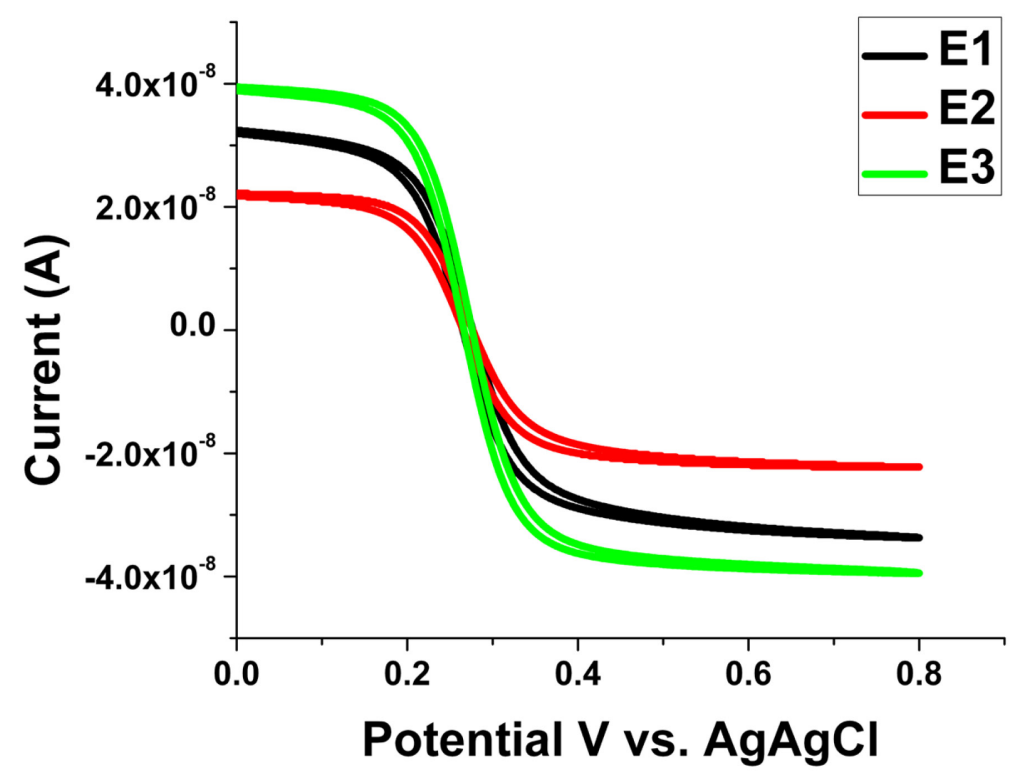

Figure 3.3. Cyclic voltammograms of the three barrels of a microelectrode. Measurements were taken in $0.03 \mathrm{~mol} / \mathrm{L}$ potassium ferricyanide solution. Scan rate was $0.1 \mathrm{~V} / \mathrm{s}$ and potential limits were from 0.0 to $+0.8 \mathrm{~V}$ versus $\mathrm{Ag} / \mathrm{AgCl}$ reference electrode.

\subsubsection{Optimization of antibody immobilization parameters}

In the development of electrochemical immunosensors the immobilization of the biorecognition element on the electrode is critical towards sensor performance. The surface of carbon fibers is well known to exhibit many reactive sites including hydroxylic, phenolic and carboxylic functionalities (Pantano and Kuhr, 1991). In order to expose these groups, the carbon fiber microelectrodes are electrochemically pretreated (Prabhulkar and $\mathrm{Li}, 2010$ ). The microelectrodes were electroactivated using a $150 \mathrm{mM}$ $\mathrm{NaCl}$ solution $(\mathrm{pH}=10)$ at $1.2 \mathrm{~V}(\mathrm{vs} . \mathrm{Ag} / \mathrm{AgCl})$ for 8 minutes at room temperature. The next step towards the construction of the immunosensor was to employ a carbodimide reaction to selectively attach the three antibodies on the surface of each of the barrels of the microelectrode. In order to test binding of the antibody to the electrode surface, we 
first conjugated HRP to the antibody. HRP provides a large oxidative signal that is easily detected by the electrode; HRP-labeled antibodies were only used to test for antibody absorption to the electrode. This involved the incubation of the pretreated microelectrodes in EDC and NHSS solutions. Initially the EDC and NHSS solutions were prepared in PBS buffer; however a negligible amount of antibody was bound to the electrode surface as measured by the electroactivity of the HRP label. We therefore switched the buffer to MES which showed a much higher peak from the HRP-labeled (mHJ5.1) antibodies as seen in Figure 3.4

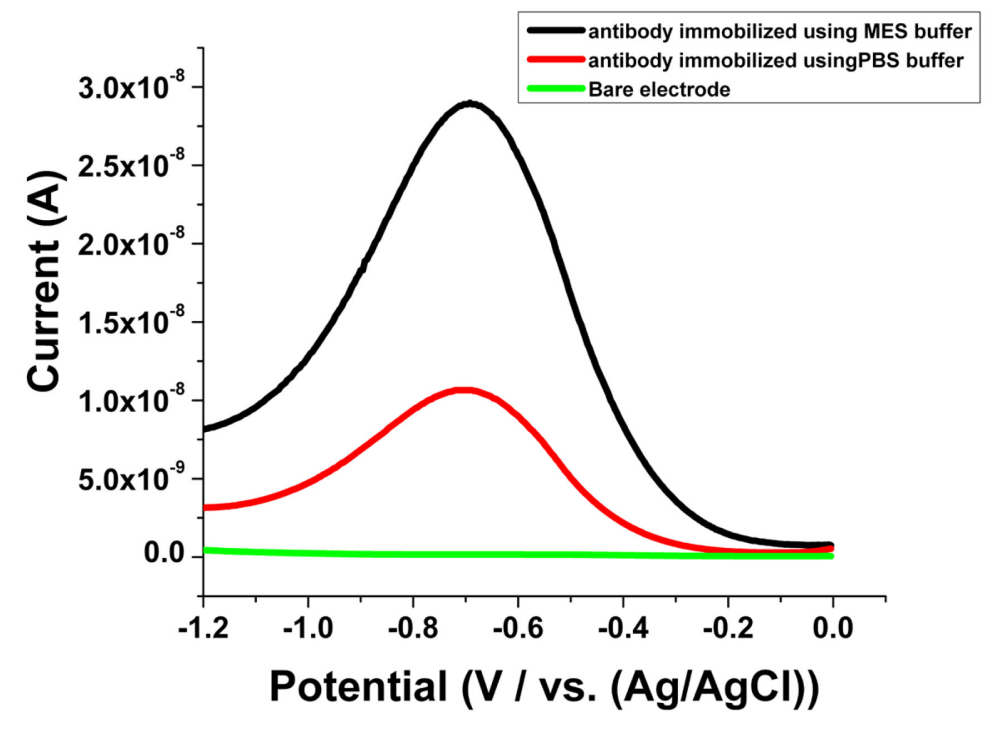

Figure 3.4. DPV response obtained from HRP labeled antibodies immobilized using PBS and MES buffer solutions.

HRP-labeled (mHJ.2) antibodies were used to optimize the parameters of the cyclic square wave (CSW) E-field which was applied to accelerate the incubation process by promoting the transport of the antibodies to the electrode surface (Wei et al., 2009). The CSW E-field creates a mass transportation effect in the incubation solution which creates 
good mixing in shorter time as compared to diffusion kinetics. The voltage applied to three electrodes was varied from $\pm 0.1 \mathrm{~V}$ to $\pm 0.5 \mathrm{~V}$ for equal positive and negative cycles. The electrodes were monitored by conducting DPV at every 1 minute interval for a period of 12 minutes. Based on the data shown in Figure 3.5 and 3.6 the optimum incubation time and applied voltage were chosen as $\pm 0.3 \mathrm{~V}$ and 7 minutes respectively.

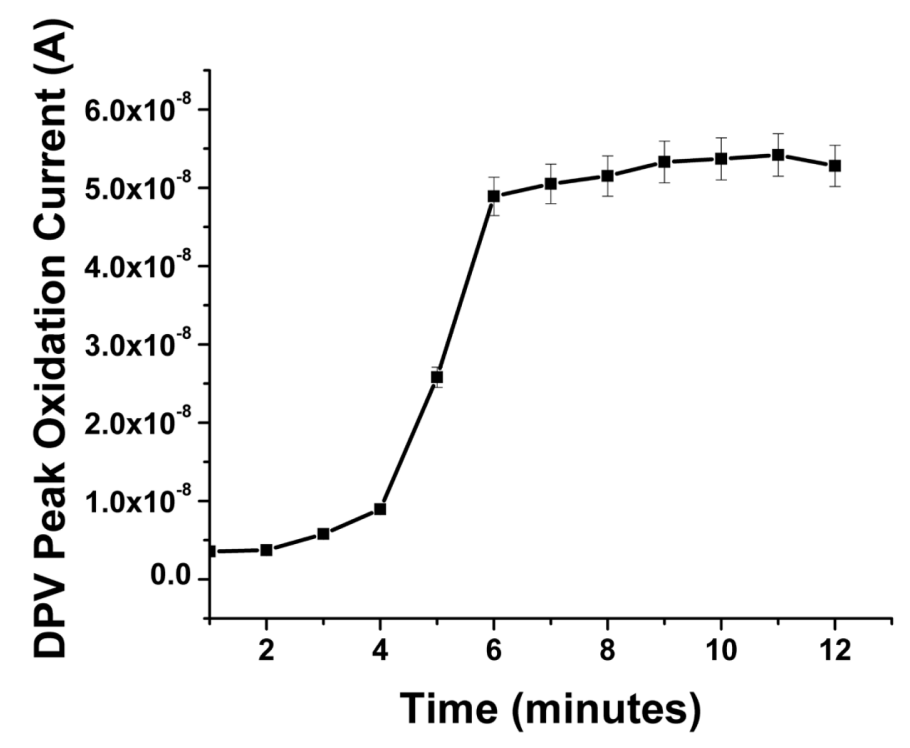

Figure 3.5. Bare triple barrel carbon fiber microelectrode incubated with a $1.5 \mu \mathrm{g} / \mathrm{ml}$ solution of HRP labeled anti-A $\beta$ antibody (mHJ5.1) solution. DPV was every 1 minute performed using $10 \mathrm{mM}$ PBS buffer and $1 \mathrm{mM} \mathrm{KCl}$ as supporting electrolyte. Oxidation peak current is plotted versus responding incubation time. 


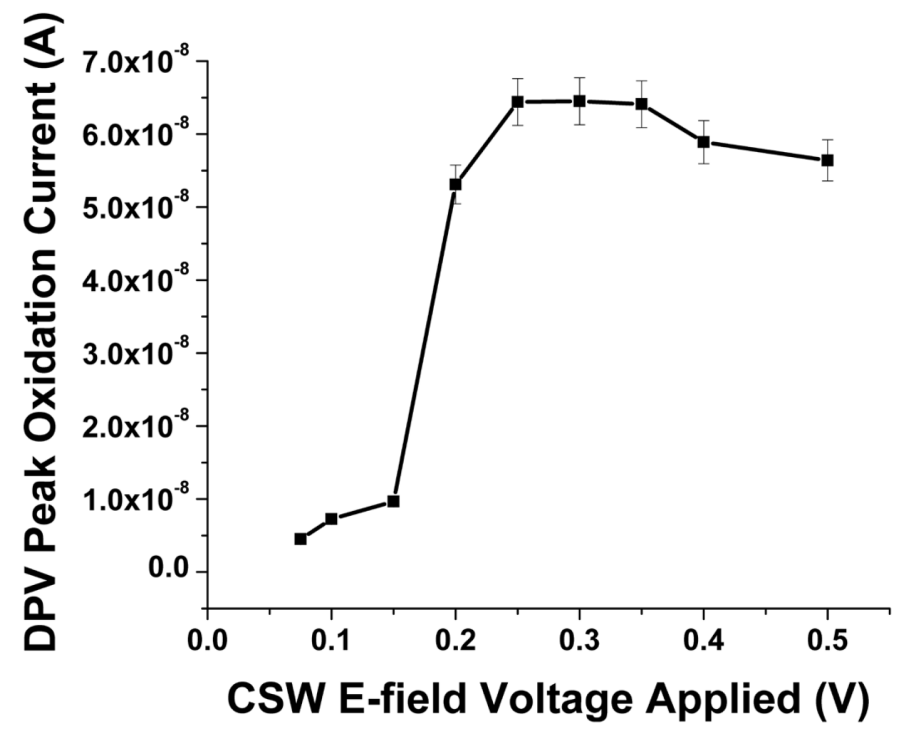

Figure 3.6. Effects of driving potential on the amount of antibody immobilized on electrode surface using $1000 \mu \mathrm{g} / \mathrm{ml}$ antibody solution and incubation time of 7 minutes.

During the immobilization of antibodies on the immunosensor, only a fraction of the total antibody applied gets bound to the electrode surface. In order to conserve a precious resource such as anti-A $\beta$ antibodies, the optimal concentration was established empirically. In these experiments, an electrochemically activated and pretreated microelectrode was incubated in solutions ranging from 0.1 to $1.5 \mu \mathrm{g} / \mathrm{ml}$ of $\mathrm{mHJ} 5.1$ antibody. The binding efficiency peaked and plateaued when more than $0.8 \mu \mathrm{g} / \mathrm{ml}$ of mHJ5.1 antibody was applied as shown in Figure 3.7. The low binding efficiency can be attributed to the presence of hydroxylic and phenolic groups in conjunction to the carboxylic groups which are not activated by EDC/NHSS and do not bind antibodies. 


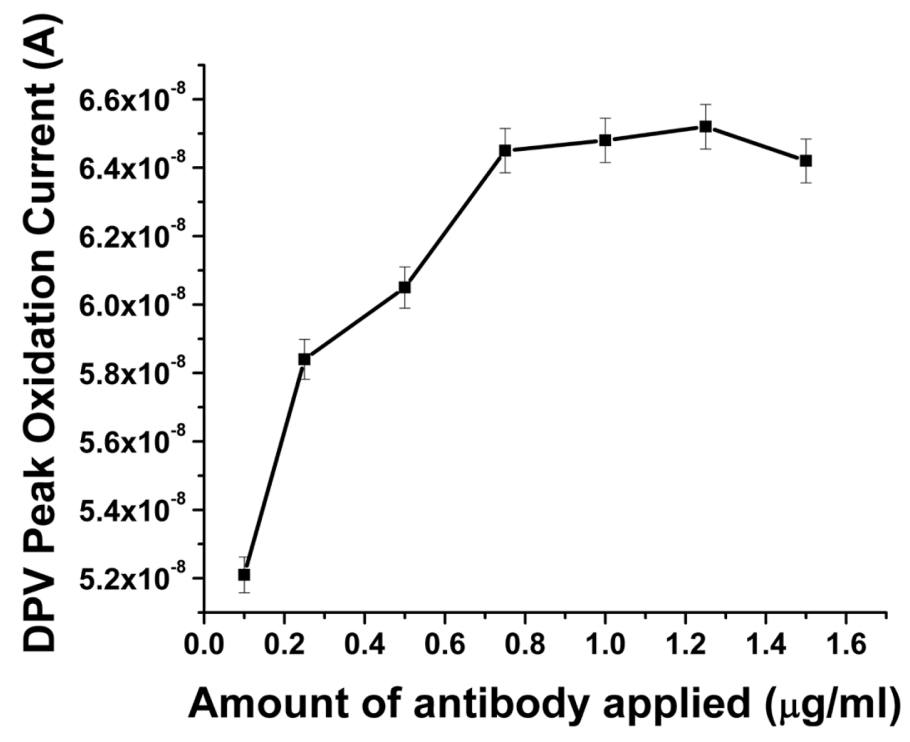

Figure 3.7. HRP signal generated by electrode following the application of an increasing load of HRP labeled antibody.

\subsubsection{Immunosensor Performance}

After completing the optimization of key steps in the molecular architecture of the sensor, we assessed the ability of the immunosensor to simultaneously quantify A $\beta 1-40$ and A 1-42 in CSF solutions using SWV with $10 \mathrm{mM}$ PBS and $1 \mathrm{mM} \mathrm{KCl}$ as the supporting electrolyte. Figure 3.8. shows the voltammetric response obtained after the incubation of the microelectrode with four solutions containing equal concentrations of $A \beta 1-40$ and A $\beta 1-42(0 \mathrm{nM}, 100 \mathrm{nM}, 500 \mathrm{nM}$ and $1 \mu \mathrm{M})$ spiked into rat CSF. In each case when the potential was scanned between 0.0 to $0.8 \mathrm{~V}$, a well-defined voltammogram consisting of an oxidation peak between 0.6 to $0.65 \mathrm{~V}$ was obtained. The oxidation current was obtained almost instantaneously in our experiments with no delay needed for equilibrium. Further, no stringent temperature control was required during electrochemical evaluation. The signal obtained for E3(TOT) which acts as the control electrode was always higher 
as compared to the signals obtained for E1(40) and E2(42). The response obtained for E3(TOT) correlates with the activity of the mHJ5.1 antibody which recognizes most isoforms of $\mathrm{A} \beta$ as it is targeted towards the central region of the peptide.
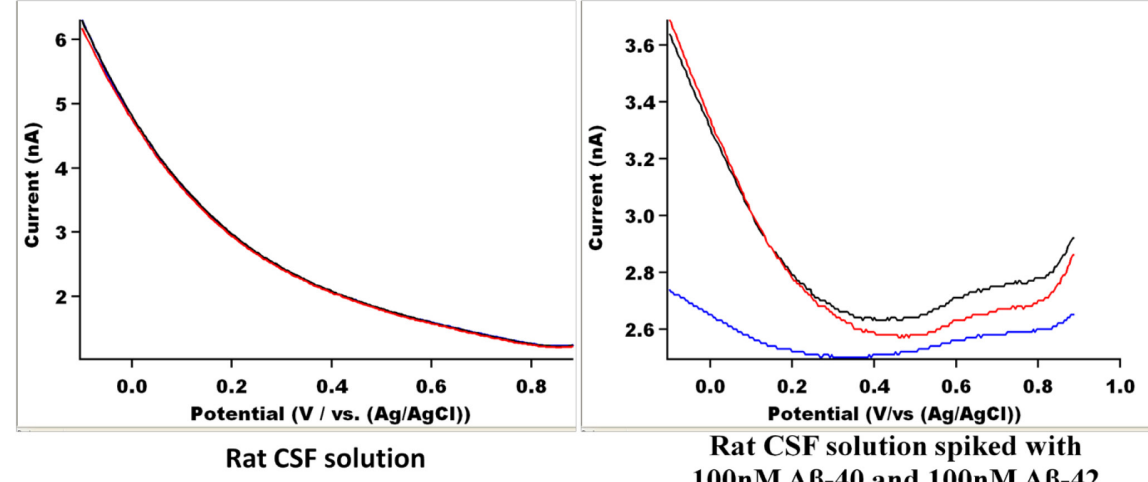

Rat CSF solution spiked with 100nM A $\beta-40$ and 100nM A $\beta-42$
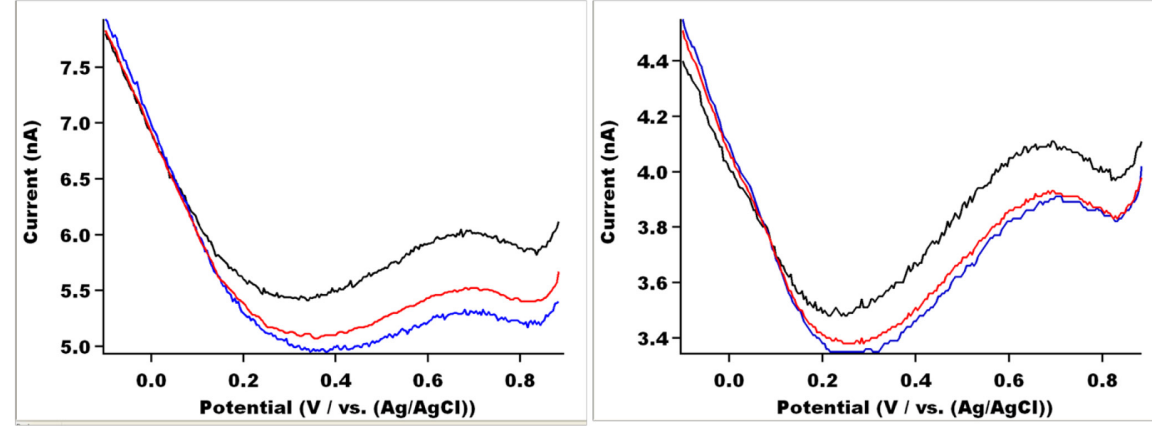

Rat CSF solution spiked with 500nM A $\beta-40$ and 500nM A $\beta-42$

Rat CSF solution spiked with $1000 \mathrm{nM} A \beta-40$ and 1000nM $A \beta-42$

Figure 3.8. Square wave voltammetric responses of 3 barrel of the immunosensors obtained in rat cerebrospinal fluid solution, spiked with $100 \mathrm{nM} \mathrm{A} \beta 1-40$ and $100 \mathrm{nM} \mathrm{A} \beta 1-42,500 \mathrm{nM}$ A $\beta 1-40$ and 500 $\mathrm{nM} A \beta 1-42,1 \mu \mathrm{M} A \beta 1-40$ and $1 \mu \mathrm{M} A \beta 1-42$ solutions. Square wave voltammetry parameters: Init $\mathrm{E}(\mathrm{V})$ $=1 ;$ Final E $(\mathrm{V})=0 ; \operatorname{Incr} \mathrm{E}(\mathrm{V})=0.004 ;$ Amplitude $(\mathrm{V})=0.04 ;$ Frequency $(\mathrm{Hz})=500$.

Linear calibration plots shown in figure 3.9A and 3.9B were then constructed based on peak oxidation currents obtained vs. $A \beta 1-40$ and $A \beta 1-42$ concentrations respectively, in order to normalize the variations between electrodes. Based on the evaluation of the calibration plots $A \beta 1-40$ and $A \beta 1-42$ could be specifically detected in CSF from rat within a detection limit of $400 \mathrm{nM}$ to $1 \mu \mathrm{M}$ and $100 \mathrm{nM}$ to $1.2 \mu \mathrm{M}$ respectively. The discrepancy observed with the detection capabilities of the immunosensor towards $A \beta 1$ - 
40 and $A \beta 1-42$ detection might be for several reasons including: 1) related to the inherent immunoreaction kinetics of each antibody, 2) differential aggregation of $A \beta$ which could limit signal multimers, 3) more non-specific absorption ("sticking") of A $\beta 1-42$ versus A $\beta 1-40$ to the apparatus.
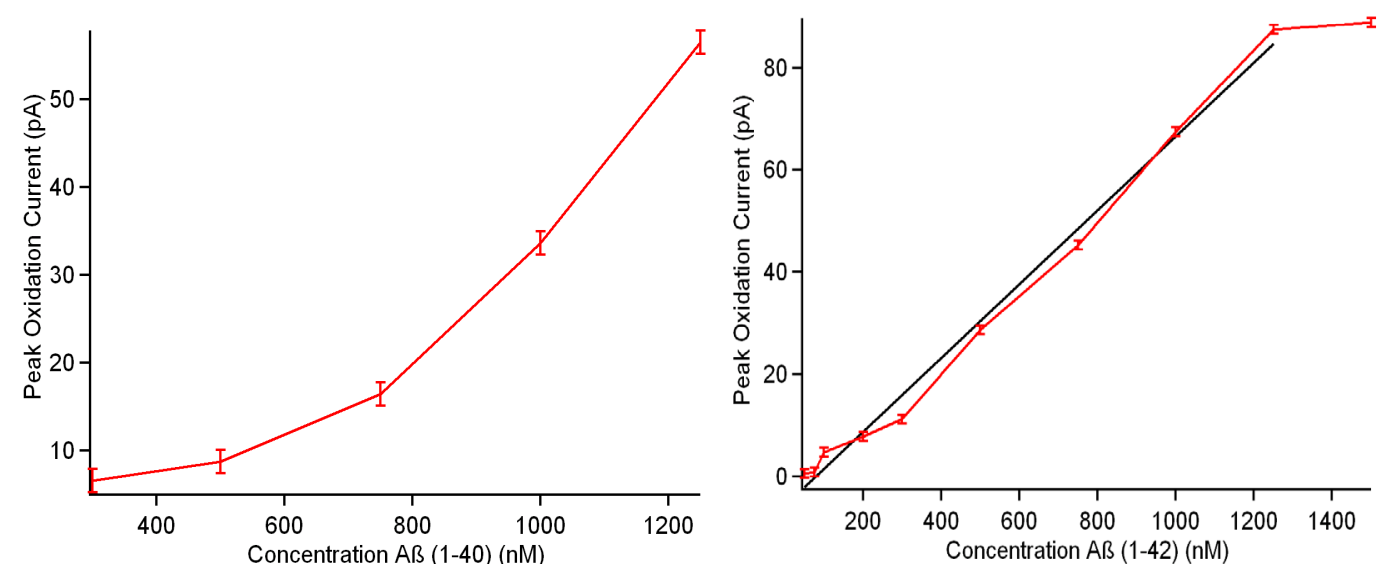

Figure 3.9. (A) Calibration curve: the relationship between peak oxidation current and A $\beta 1-40$ concentration. (B) Calibration curve: the linear relationship between peak oxidation current and A $\beta 1-42$ concentration.

Specificity is a crucial parameter which influences the performance of an immunosensor in real matrices, especially when an analyte at low concentrations needs to be detected in the presence of a much larger concentration of non-specific molecules. We need to prove that the presented sensor responds only to the $A \beta$ and anti-A $\beta$ immunoreaction and not to the nonspecific adsorption of other proteins. CSF contains free tyrosine and other proteins containing tyrosine amino acid residues, which could cause false signaling. Ethanolamine which has been proven to be a successful blocking agent in previous studies (Frederix et al., 2004) was used to minimize these non-specific binding reactions. In order to measure the specificity of each of the barrels towards a specific $A \beta$ isotope, 
three immunosensors were challenged using each of the following solutions 1) $1000 \mathrm{nM}$ $\mathrm{A} \beta 1-40$ 2) $1000 \mathrm{nM} \mathrm{A} \beta 1-42$ and 3) $500 \mathrm{nM} \mathrm{A} \beta 1-40$ and $500 \mathrm{nM} \mathrm{A} \beta 1-42$. SWV was performed before and after incubation of each microelectrode with analyte solution. Figure 3.10 shows the average values of peak oxidation currents obtained after incubation from each of the barrel of three separate electrodes incubated in each of the abovementioned solutions. From the evaluation of figure 3.10 we can deduce that each of the barrels showed highly specific recognition properties. The signal obtained due the non-specific adsorption of non- $A \beta$ proteins and non-corresponding $A \beta$ isoforms from each of the barrels was found to be minimum and statistically insignificant. 


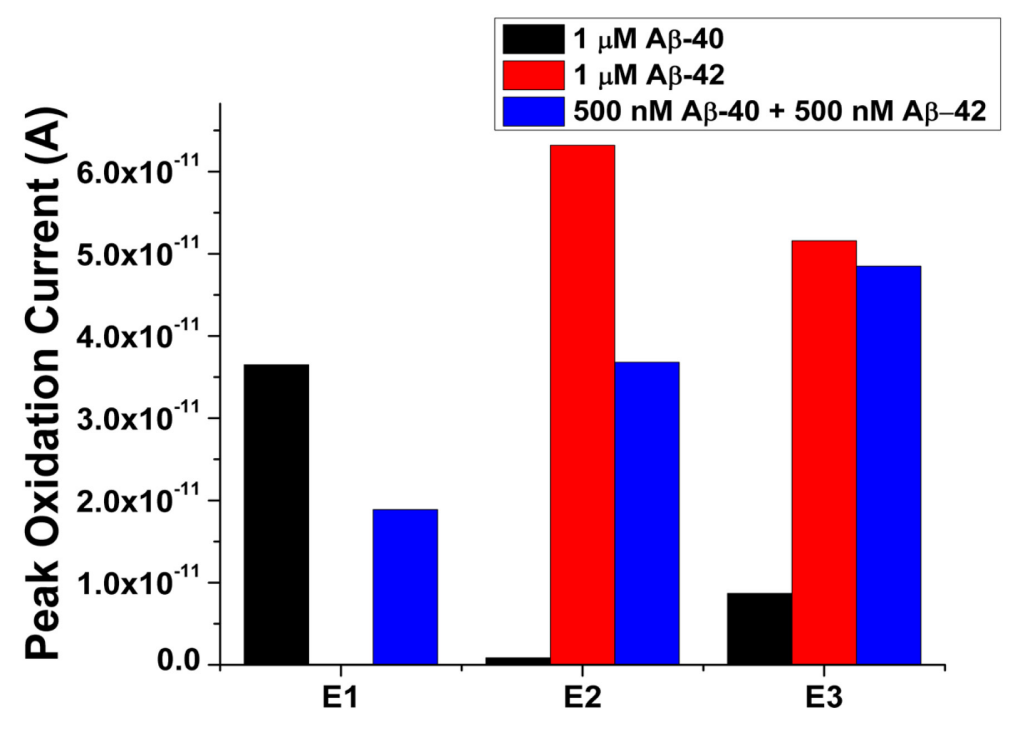

Figure 3.10. Oxidation peak current obtained from three anti-A $\beta$ modified carbon fiber microelectrodes after being incubated with $1 \mu \mathrm{M}$ of $\mathrm{A} \beta 1-40,1 \mu \mathrm{M}$ of $\mathrm{A} \beta 1-42$ and $500 \mathrm{nM}$ of $\mathrm{A} \beta 1-40+500 \mathrm{nM}$ of $\mathrm{A} \beta 1-42$ spiked into rat cerebrospinal fluid solutions respectively. Measurements were performed in $10 \mathrm{mM}$ PBS buffer and $1 \mathrm{mM} \mathrm{KCl}$ versus $\mathrm{Ag} / \mathrm{AgCl}$.

The stability of the microelectrodes with anti-A $\beta$ antibodies immobilized on their surface was evaluated over a period of one month. The micro immunosensors were stored in 0.1 M PBS solution at $4{ }^{\circ} \mathrm{C}$ after fabrication. The stability of the stored electrodes was studied by incubating them in freshly prepared solution containing $0.1 \% \mathrm{BSA}, 500 \mathrm{nM}$ $\mathrm{A} \beta 1-40,500 \mathrm{nM} \mathrm{A} \beta 1-42$ in $0.1 \mathrm{M}$ PBS at $\mathrm{pH}$ 7.2. The stability of the electrodes was evaluated by measuring their electrochemical response using square wave voltammetry. The electrochemical response of the microelectrodes progressively degraded after 4 days in storage. To test the inter-sensor reproducibility of the proposed system, three samples of different concentrations (100, 500 and $1000 \mathrm{nM})$ of $\mathrm{A} \beta 1-40$ and $\mathrm{A} \beta 1-42$ were tested first with different electrodes. This indicates that our detection strategy offers an acceptable reproducibility towards the detection of $A \beta 1-40$ and $A \beta 1-42$. 


\subsection{Conclusion}

In this work, a simple, sensitive and fast electrochemical multiplexed immunoaasay for Alzheimer's disease biomarkers is presented. The current signal generated due to the oxidation of $A \beta$ was demonstrated to be feasible in the development of a direct, one-step biosensor. The reagentless detection process based on the inherent electroactivity of $A \beta$ greatly simplifies the sensor utilization. The incorporation of an electric field-driven strategy greatly shortened the sensor fabrication and response time to 7 minutes enabling real-time measurement of $A \beta$. The results show detection limit of sensor towards $A \beta-40$ and $\mathrm{A} \beta-42$ to be $400 \mathrm{nM}$ and $100 \mathrm{nM}$ respectively. The single use sensor displays specificity towards respective $A \beta$ isoform and no cross-talk between the barrels of the microelectrode. The detction strategy enables the direct detection of electroactive biomolecules and can be generally used for the detection of any other electroactive biomarker by using an appropriate antibody. The limitations of the detection strategy are that sensitivity is compromised as compared to the approach described in Chapter 2, due to direct measurement. In addition, incubation time of 7 minutes is still long as some biological reactions occur on the scale of seconds. To remedy these shortcomings the direct dtection strategy was developed in Chapter 4. 


\section{Chapter 4}

Assessment of oxidative DNA damage and repair at single cellular level via real-time monitoring of 8-OHdG biomarker 


\subsection{Introduction}

Reactive oxygen species (ROS) or free radicals have been implicated as the cause of cancer, diabetes, cardiovascular disease, and neurodegenerative diseases (Wu et al., 2004). In living cells, endogenous ROS are produced as a result of various metabolic, physiological processes, and other biochemical reactions. The cell can protect itself from ROS using enzymes such as superoxide dismutases, catalases, lactoperoxidases, and glutathione peroxidases. Antioxidants such as ascorbic acid, tocopherol, glutathione and uric acid present in the cell, act as scavengers of ROS (Jackson and Loeb, 2001). Under normal physiological conditions a balance is maintained between the endogenous ROS and antioxidants. However, an imbalance can be caused due to a drop in the level of antioxidants or an increase in the level of ROS from exogenous sources such as cigarette smoke, UV or ionizing radiation, hazardous chemicals, inflammation, etc. (Martin and Barrett, 2002). When an imbalance occurs lipids, proteins and nucleic acids present in the cell may undergo oxidative damage. The site of oxidative damage is usually nuclear and mitochondrial DNA in tissue. Numerous DNA damage products are formed during oxidative damage due to bases and sugar modifications, covalent crosslinks, single and double stranded breaks. However, most research interest has focused on nucleobase modifications (Cooke et al., 2003). Among the common DNA nucleobases, guanine has the lowest oxidation potential and is the most prone to oxidative damage. Nucleobases such as 8 -hydroxyguanine $(8-\mathrm{OxoG})$ are less common but act as deep traps for radical

cations since they have a much lower oxidation potential than guanine (Kanvah and Schuster, 2006). Upon oxidation of $8-\mathrm{OxoG}$, a hydroxyl group is added to the 8th 
position of the guanine molecule and the oxidatively modified product is called 8-OHdG (Floyd et al, 1986). DNA damage lesions such as 8 -OHdG are recognized and cleaved by the base excision repair mechanism (BER). Once recognized, $8-\mathrm{OHdG}$ is cleaved by enzymes such as endonuclease and glycosylase to prevent DNA mutations (Hollstein et al., 1991; Cheng et al., 1992). 8-OHdG being water soluble is secreted out of the cell into the extracellular space after being removed from the DNA helix. Thus monitoring extracellular 8-OHdG will provide insight into oxidative DNA damage (formation of 8OHdG) and DNA repair mechanisms (cleavage of 8-OHdG) (Zhang et al., 2006).

8-OHdG was first discovered by Kasai and Nishimura in 1984 during their attempt to study and isolate mutagens in heated glucose (Kasai et al., 1984). Thereafter, numerous papers have analyzed 8-OHdG levels in human organs, cell lines, and body fluids in relation to oxidative stress, diet, cancer incidence, aging, heart disease and neurological disorders. On account of these studies, 8 -OHdG has been established as a crucial biomarker of oxidative stress (Kasai, 1997; Shigenaga et al., 1989), cancer instigation by free radicals (Halliwell 1998; Marnett 2000), and aging including degenerative diseases (Fraga et al., 1990; Sayre et al., 2001). 8-OHdG is also a biological marker of lifestyle and the effects of diet (Kasai et al., 2001; Halliwell, 2002). The significance of 8-OHdG is such that a search done on Google Scholar for articles published during the last 20 years showed about 6,680 papers.

Electrochemical detection of $8-\mathrm{OHdG}$ is possible as it undergoes oxidation via a twoelectron two-proton charge transfer reaction, shown in figure 4.1. (Goyal et al., 1997). Due to the dissociation of protons the oxidation potential of 8 -OHdG is heavily dependent upon the $\mathrm{pH}$ of the supporting electrolyte ( $\mathrm{Li}$ et al., 2007). The rate of the 
charge transfer reaction has been observed to be fastest at the surface of carbonaceous electrodes (Langmaier et al., 2003). Carbon-fiber microelectrodes were introduced by Pujol et al. nearly 30 years ago, who used them with normal pulse polarography to measure the oxidation of several neurotransmitters, including dopamine, norepinephrine and serotonin (Ponchon et al., 1979). Since then, the most popular applications for carbon fiber electrodes have been as sensors for in-vivo detection of neurotransmitters. Carbon fiber microelectrodes have been used for biological applications due to advantages such as: excellent biocompatibility and non-toxicity towards cells, good electrochemical properties which have been extensively studied and characterized, miniature size $(<10$ $\mu \mathrm{m}$ in diameter) of electrodes makes them ideal for implantation with minimal damage to cells, enable rapid measurements when used with fast electrochemical techniques such as amperometry, chronoamperometry and fast scan cyclic voltammetry.

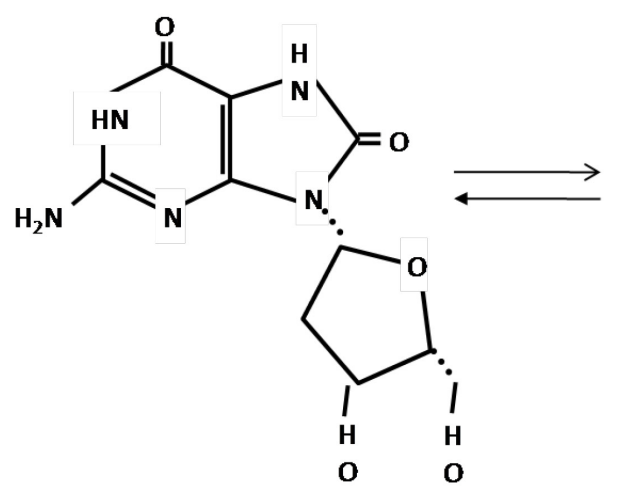

8-OHdG

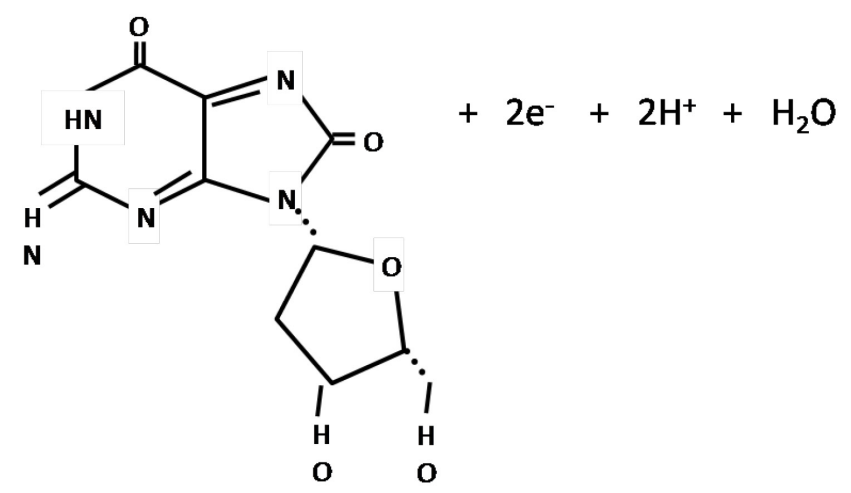

Oxidized 8-OHdG

Figure 4.1. Schematic showing the electroactive behavior of 8-OHdG.

Classic analytical methods used for the detection of 8-OHdG include high-performance liquid chromatography with electrochemical detection (HPLC-ED) (Martinis and De 
Lourdes, 2002), gas-chromatography-mass spectroscopy (GC-MS) (Teixeira et al., 1993), enzyme-linked immunosorbent assay (ELISA) (Chiou et al., 2003), immunohistochemical methods (Toyokuni et al., 1997), and single cell gel electrophoresis (comet assay) (Hartmann et al., 1998). These methods have been successfully used to analyze 8-OHdG in animal and human organs, fluid samples (urine, saliva, and cerebrospinal fluid) and cell lysates. Techniques such as ELISA, HPLC-ED, and GC-MS when used to monitor 8-OHdG levels in cell lysates or cell media report the average behavior of cells in a population, thus concealing any cell to cell variations that may characterize each cell's survival under stress. Current techniques to determine 8OHdG in single cells are immunostaining, and comet assay. These techniques can monitor cells only at a single time point and therefore do not allow for real-time monitoring. Also, these techniques have been developed to look at the intracellular 8OHdG deposits. To overcome the disadvantages of the current techniques, we report a strategy to measure extracellular levels of $8-\mathrm{OHdG}$ in real time.

In our previous studies, we have successfully used carbon fiber microelectrodes to detect analytes such as vascular endothelial growth factor and nitric oxide (Prabhulkar et al., 2009; Li et al., 2009). Activated carbon nanotube based electrodes have been effectively used for the simultaneous detection of neurotransmitters (Alwarappan et al., 2009; Alwarappan et al., 2010). In this study, we have detected extracellular 8-OHdG secreted from single lung epithelial cells exposed to varying concentrations of nicotine using carbon fiber microelectrodes. Cigarette smoking and chewing tobacco have been linked to the development of several cancers such as lung, oral, esophageal and bladder (Boffetta et al., 2005; Campain, 2004). Nicotine, which is responsible for the addictive 
nature of tobacco use, is also one of the most biologically active chemicals present in cigarette smoke and smokeless tobacco. Due to its highly reactive nature, nicotine has been implicated in free radical generation in rodent and human cells of various types (Wetscher et al., 1995; Wetscher et al., 1995; Ferger et al., 1998). Nicotine is also the precursor to many tobacco carcinogens (Wu et al., 2005). Most of the research conducted to determine the mutagenicity of nicotine shows inconsistent findings (Doolittle et al., 1995; Trivedi et al., 1990). Therefore, there is a need for further exploration to clarify this issue.

\subsection{Experimental}

\subsubsection{Materials}

Carbon fibers $(5 \mu \mathrm{m}$ in dia.) were friendly donated by World Precision Instruments (Sarasota, FL). Borosilicate glass capillaries (outer dia. $0.5 \mathrm{~mm}$, inner dia $0.3 \mathrm{~mm}$ ) were obtained from Sutter Instrument Company (Novato, CA). Sylgard 184 was obtained from Dow Corning Corporation (Midland, MI). Human alveolar epithelial cell line L-132 was purchased from American Type Culture Collection (VA, USA). Dulbecco's Modified Eagle Medium and $10 \%$ heat-inactivated fetal bovine serum were purchased from Gibco BRL (Grand Island, NY). 8-OHdG stock solution was obtained from Biolog Inc. (Hayward, CA) at a concentration of $5 \mu \mathrm{mol}$. Calcium Ionophore (A23187), hydrogen peroxide $(97 \%)$, nicotine ( $\geq 99 \%$ ), and other reagents were purchased from SigmaAldrich (St. Louis, MO). 


\subsubsection{Instrumentation}

Carbon fiber microelectrodes were prepared using P-97 Micropipette Puller and BV-10 Beveller acquired from Sutter Instrument Company (Novato, CA). Electrochemical measurements were carried out using the $600 \mathrm{C}$ Electrochemical Analyzer attached to a Picoamp Booster from CH Instruments, Inc. (Austin, TX). PV830 Pneumatic Picopump purchased from World Precision Instruments (Sarasota, FL). LU-CB1 Leiden microincubator purchased from Harvard Apparatus (Holliston, MA). MS3114 micromanipulators purchased from World Precision Instruments (Sarasota, FL), one to position the working electrode for the cell and the second to position the injection pipette containing the secretagogue. Faraday Cage and Anti-Vibration Workstation purchased from Kinetic Systems, Inc. (Boston, MA). A conventional three electrode cell consisting of an $\mathrm{Ag} / \mathrm{AgCl}$ reference electrode (3 $\mathrm{M} \mathrm{KCl}$ ) (Bioanalytical Systems, IN, USA), and a platinum wire as an auxiliary electrode was employed.

\subsubsection{Preparation and activation of carbon fiber microelectrodes}

Carbon fiber microelectrodes were fabricated using the method described in our previous work (Prabhulkar et al., 2009). Briefly, a single carbon fiber of diameter $5 \mu \mathrm{m}$ was attached to the stripped end of an insulated copper wire (dia. $0.2 \mathrm{~mm}$ ) using a silver conductive paste. The silver paste was allowed to dry, after which the free end of the copper wire was cannulated into a borosilicate glass capillary. The copper wire was fixed to the capillary using a fast drying epoxy resin. The capillary was then pulled using a micropipette puller. This pulling procedure results in two glass pipettes, one of which is discarded, and the other part which holds the carbon fiber protruding from its tip. The 
junction between the carbon fiber and capillary is sealed with a drop of the Sylgard silicone preparation and allowed to cure until it becomes firm. The microelectrodes were then beveled at $45^{\circ}$ using diamond abrasive plate, to obtain a disk shaped active electrode surface. The carbon fiber surface was then cleaned by 5 second sonication in acetone, 1 $\mathrm{M}$ nitric acid, $1 \mathrm{M} \mathrm{KOH}$ and distilled water sequentially. The microelectrodes were electroactivated using a $150 \mathrm{mM} \mathrm{NaCl}$ solution $(\mathrm{pH}=10)$ at $1.2 \mathrm{~V}(\mathrm{vs} . \mathrm{Ag} / \mathrm{AgCl})$ for 8 minutes at room temperature.

\subsubsection{Cell culture of lung endothelial cells}

Human alveolar epithelial cells were cultured in Dulbecco's Modified Eagle Medium supplemented with $10 \%$ heat-inactivated fetal bovine serum. The cells were stored at $37{ }^{\circ} \mathrm{C}$ in $5 \% \mathrm{CO}_{2}, 95 \% \mathrm{O}_{2}$ in a humidified cell incubator. The cell medium was changed every 48 hours.

\subsubsection{Calibration of microelectrode for 8-OHdG measurements}

Standard solutions of different concentrations $(10 \mathrm{pM}, 20 \mathrm{pM}, 30 \mathrm{pM}, 40 \mathrm{pM}, 50 \mathrm{pM}$ and $60 \mathrm{pM}$ ) were made by gradually diluting the 8 -OHdG stock solution using $0.1 \mathrm{M}$ phosphate buffer saline (PBS) at $\mathrm{pH}=7$, which correlates to physiological $\mathrm{pH}$. Calibration of the microelectrode for $8-\mathrm{OHdG}$ detection was carried out using CPA, with the potential on the microelectrode held at $0.42 \mathrm{~V}$ (vs. $\mathrm{Ag} / \mathrm{AgCl}$ ). The microelectrode to be tested and a microcapillary (inner diameter $20 \mu \mathrm{m}$ ) were both placed in petri dish containing saline buffer $\left(137 \mathrm{mM} \mathrm{NaCl}, 5 \mathrm{mM} \mathrm{KCl}, 0.7 \mathrm{mM} \mathrm{Na}_{2} \mathrm{HPO}_{4}, 25 \mathrm{nM}\right.$ HEPES, $10 \mathrm{mM}$ glucose, $2 \mathrm{mM} \mathrm{CaCl}_{2}$ at $\mathrm{pH}=7.2$ ). The tip of the carbon fiber microelectrode was 
placed at the outlet of the microcapillary as shown in figure 4.2. The microcapillary filled with 8-OHdG standard solution was connected to the PV830 Pneumatic Picopump. This calibration system was used to simulate the situation of $8-\mathrm{OHdG}$ detection near the surface of a single cell.

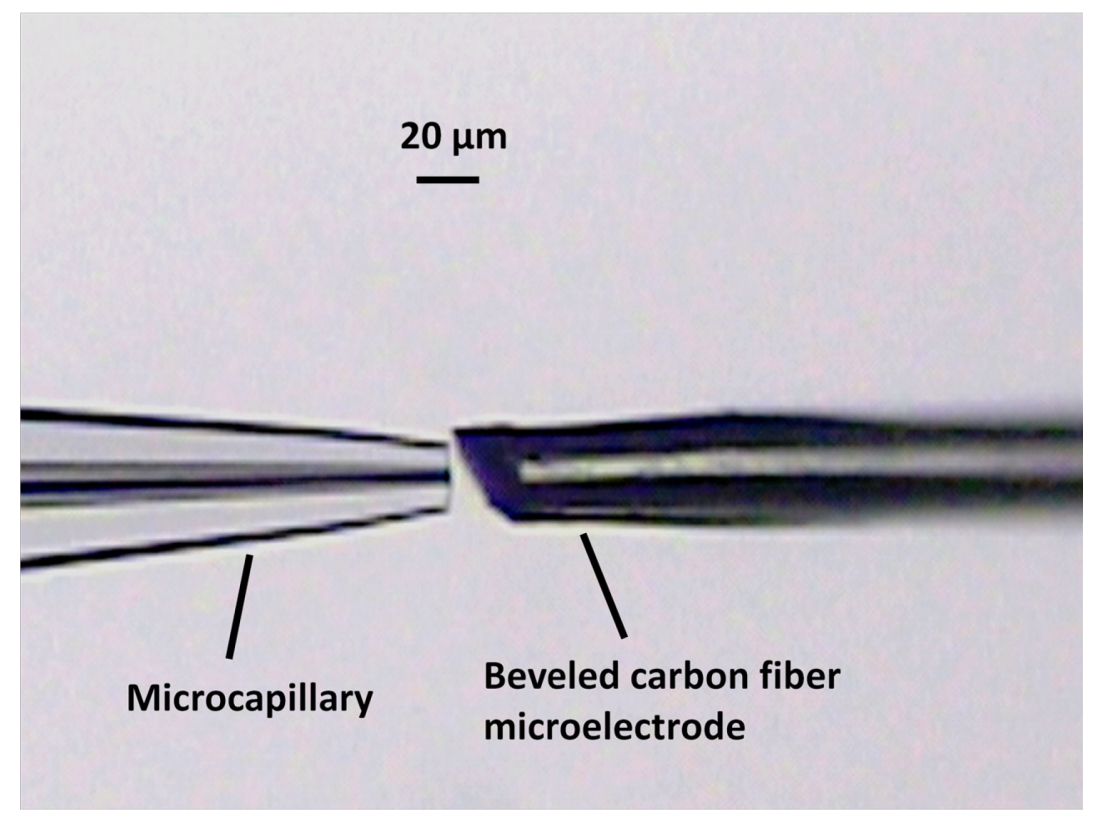

Figure 4.2. View of calibration system to measure $8-\mathrm{OHdG}$ response at the surface of an activated carbon fiber microelectrode.

\subsubsection{Single-cell measurements}

Prior to experimentation, cell culture media was discarded and the petri dishes $(35 \mathrm{~mm}$ outer diameter X $10 \mathrm{~mm}$ high) containing $1 \times 10^{2}$ cells were rinsed twice with a saline buffer. The petri dish was refilled with saline buffer warmed to $37{ }^{\circ} \mathrm{C}$ and placed on the LU-CB1 Leiden microincubator. The microincubator placed on the stage of an inverted microscope, maintains the cell bath temperature to $37{ }^{\circ} \mathrm{C}$ and the $\mathrm{CO}_{2}$ content to $5 \%$. A single isolated cell was located with the microscope and an activated carbon fiber microelectrode was positioned at a distance $0.5 \mu \mathrm{m}$ over its surface using the MS3114 
micromanipulators as shown in figure 4.3. All the experiments were isolated from electromagnetic interference and physical disturbances using a Faraday Cage and an Anti-Vibration Workstation. Any cables running into the Faraday Cage were additionally shielded using aluminum tape. Secretagogues, such as Calcium Ionophore (A23187) were applied to the cell via pressure ejection from the tips of micropipettes (inner diameter 20 $\mu \mathrm{m})$ placed at a distance of $1 \mathrm{~cm}$ from the cell. Flow rate through the pipette tips was determined to be $0.2 \mu \mathrm{L} / \mathrm{s}$. Hydrogen peroxide was used as a positive control to induce oxidative DNA damage while a saline buffer was used as a negative control. Cells were treated with $10 \mathrm{mM}$ hydrogen peroxide dissolved in the cell bath solution. Nicotine was introduced at varying concentrations into the cell bath solution in order to study its effects on DNA damage and 8-OHdG secretion.

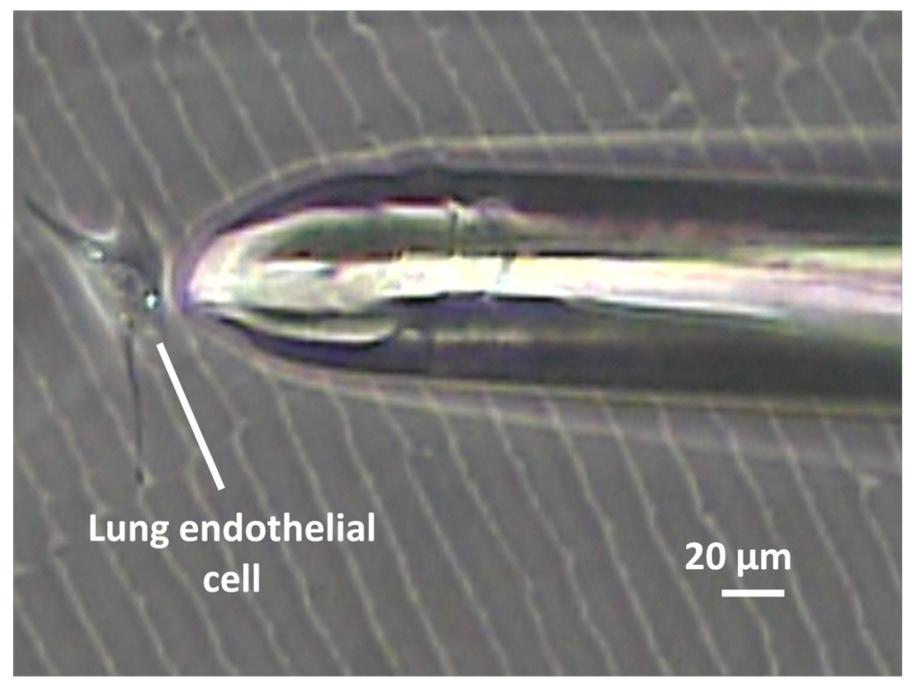

Figure 4.3. View of the detection system in single cell experiments. A carbon fiber microelectrode was placed at a fixed distance of $0.5 \mu \mathrm{m}$ away from the surface of a cell. 


\subsubsection{Electrochemical measurements}

CPA in conjunction with Fast Scan Cyclic Voltammetry (FSCV) was used to monitor 8OHdG release from single cells. CPA was performed by holding the microelectrode at constant potential of $0.42 \mathrm{~V}$. FSCV was performed in the potential window of 0.2 to 0.8 $\mathrm{V}$, at a scan rate of $200 \mathrm{~V} / \mathrm{s}$. Background CPA and FSCV measurements were conducted at the surface of the cell in bath buffer before addition of hydrogen peroxide or nicotine. In order to eliminate noise and enhance signal the background measurements were subtracted from the averaged CPA and FSCV measurements conducted at cells under the influence of hydrogen peroxide or nicotine

\subsection{Results and discussion}

\subsubsection{Calibration for 8-OHdG}

A typical amperometric response to the injection of $8-\mathrm{OHdG}$ is shown in figure 4.4. After each injection the activated carbon fiber microelectrode displayed a quick amperometric response which reaches a maximum plateau value and then rapidly drops. A calibration curve of peak amperometric response against the corresponding 8-OHdG standard solution concentration was plotted in figure 4.5. The calibration curve indicates that the activated microelectrode displayed a linear response from $10 \mathrm{pM}$ to $60 \mathrm{pM}$ solution of 8-

OHdG. The linear response of the microelectrode proves that it is well suited for the direct detection of 8-OHdG. 


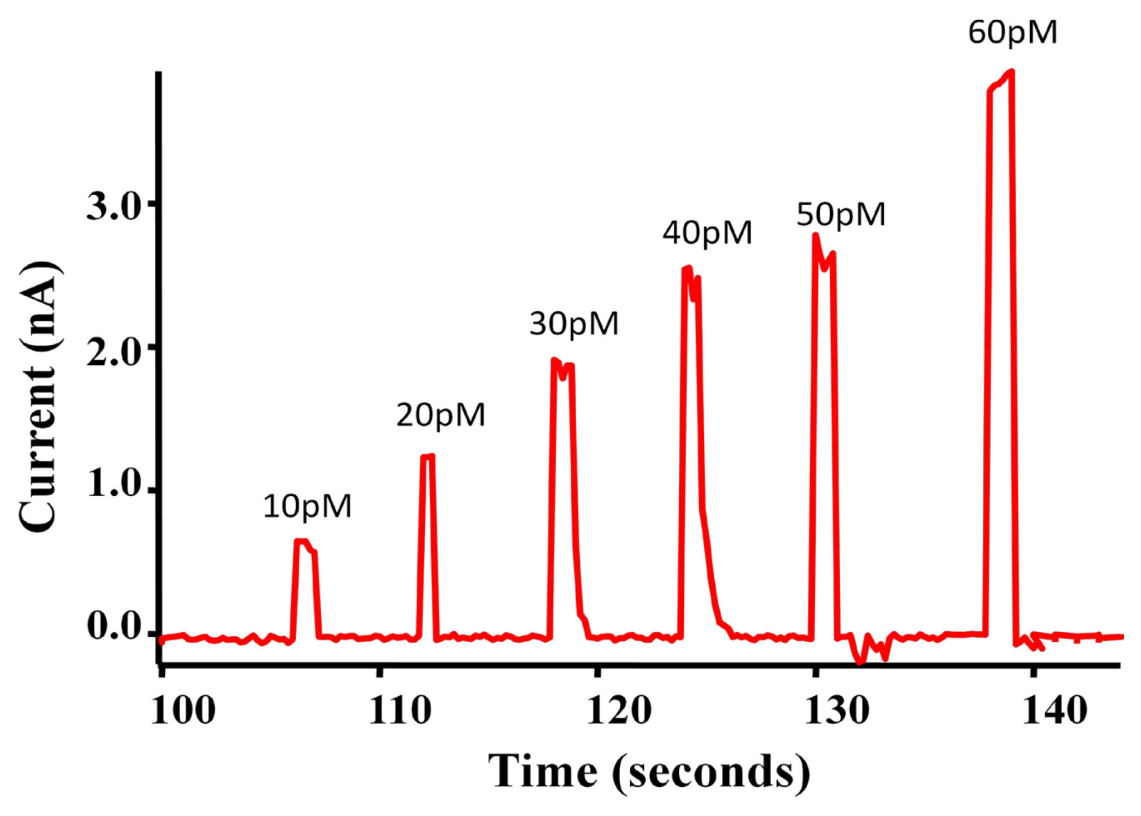

Figure 4.4. Typical amperometric response to the injection of $10 \mathrm{pM}, 20 \mathrm{pM}, 30 \mathrm{pM}, 40 \mathrm{pM}, 50 \mathrm{pM}$, and $60 \mathrm{pM} 8-\mathrm{OHdG}$ by using the calibration system.

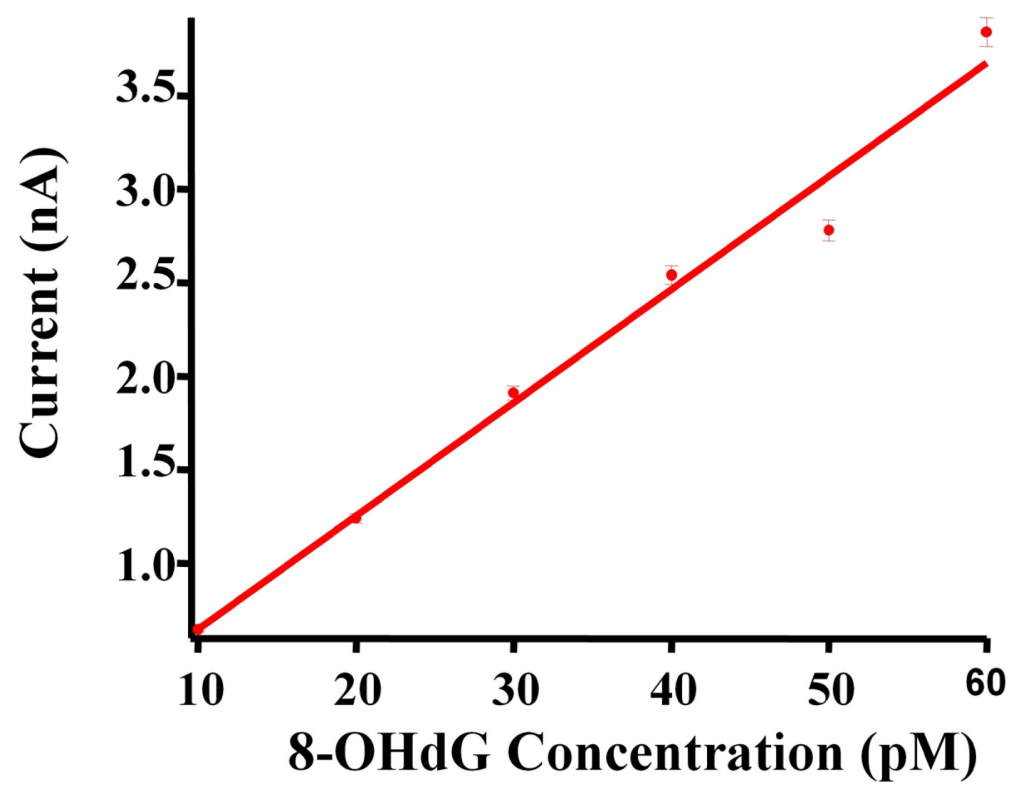

Figure 4.5. The calibration curve for microelectrode response towards 8-OHdG solution over the concentration range of $10-60 \mathrm{pM}$. 


\subsubsection{Detection of 8-OHdG secretion from single lung epithelial cells}

Initially, in order to establish a negative control or background readings, electrochemical measurements were conducted at the surface of a single isolated cell incubated in saline buffer. An activated carbon fiber microelectrode (working electrode) was positioned at $0.5 \mu \mathrm{m}$ above the cell surface, $\mathrm{Ag} / \mathrm{AgCl}$ electrode (reference electrode) and a $0.5 \mathrm{~mm}$ diameter platinum wire (counter electrode) were also placed in the saline buffer. Calcium ionophore (A21387) was used in order to stimulate exocytosis in cells. A21387 facilitates the influx of $\mathrm{Ca}^{2+}$ from the bath buffer into the cell. This results in an escalation of free intracellular $\mathrm{Ca}^{2+}$ which triggers rapid exocytosis. $500 \mu \mathrm{M}$ calcium ionophore dissolved in dimethyl sulfoxide was injected at rate of $0.2 \mu \mathrm{L} / \mathrm{s}$ at a distance of $1 \mathrm{~cm}$ from the cell under study using the Picopump. The actual concentration of ionophore affecting the cell would be far less due to its diffusion into the cell bath solution. Secretion of $8-\mathrm{OHdG}$ from the single cell surface was mapped using CPA and FSCV. Cells were monitored using CPA for a period of 2 hours with calcium ionophore stimulation applied every 100 seconds. Figure 4.6. shows the CPA response of the microelectrode recorded at the surface of a single lung cell incubated in saline buffer. We do not observe any current peaks higher than the background signal, which indicates that significant secretion of $8-\mathrm{OHdG}$ from cell was not observed in the saline buffer. 


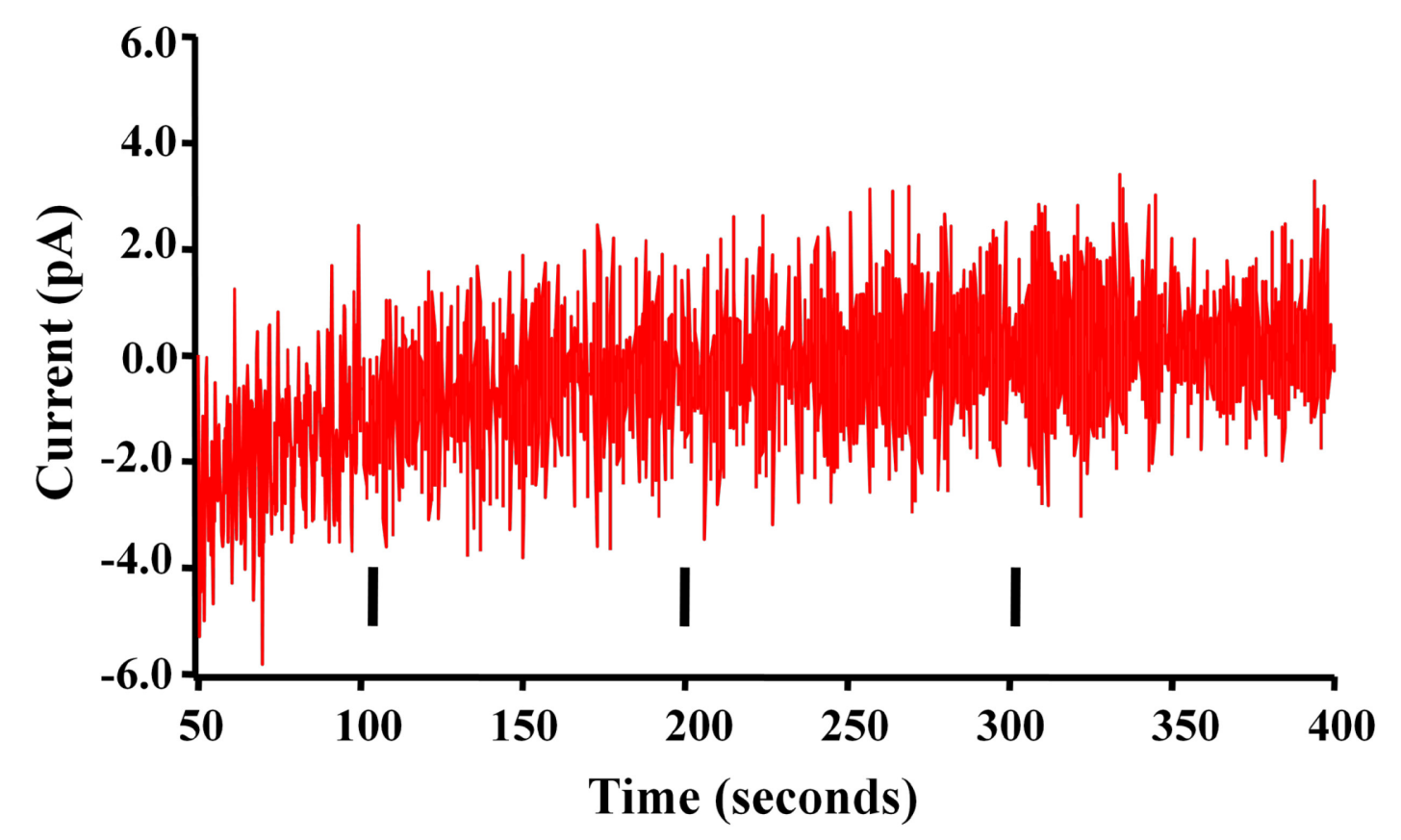

Figure 4.6. Current recordings made at a single lung endothelial cell in saline buffer with the electrode potential was held at $+0.42 \mathrm{~V}$. The bars indicate calcium ionophore injection via microcapillary placed 1 $\mathrm{cm}$ from cell surface.

Hydrogen peroxide was used as a positive control or model ROS to induce oxidative damage in lung epithelial cells (Halliwell and Aruoma, 1991). Hydrogen peroxide has been proven to cause DNA strand breakage and is highly correlated with multiple chemical modifications of DNA bases, suggesting damage due to hydroxyl radical (Spencer et al., 1995). In order to induce oxidative DNA damage, lung epithelial cells were subjected to $10 \mathrm{mM}$ hydrogen peroxide solution made using saline buffer. Electrochemical recording was started 15 minutes after incubating cells with saline solution containing hydrogen peroxide. Hydrogen peroxide was present in the cell bath during the entire course of the CPA measurements. These experiments were conducted as a proof of concept to verify if $8-\mathrm{OHdG}$ release could be recorded from a single lung epithelial cell. CPA was conducted at the cell surface using calcium ionophore 
stimulation. From the background subtracted CPA signal shown in figure 4.7., we observe that $8-\mathrm{OHdG}$ is sporadically released after stimulation. The average peak current calculated by taking into account peaks obtained during the first three stimulations given to 20 different cells is $6.17 \pm 0.5 \mathrm{pA}$.

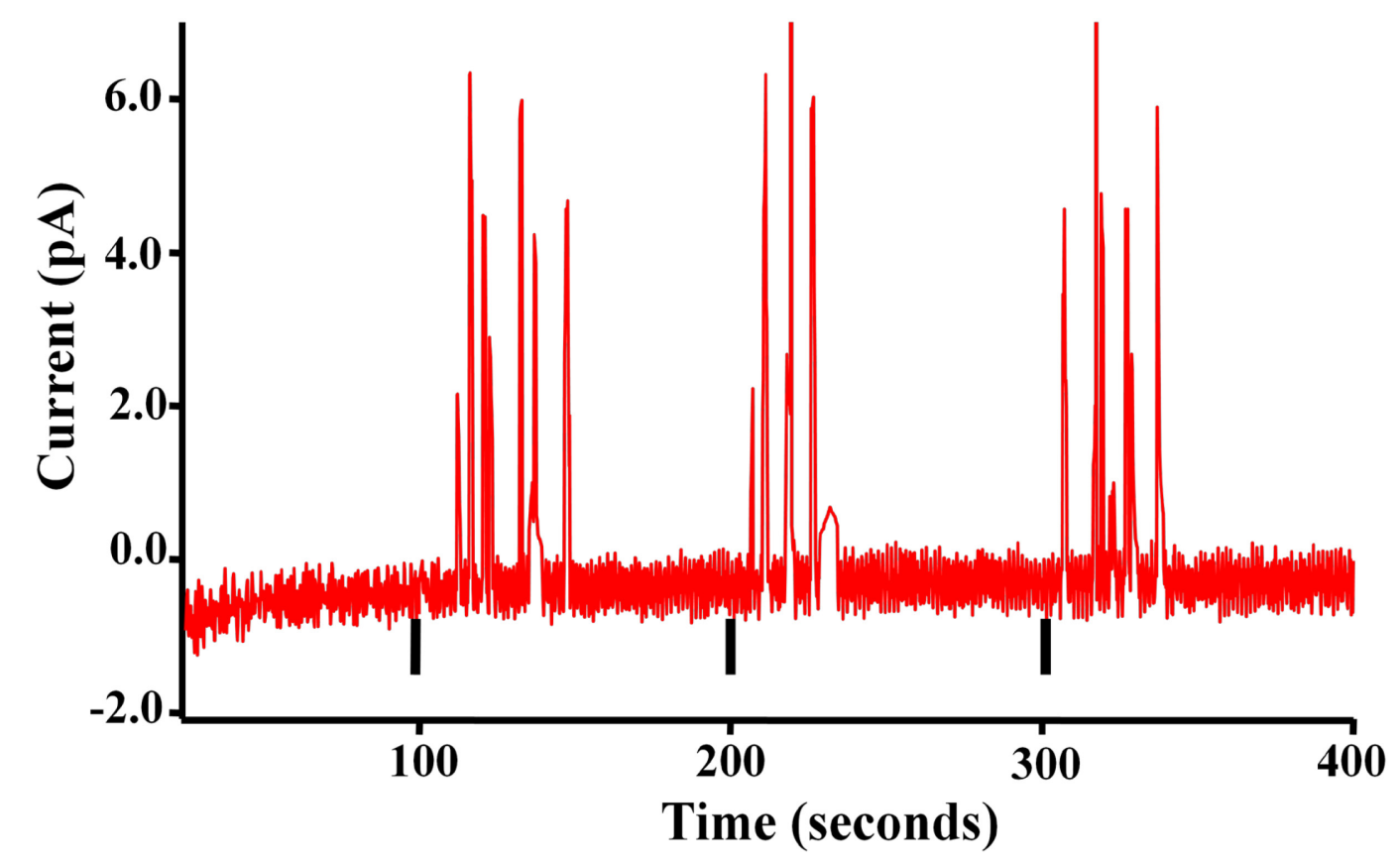

Figure 4.7. Current recordings made at single lung endothelial cell with $10 \mathrm{mM}$ hydrogen peroxide exposure. The bars indicate calcium ionophore injection via microcapillary placed $1 \mathrm{~cm}$ from cell surface.

We also conducted repetitive FSCV measurements at the surface of the cells. The background subtracted voltammogram shown in figure 4.8. shows an oxidation peak at $0.42 \mathrm{~V}(\mathrm{Ag} / \mathrm{AgCl})$ which corresponds to the electrochemical behavior of $8-\mathrm{OHdG}$ ( $\mathrm{Li}$ et al., 2007; Wan et al., 2008; Brett et al., 2000). Therefore, using CPA we were able to record the release kinetics of 8-OHdG from the surface of a single lung epithelial. Based on the oxidation peak observed in the background subtracted FSCV signal, we are able to verify that the analyte being measured by the microelectrode is in fact 8 -OHdG. 


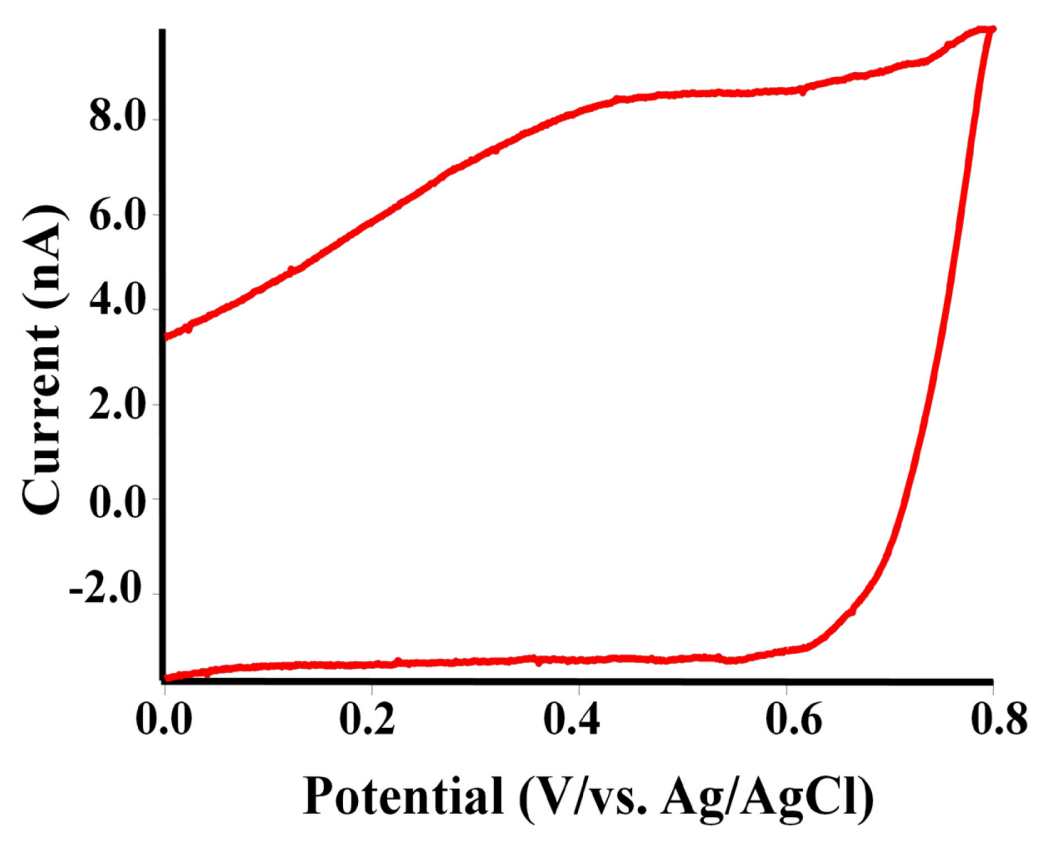

Figure 4.8. Background subtracted fast scan cyclic voltammogram at the surface of single lung epithelial cell incubated with $10 \mathrm{mM}$ hydrogen peroxide. The potential sweep was carried out from 0.2 to $0.8 \mathrm{~V}$, at a scan rate of $200 \mathrm{~V} / \mathrm{s}$.

4.3.3. Test effects of nicotine on oxidative DNA damage and repair / Test effects of nicotine on 8-OHdG secretion

The concentration of nicotine in the plasma and saliva of smokers can reach up to 100 $\mathrm{ng} / \mathrm{mL}(0.0006 \mathrm{mM})$ and $4000 \mathrm{ng} / \mathrm{ml}(0.025 \mathrm{mM})$, respectively (Hukkanen et al., 2005; Schneider et al., 2001; Teneggi et al., 2002). In order to conduct our studies at a physiologically relevant range, we have tested lung epithelial cell exposure to 0.025 , $0.05,0.1,0.5,1,2,4,6$ and $8 \mathrm{mM}$ of pure nicotine dissolved in the saline cell bath buffer. In order to study the time release kinetics of $8-\mathrm{OHdG}$ secretion, single lung epithelial cells were monitored up to a period of 2 hours. Figure 4.9. shows the image of a healthy attached cell present in saline buffer solution, recorded two hours after the petri dish was 
placed on the microincubator. This image demonstrates that the lung epithelial cells are healthy for the entire duration of the electrochemical investigation.

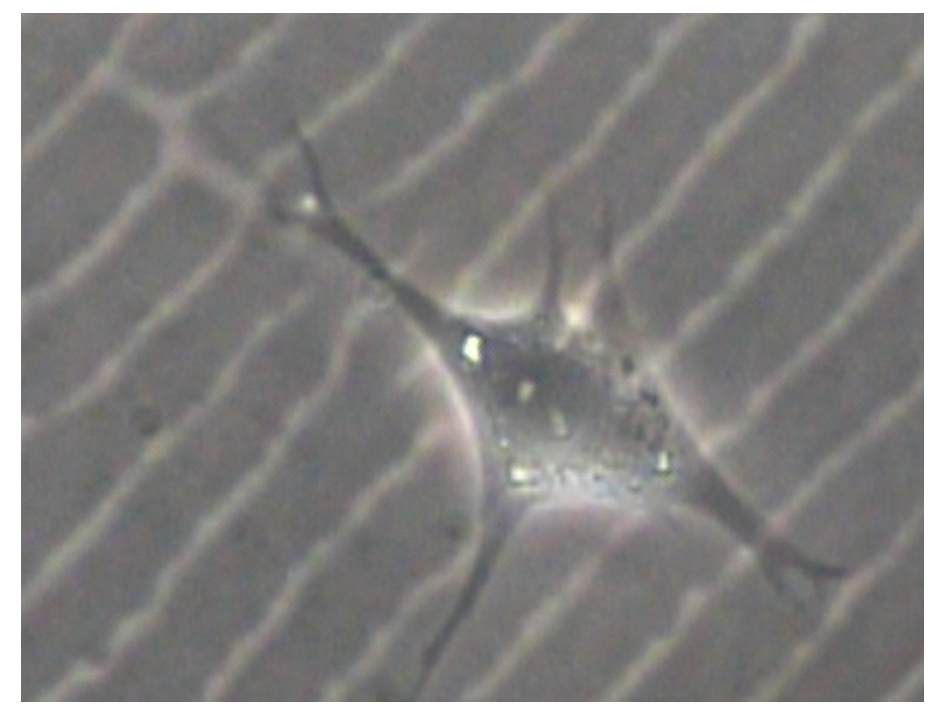

Figure 4.9. Image of single lung epithelial cell in saline buffer solution, recorded $2 \mathrm{~h}$ after the petri dish was placed on the microincubator.

\subsubsection{Concentration effects of nicotine}

Nicotine was dissolved in the saline buffer to obtain standard test solutions from 0.025 to $8 \mathrm{mM}$. Figure 4.10. shows the background subtracted CPA signal recorded at the surface of a single lung epithelial cell exposed to $4 \mathrm{mM}$ nicotine solution. Therefore, we confirmed that $8-\mathrm{OHdG}$ is released from a single cell under the influence of nicotine, after calcium ionophore stimulation. 


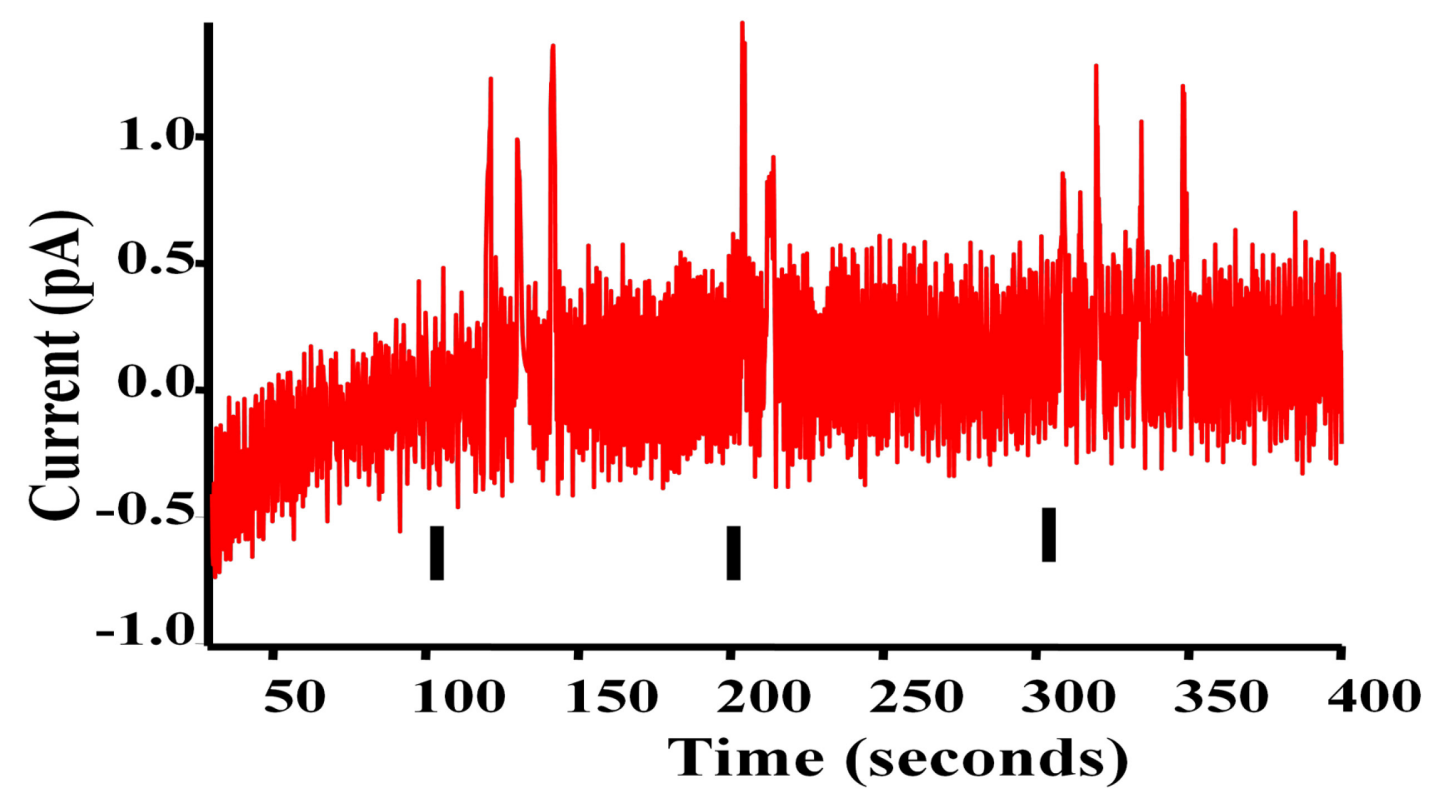

Figure 4.10. Current recordings made at a single lung endothelial cell in saline buffer with the electrode potential was held at $+0.42 \mathrm{~V}$. The bars indicate calcium ionophore injection via microcapillary placed 1 $\mathrm{cm}$ from cell surface.

Figure 4.11. shows results of average peak currents obtained from 3 individual cells subjected to each standard nicotine solution for a period of 1 hour. We did not observe any peaks greater than the background signal for exposure to nicotine solution of 0.025 , $0.05,0.1,0.5$, and $1 \mathrm{mM}$ of nicotine solutions. However $8-\mathrm{OHdG}$ secretion displayed a dose related response for nicotine exposures of 2, 4, 6 and $8 \mathrm{mM}$. Instantaneous cell detachment was observed for nicotine exposures over $9 \mathrm{mM}$, as shown in figure 4.12 . These results are in concordance with studies performed by Yildiz, to compare the formation of $8-\mathrm{OHdG}$ in Chinese Hamster Ovary cells due to nicotine and smokeless tobacco extract containing the same amounts of nicotine (Yildiz, 2004). 

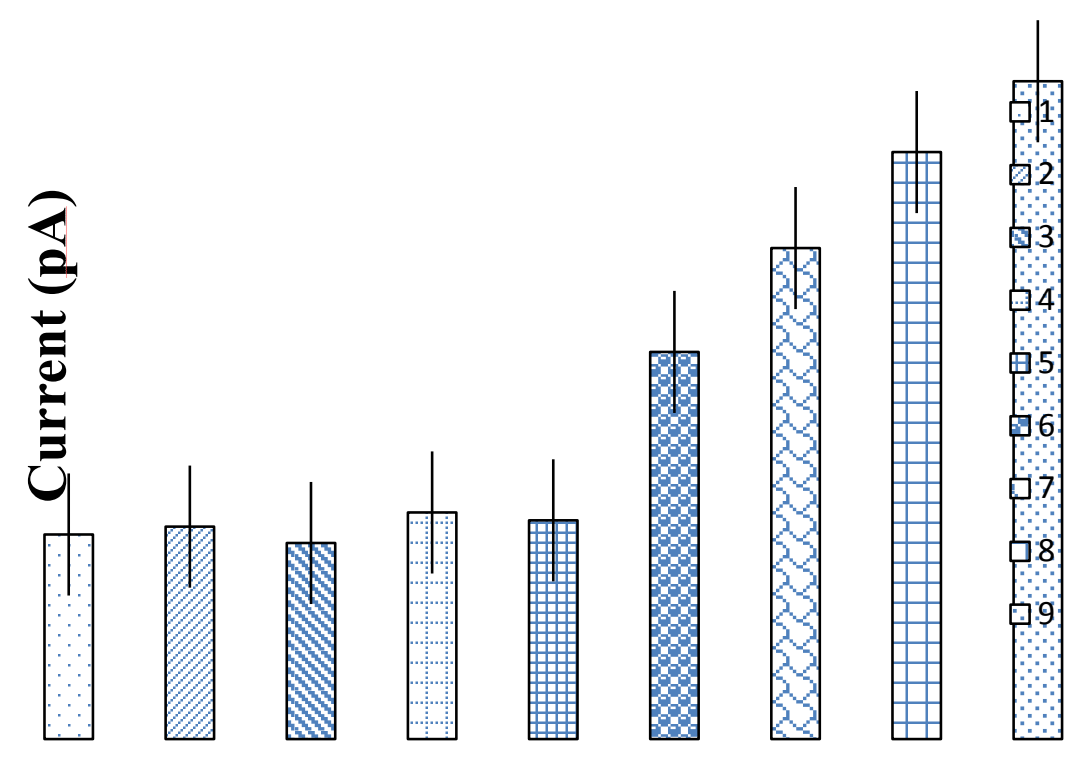

Figure 4.11. Average peak currents obtained from 3 individual isolated cells after $1 \mathrm{~h}$ of incubation with $0.025,0.05,0.1,0.5,1,2,4,6$, and $8 \mathrm{mM}$ nicotine solution respectively.

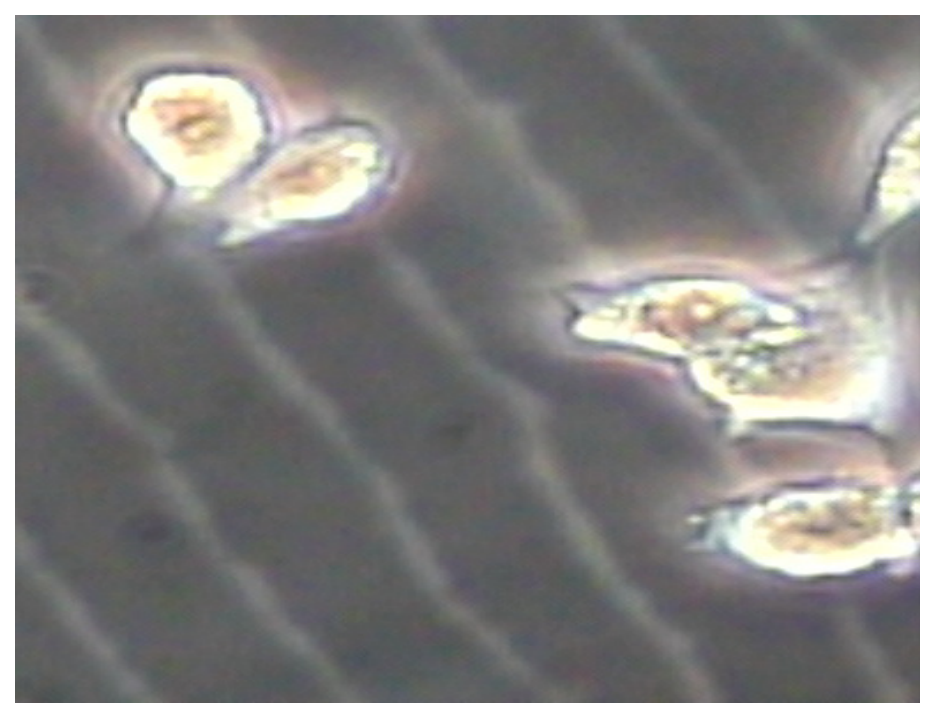

Figure 4.12. Image of detached and unhealthy lung epithelial cells, recorded after the addition of $9 \mathrm{mM}$ nicotine solution.

\subsubsection{Time effects of 8-OHdG nicotine induced measurements}

CPA was used to study the release kinetics of $8-\mathrm{OHdG}$ from single lung epithelial cells exposed to $4 \mathrm{mM}$ of nicotine, as shown in Fig. 4.13. A $4 \mathrm{mM}$ nicotine solution was 
selected to study the time release kinetics as this concentration of nicotine lies at the center of the damage causing range of 2 to $8 \mathrm{mM}$, as observed from our previous experiments. 20 individual isolated cells were studied under similar experimental conditions for a period of 2 hours. The same carbon fiber microelectrode was used to study each of the cells to eliminate any variability due to sensor response. The carbon fiber microelectrode was cleaned and pretreated before analyzing every cell. Calcium ionophore stimulation was given every 100 seconds. The first $8-\mathrm{OHdG}$ secretion peaks were observed at an average time period of $12.37 \pm 1.5$ minutes as shown in Fig. 4.13. The amount of 8-OHdG secreted thereafter escalated until it reached a plateau period between $47 \pm 2.3$ and $82 \pm 2.3$ minutes. Following the plateau, 8-OHdG secretion decreased and finally ceased after an average of $110 \pm 3.8$ minutes. The cessation of 8OHdG secretion can be related to the inhibition of DNA repair by the base excision repair pathway. DNA repair suppression has also been reported during exposure of cells to oxidants such as hydrogen peroxide (Hu et al., 1995; Li et al., 2000), formaldehyde (Grafstrom et al., 1983) and nicotine (Kozlovskis-Wade et al., 1998). 


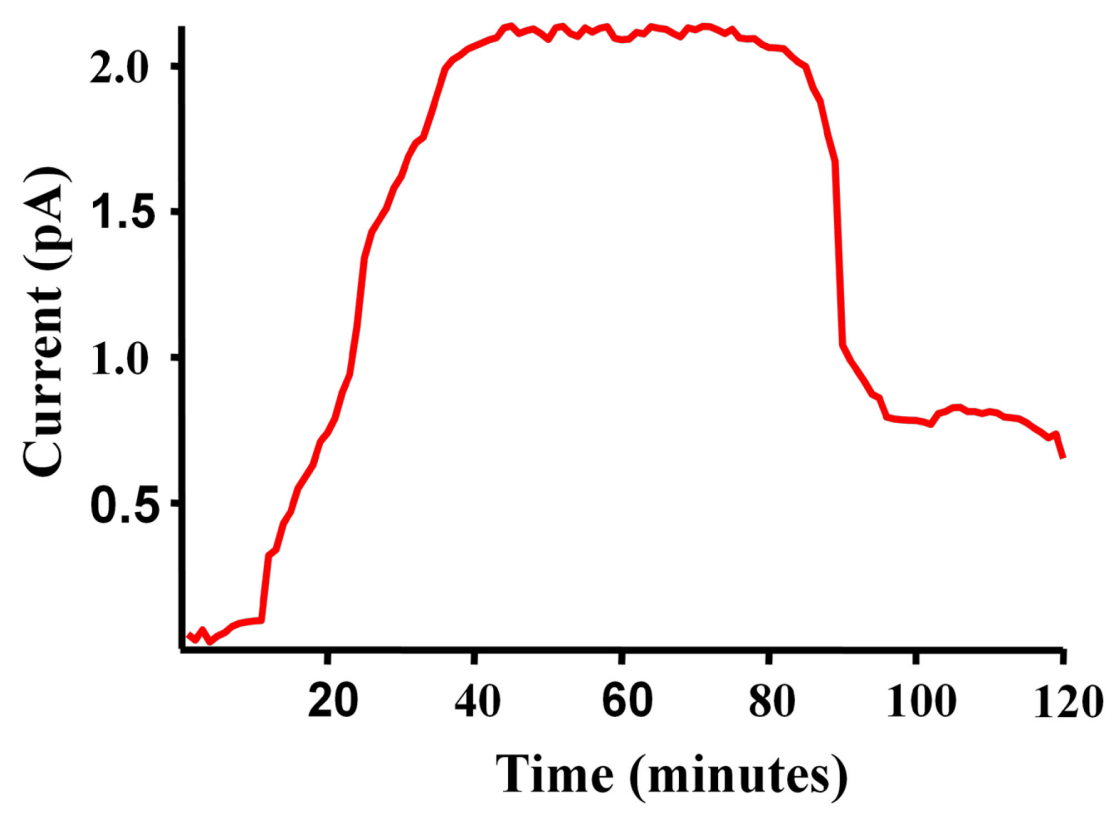

Figure 4.13. Average current recordings made at the surface of 20 single isolated lung epithelial cells with $4 \mathrm{mM}$ nicotine exposure for a period of $2 \mathrm{~h}$.

\subsection{Conclusions}

In this study, we have monitored the release kinetics of $8-\mathrm{OHdG}$ at the surface of a single lung epithelial cell using an activated carbon fiber microelectrode. To the best of our knowledge, this is the first report showing direct and continuous measurements of 8OHdG release at the surface of a single isolated cell. Activated carbon fiber microelectrodes exhibit excellent sensitivity towards 8 -OHdG, discerning currents as small as $1 \mathrm{pA}$. FSCV conducted to verify the release of 8-OHdG showed an oxidation peak at $0.42 \mathrm{~V}$. Lung epithelial cells were incubated with varying concentrations of nicotine in order to study its genotoxic effects. Nicotine showed a dose dependent increase in DNA damage which was mirrored in the amount of 8 -OHdG secreted. Studying the temporal release kinetics reveals cessation of 8-OHdG after 110 minutes of 
exposure to $4 \mathrm{mM}$ nicotine. We have outlined a highly sensitive strategy for the real time measurements of $8-\mathrm{OHdG}$ at a single cell level. It is hopeful that a similar strategy may be employed to detect 8-OHdG in-vivo. Multiple carbon fiber nanoelectrodes may also be used to determine spatial distribution of $8-\mathrm{OHdG}$ release from a single cell. 
Chapter 5

Conclusions and Future Work

5.1. Conclusions 
Electrochemical sensors developed to measure disease biomarkers allow us to diagnose and study diseases such as cancer and Alzheimer's. Electrochemical detection allows highly sensitive, real-time detection of biomarkers in solution and at the surface of single cells. Incorporation of antibodies to the sensor surface enhances sensitivity and imparts specificity. This thesis mainly deals with the development of direct, one-step microsensors towards measurement of disease biomakers.

Chapter 2 deals with the development of a direct reagentless immunosensor for the detection of VEGF. A highly sensitive, reagentless, electrochemical strategy is reported for the detection of a cancer biomarker VEGF. Disc shaped carbon fiber microelectrodes were used as the immunosensor platform. Ferrocene monocarboxylic acid labeled antiVEGF was covalently immobilized on the microelectrode surface using a Jeffamine cross-linker. The formation of immuno- complexes leads to a decrease in the electrochemical signal of ferrocene monocarboxylic acid owing to increased spatial blocking of microelectrode surface. These signal changes enable quantitative detection of VEGF in solution. Voltammetric measurements were conducted to evaluate the interfacial immunore- actions and to quantitatively detect VEGF biomarker. The proposed immunosensing strategy allows a rapid and sensitive means of VEGF analysis with a limit of detection of about $38 \mathrm{pg} / \mathrm{mL}$. This opens up the possibility of employing these electrodes for various single cell analysis and clinical applications. Further, experimental conditions such as concentration of the immobilized antibodies and incubation period were optimized. Following this, the stability and specificity of the immunosensors were also evaluated. 
Chapter 3 describes the development of a multiplex, direct immunosensor for the detection of $\mathrm{A} \beta$ isoforms which are key biomarkers related to $\mathrm{AD}$. $\mathrm{AD}$ affects about 35.6 million people worldwide, and if current trends continue with no medical advancement, 1 in 85 people will be affected by 2050 . Thus, there is an urgent need to develop a cost effective, easy to use, sensor platform to diagnose and study AD. The measurement of peptide $A \beta$ found in CSF has been assessed as an avenue to diagnose and study the disease. The quantification of the ratio of $A \beta 1-40 / 42$ (or $A \beta$ ratio) has been established as a reliable test to diagnose $\mathrm{AD}$ through human clinical trials. Therefore we have developed a multiplexed, implantable immunosensor to detect $A \beta$ isoforms using triple barrel carbon fiber microelectrodes as the sensor platform. Antibodies act as the biorecognition element of the sensor and selectively capture and bind $A \beta 1-40$ and $A \beta 1-42$ to the electrode surface. Electrochemistry was used to measure the intrinsic oxidation signal of $\mathrm{A} \beta$ at $0.65 \mathrm{~V}(\mathrm{vs} \mathrm{Ag} / \mathrm{AgCl})$, originating from a single Tyr residue found at position $10 \mathrm{in}$ its amino acid sequence. Using the proposed immunosensor $A \beta 1-40$ and $A \beta 1-42$ could be specifically detected in CSF from mice within a detection range of $100 \mathrm{nM}$ to $1.2 \mu \mathrm{M}$ and $400 \mathrm{nM}$ to $1 \mu \mathrm{M}$ respectively. The immunosensor enables real-time, highly sensitive detection of $\mathrm{A} \beta$ and opens up the possibilities for diagnostic ex-vivo applications and research-based in-vivo studies.

Chapter 4 involves the mesurement of DNA damage biomarker 8-OHdG at the surface of single cells under the influence of ROS. 8-OHdG is the most important and bestdocumented biomarker of oxidative stress, which is involved in the instigation of various diseases. 8-OHdG levels correlate to oxidative DNA damage which is known to be the root cause of a variety of age-related chronic diseases. The purpose of our research was to 
develop a detection strategy capable of measuring $8-\mathrm{OHdG}$ in real-time at the surface of a single cell. Activated carbon fiber microelectrodes were used as the sensing platform. The microelectrodes were used to measure 8 -OHdG release from single lung epithelial cells under the influence of nicotine. In order to evaluate the direct role of nicotine in tobacco induced genotoxicity, we studied the influence of parameters such as nicotine concentration and exposure times on $8-\mathrm{OHdG}$ secretion. $2-8 \mathrm{mM}$ nicotine solutions induced dose-dependent DNA damage in single cells, which was observed via amperometric measurements of secreted 8-OHdG biomarker. Real-time 8-OHdG measure- ments from single cells exposed to $4 \mathrm{mM}$ nicotine solution revealed cessation of 8 -OHdG secretion after $110 \mathrm{~min}$. We have successfully outlined a methodology to detect $8-\mathrm{OHdG}$ at the surface of single cells. A similar protocol can be used to evaluate oxidative DNA damage and repair mechanisms in other disease models.

\subsection{Future Work}

The multiplex sensor developed for the detection $A \beta$ isoforms will be further tested invivo using amyloid precursor protein transgenic mice. The triple barell sensors will further used to study the effects of drug candidates on $A \beta$ production or clearance.

Electrochemical measurements of $8-\mathrm{OHdG}$ at the surface of single cells will be using chip based microfluidic sensors. Micro-wells capable of capturing a single cell and containing a gold/carbon electrode at the base of the well will be fabricated. 8-OHdG measurements will be performed under the effects of anti-oxidants and pro-oxidants. 


\section{REFERENCES}

Akram, M., Stuart, M. C. \& Wong, D. K. (2006) Signal Generation at an Electrochemical Immunosensor via the Direct Oxidation of an Electroactive Label. ElectroanalysisWeinheim, 18, 237.

Albillos, A., Dernick, G., Horstmann, H., Almers, W., Alvarez De Toledo, G. \& Lindau, M. (1997) The exocytotic event in chromaffin cells revealed by patch amperometry. Nature-London, 509-511.

Alwarappan, S., Liu, G., Li, C. Z. (2010) Simultaneous detection of dopamine, ascorbic acid, and uric acid at electrochemically pretreated carbon nanotube biosensors. Nanomedicine, 6, 52-57.

Alwarappan, S., Prabhulkar, S., Durygin, A., Li, C. Z. (2009) The effect of electrochemical pretreatment on the sensing performance of single walled carbon nanotubes. Journal of Nanoscience Nanotechnology, 9, 2991-2996.

Aly, M., Wiklund, F., Grönberg, H. (2011) Early detection of prostate cancer with emphasis on genetic markers. Acta Oncologica 50,18-23.

Andreasen, N., Hesse, C., Davidsson, P., Minthon, L., Wallin, A., Winblad, B., Vanderstichele, H., Vanmechelen, E., Blennow, K. (1999) Cerebrospinal fluid \{beta\}amyloid (1-42) in Alzheimer disease: differences between early-and late-onset Alzheimer disease and stability during the course of disease. Archives of Neurology, 56, 673-680.

Armstrong-James, M., Millar, J. (1979) Carbon fibre microelectrodes. Journal of Neuroscience Methods, 1, 279-287.

Armstrong, F. A. (1990) Probing metalloproteins by voltammetry. Structure and Bonding, 72, 137-230.

Ates, M., Castillo, J., Sezai Sarac, A. \& Schuhmann, W. (2008) Carbon fiber microelectrodes electrocoated with polycarbazole and poly (carbazole-co-p-tolylsulfonyl pyrrole) films for the detection of dopamine in presence of ascorbic acid. Microchimica Acta, 160, 247-251. 
Bibl, M., Mollenhauer, B., Lewczuk, P., Esselmann, H., Wolf, S., Trenkwalder, C., Otto, M., Stiens, G., Ruther, E., Kornhuber, J., Wiltfang, J. (2007) Validation of amyloid-[beta] peptides in CSF diagnosis of neurodegenerative dementias. Molecular Psychiatry, 12, 671-680.

Blennow, K. (2004) Cerebrospinal fluid protein biomarkers for Alzheimer's disease. NeuroRx, 1, 213-225.

Boffetta, P., Aagnes, B., Weiderpass, E., Andersen, A. (2005) Smokeless tobacco use and risk of cancer of the pancreas and other organs. International Journal of Cancer, 114, 992995.

Brabec, V., Schindlerova, I. (1981) Electrochemical behaviour of proteins at graphite electrodes Part III. The effect of protein adsorption. Bioelectrochemistry and Bioenergetics, 8, 451-458.

Brett, A. M. O., Piedade, J. A. P., Serrano, S. H. P. (2000) Electrochemical Oxidation of 8-Oxoguanine. Electroanalysis. 12, 969-973.

Campain, J. A. (2004) Nicotine: Potentially a multifunctional carcinogen? Toxicological Science, 79, 1-3.

Cao, T., Wang, A., Liang, X., Tang, H., Auner, G. W., Salley, S. O. \& Ng, K. Y. (2007) Investigation of spacer length effect on immobilized Escherichia coli pili-antibody molecular recognition by AFM. Biotechnology and Bioengineering, 98, 1109.

Cheng, K.C., Cahill, D.S., Kasai, H., Nishimura, S., Loeb, L.A. (1992) 8Hydroxyguanine, an abundant form of oxidative DNA damage, causes $\mathrm{G} \rightarrow \mathrm{T}$ and $\mathrm{A} \rightarrow$ C substitutions. Journal of Biological Chemistry, 267, 166-172.

Chikae, M,. Fukuda, T., Kerman, K., Idegami, K., Miura, Y., Tamiya, E. (2008) Amyloid-[beta] detection with saccharide immobilized gold nanoparticle on carbon electrode. Bioelectrochemistry, 74, 118-123. 
Chiou, C. C., Chang, P. Y., Chan, E. C., Wu, T. L., Tsao, K. C., Wu, J. T. (2003) Urinary 8-hydroxydeoxyguanosine and its analogs as DNA marker of oxidative stress: development of an ELISA and measurement in both bladder and prostate cancers. Clinica Chimica Acta, 334, 87-94.

Cirrito, J.R., Kang, J.E., Lee, J., Stewart, F.R., Verges, D.K., Silverio, L.M, Bu, G., Mennerick, S., Holtzman, D.M. (2008) Endocytosis Is Required for Synaptic ActivityDependent Release of Amyloid-[beta] In Vivo. Neuron, 58, 42-51.

Cirrito, J.R., Yamada, K.A., Finn, M.B., Sloviter, R.S., Bales, K.R., May, P.C., Schoepp, D.D., Paul, S.M., Mennerick, S., Holtzman, D.M. (2005) Synaptic activity regulates interstitial fluid amyloid-[beta] levels in vivo. Neuron, 48, 913-922.

Cooke, M. S., Evans, M. D., Dizdaroglu, M., Lunec, J., (2003) Urinary 8hydroxydeoxyguanosine and its analogs as DNA marker of oxidative stress: Development of an ELISA and measurement in both bladder and prostate cancers. The FASEB Journal, 17, 1195-1214.

D'Agostino, G., Alberti, G., Biesuz, R., Pesavento, M. (2006) Potentiometric sensor for atrazine based on a molecular imprinted membrane. Biosensors and Bioelectronics, 22, $152-154$.

Das, P. M., Singal, R. (2004) DNA Methylation and Cancer. Journal of Clinical Oncology, 22, 4632-4642.

De Martinis, B.S., de Lourdes Pires Bianchi M. (2002) Methodology for urinary 8hydroxy-2'-deoxyguanosine analysis by HPLC with electrochemical detection. Pharmacological Research, 46, 129-131.

Doolittle, D. J., Winegar, R., Lee, C. K., Caldwell, W. S., Hayes, A. W., de Bethizy, J. D. (1995) The genotoxic potential of nicotine and its major metabolites. Mutatation Research, 344, 95-102. 
Dörner, T., Kinnman, N., Tak, P. P. (2010) Targeting B cells in immune-mediated inflammatory disease: a comprehensive review of mechanisms of action and identification of biomarkers. Pharmacology and Therapeutics, 125, 464-475.

Ercole, C., Gallo, M. D., Pantalone, M., Santucci, S., Mosiello, L., Laconi, C., Lepidi, A. A. (2002) A biosensor for Escherichia coli based on a potentiometric alternating biosensing (PAB) transducer. Sensors and Actuators B Chem, 83, 48-52.

Ferger, B., Spratt, C., Earl, C. D., Teismann, P., Oertel, W. H., Kuschinsky, K. (1998) Effects of nicotine on hydroxyl free radical formation in vitro and on MPTP-induced neurotoxicity in vivo. Naunyn-Schmiedeberg's Arch. Pharmacol. 358, 351-359.

Ferrara, N. \& Davis-Smyth, T. (1997) The Biology of Vascular Endothelial Growth Factor. Endocrine Reviews, 18, 4-25.

Floyd, R. A., Watson, J. J., Wong, P. K., Altmiller, D. H., Rickard, R. C. (1986) Hydroxyl free radical adduct of deoxyguanosine: sensitive detection and mechanisms of formation. Free Radical Research, 1, 163-172.

Fraga, C. G., Shigenaga, M. K., Park, J. W., Degan, P., Ames, B. N. (1990) Oxidative damage to DNA during aging: 8-Hydroxy-2'-deoxyguanosine in rat organ DNA and urine. Proceedings of National Academy of Science. U. S. A. 87, 4533-4537.

Frederix, F., Bonroy, K., Reekmans, G., Laureyn, W., Campitelli, A., Abramov, M.A., Dehaen, W., Maes, G. (2004) Reduced nonspecific adsorption on covalently immobilized protein surfaces using poly (ethylene oxide) containing blocking agents. Journal of Biochemical Biophysical Methods. 58, 67-74.

Goyal, R. N., Jain, N., Garg, D. K. (1997) Electrochemical and enzymic oxidation of guanosine and 8-hydroxyguanosine and the effects of oxidation products in mice. Bioelectrochemistry and Bioenergetics. 43, 105-114.

Grafstrom, R. C., Fornace Jr, A. J., Autrup, H., Lechner, J. F., Harris, C. C. (1983) Formaldehyde damage to DNA and inhibition of DNA repair in human bronchial cells. Science. 220, 216-218. 
Halliwell, B. (1998) Can oxidative DNA damage be used as a biomarker of cancer risk in humans? Problems, resolutions and preliminary results from nutritional supplementation studies. Free Radical Research. 29, 469-486.

Halliwell, B., Aruoma, O.I. (1991) DNA damage by oxygen-derived species. Its mechanism and measurement in mammalian systems. FEBS Letters. 281, 9-19.

Hampel, H., Frank, R., Broich, K., Teipel, S.J., Katz, R.G., Hardy, J., Herholz, K., Bokde, A.L.W., Jessen, F., Hoessler, Y.C. (2010) Biomarkers for Alzheimer's disease: academic, industry and regulatory perspectives. Nature Reviews Drug Discovery, 7, 560574.

Hardy, J.A., Higgins, G.A. (1992) Alzheimer's disease: The amyloid cascade hypothesis. Science, 256, 184-185.

Hartmann, A., Pfuhler, S., Dennog, C., Germadnik, D., Pilger, A., Speit, G. (1998) Exercise-induced DNA effects in human leukocytes are not accompanied by increased formation of 8-hydroxy-2'-deoxyguanosine or induction of micronuclei. Free Radical Biology and Medicine, 24, 245-251.

Hebert, L.E., Scherr, P.A., Bienias, J.L., Bennett, D.A., Evans, D.A. (2003) Alzheimer disease in the US population. Archives of Neurology, 60, 1119-1122.

Heien, M., Johnson, M. A., Wightman, R. M. (2004) Resolving neurotransmitters detected by fast-scan cyclic voltammetry. Analytical Chemistry, 76, 5697-5704.

Hollstein, M., Sidransky, D., Vogelstein, B., Harris, C. C. (1991) p53 Mutations in human cancers. Science, 253, 49-53.

Horvatovich, P.L., Bischoff, R. (2010) Current technological challenges in biomarker discovery and validation. European Journal of Mass Spectrometry, 16, 101-121.

Hu, J. J., Dubin, N., Kurland, D., Ma, B. L., Roush, G. C. (1995) The effects of hydrogen peroxide on DNA repair activities. Mutation Research/DNA Repair, 336, 193-201. 
Huang, L., Kennedy, R. T. (1995) Exploring single-cell dynamics using chemicallymodified microelectrodes. Trends in Analytical Chemistry, 14, 158-164.

Huffman, M.L., Venton, B.J. (2008) Carbon-fiber microelectrodes for in vivo applications. Analyst, 134, 18-24.

Hukkanen, J., Jacob, P., Benowitz, N.L. (2005) Metabolism and disposition kinetics of nicotine. Pharmacology Reviews, 57, 79-115.

Ihara, T., Maruo, Y., Takenaka, S., Takagi, M. (1996) Ferrocene-oligonucleotide conjugates for electrochemical probing of DNA. Nucleic Acids Research, 24, 4273-4280.

Jackson, A. L., Loeb, L. A., (2001). The contribution of endogenous sources of DNA damage to the multiple mutations in cancer. Mutatation Research, 477, 7-21.

Kakiuchi, T., Usui, H., Hobara, D., Yamamoto, M. (2002) Voltammetric properties of the reductive desorption of alkanethiol self-assembled monolayers from a metal surface. Langmuir, 18, 5231-5238.

Kanvah, S., Schuster, G. B. (2006) Oxidative damage to DNA: Inhibition of guanine damage. Pure and Applied Chemistry, 78, 2297-2304.

Karakus, E., Erden, P. E., Pekyardimci, S., Kilic, E. (2006) Determination of creatine in commercial creatine powder with new potentiometric and amperometric biosensors. Artificial Cells, Blood Substitutes and Immobilization Biotechnology, 34, 337-347.

Karayiannakis, A., Syrigos, K., Polychronidis, A., Zbar, A., Kouraklis, G., Simopoulos, C., Karatzas, G. (2002) Circulating VEGF levels in serum of gastric cancer patients. Annals of Surgery, 236, 37-42.

Kasai, H. (1997) Analysis of a form of oxidative DNA damage, 8-hydroxy-2'deoxyguanosine, as a marker of cellular oxidative stress during carcinogenesis. Mutation Research, 387, 147-163. 
Kasai, H., Hayami, H., Yamaizumi, Z., Saitô, H., Nishimura, S. (1984) Detection and identification of mutagens and carcinogens as their adducts with guanosine derivatives. Nucleic Acids Research. 12, 2127-2136.

Kasai, H., Iwamoto-Tanaka, N., Miyamoto, T., Kawanami, K., Kawanami, S., Kido, R., Ikeda, M. (2005) Life Style and Urinary 8-Hydroxydeoxyguanosine, a Marker of Oxidative DNA Damage: Effects of Exercise, Working Conditions, Meat Intake, Body Mass Index, and Smoking. Cancer Science, 92, 9-15.

Kauffmann, J. M., Guilbault, G. G. (1991) Potentiometric enzyme electrodes. Bioprocess Technology, 15, 63-82.

Kerman, K., Nagatani, N., Chikae, M., Yuhi, T., Takamura, Y., Tamiya, E. (2006) Labelfree electrochemical immunoassay for the detection of human chorionic gonadotropin hormone. Analytical Chemistry, 78, 5612-5616.

Kerman, K., Vestergaard, M., Chikae, M., Yamamura, S., Tamiya, E. (2007) Label-free electrochemical detection of the phosphorylated and non-phosphorylated forms of peptides based on tyrosine oxidation. Electrochemical communications, 9, 976-980.

Kinoshita, K. (1988) Carbon: electrochemical and physicochemical properties. John Wiley \& Sons, Inc., New York, 13, 533.

Kitade, T., Kitamura, K., Konishi, T., Takegami, S., Okuno, T., Ishikawa, M., Wakabavashi, M., Nishikawa, K., Muramatsu, Y. (2004) Potentiometric immunosenor using artificial antibody based on molecularly imprinted polymers. Analytical Chemistry, $76,6802-6807$.

Kloor, M., von Knebel Doeberitz, M., Gebert, J. F. (2005) Molecular testing for microsatellite instability and its value in tumor characterization. Expert Reviews in Molecular Diagnostics, 5, 599-611.

Korpan, Y. I., Raushel, F. M., Nazarenko, E. A., Soldatkin, A. P., Jaffrezic-Renault, N., Martelet, C. (2006) Sensitivity and specificity improvement of an ion sensitive field effect transistors-based biosensor for potato glycoalkaloids detection. Journal of Agriculture and Food Chemistry, 54, 707-712. 
Kozlovskis-Wade, P. L., Smets, M. J. D., Myerburg, R. J. (1998) The effect of nicotine on DNA repair in adult myocytes. Journal of Molecular and Cellular Cardiology, 30, 1483-1491.

Kranz, A., Mattfeldt, T. \& Waltenberger, J. (1999) Molecular mediators of tumor angiogenesis: enhanced expression and activation of vascular endothelial growth factor receptor $k d r$ in primary breast cancer. Cancer (Pred. Oncol.), 84, 293-298.

Kurebayashi, J., Otsuki, T., Kunisue, H., Mikami, Y., Tanaka, K., Yamamoto, S. \& Sonoo, H. (1999) Expression of Vascular Endothelial Growth Factor (VEGF) Family Members in Breast Cancer. Cancer Science, 90, 977-981.

Kwon, S. J., Kim, E., Yang, H. \& Kwak, J. (2006) An electrochemical immunosensor using ferrocenyl-tethered dendrimer. The Analyst, 131, 402-406.

Langmaier, J., Samec, Z., Samcová E., (2003). Electrochemical Oxidation of 8-Oxo-2'Deoxyguanosine on Glassy Carbon, Gold, Platinum and Tin(IV) Oxide Electrodes. Electroanalysis. 15, 1555-1560.

Leland, C. Clark Jr, C. L. (1962) Electrode Systems For Continuous Monitoring In Cardiovascular Surgery. Annals of the New York Academy of Sciences, 102, 29-45.

Leszczyszyn, D. J., Jankowski, J. A., Viveros, O. H., Diliberto, E. J., Near, J.A., Wightman R. M. (1990) Nicotinic receptor-mediated catecholamine secretion from individual chromaffin cells. Journal Biological Chemistry, 265, 14736-14737.

Li, C.-Z., Alwarappan, S., Zhang, W., Scafa, N., Zhang, X. (2009) Metallo Protoporphyrin Functionalized Microelectrodes for Electrocatalytic Sensing of Nitric Oxide. American Journal of Biomedical Sciences, 3, 274-282.

Li, C.-Z., Nishiyama, K., Taniguchi I. (2000) Metallo Protoporphyrin Functionalized Microelectrodes for Electrocatalytic Sensing of Nitric Oxide. Electrochimica Acta, 45, 2883-2888. 
Li, T. H., Jia, W. L., Wang, H. S., Liu, R. M., (2007). Electrochemical and spectroelectrochemical studies on cobalt myoglobin. Biosensors and Bioelectronics, 22, 1245-1250.

Lim, T. K., Matsunaga, T. (2001) Construction of electrochemical flow immunoassay system using capillary columns and ferrocene conjugated immunoglobulin $G$ for detection of human chorionic gonadotrophin. Biosensors and Bioelectronics, 16, 10631069.

Maeda, K., Chung, Y. S., Ogawa, Y., Takatsuka, S., Kang, S. M., Ogawa, M., Sawada, T. \& Sowa, M. (1996) Prognostic value of vascular endothelial growth factor expression in gastric carcinoma. Cancer, 77, 858-863.

Marnett, L. J. (2000) Oxyradicals and DNA damage. Carcinogenesis, 21, 361-370.

Martin, K. R., Barrett, J. C. (2002) Reactive oxygen species as double-edged swords in cellular processes: Low-dose cell signaling versus high-dose toxicity. Human and Experimental Toxicology, 21, 71-75.

Marzouk, S. A., Ashraf, S. S., Tayyari, K. A. (2007) Prototype amperometric biosensor for sialic acid determination. Analytical Chemistry, 79, 1668-1674.

McShane, L. M., Altman, D. G., Sauerbrei, W., Taube, S. E., Gion, M., Clark, G. M. (2005) REporting recommendations for tumor MARKer prognostic studies (REMARK). Natural Clinical Practice Urology, 2, 416-422.

Okochi, M., Ohta, H., Tanaka, T., Matsunaga, T. (2005) Electrochemical probe for onchip type flow immunoassay: Immunoglobulin $\mathrm{G}$ labeled with ferrocenecarboaldehyde. Biotechnology and Bioengineering, 90, 14-19.

Moran, M. F., Tong, J., Taylor, P., Ewing, R. M. (2006) Emerging applications for phospho-proteomics in cancer molecular therapeutics. Biochimica et Biophysica Acta, 1766, 230-241.

Murphy, M.P., LeVine, H. (2010) Alzheimer's Disease and the Amyloid-Beta Peptide. Journal of Alzheimers Disease, 19, 311-323. 
Nakao, M., Kawauchi, S., Uchiyama, T., Adachi, J., Ito, H., Chochi, Y., Furuya, T., Oga, A., Sasaki, K. (2011) DNA copy number aberrations associated with the clinicopathological features of colorectal cancers: Identification of genomic biomarkers by array-based comparative genomic hybridization. Oncology Reports, 6, 1603-1611.

Nakayama, M., Ihara, T., Nakano, K. \& Maeda, M. (2002) DNA sensors using a ferrocene-oligonucleotide conjugate. Talanta, 56, 857-866.

Newman, J. D., Setford, S. J. (2006) Enzymatic biosensors. Molecular Biotechnology, 32, 249-268.

Ohnuki, H., Saiki, T., Kusakari, A., Endo, H., Ichihara, M., Izumi, M. (2007) Incorporation of glucose oxidase into languir-blodgett films based on prussian blue applied to amperometric glucose biosensor. Langmuir, 23, 4675-4681.

Okuno, J., Maehashi, K., Kerman, K., Takamura, Y., Matsumoto, K., Tamiya, E. (2007) Label-free immunosensor for prostate-specific antigen based on single-walled carbon nanotube array-modified microelectrodes. Biosensors and Bioelectronics, 22, 2377-2381.

Okuno, J., Maehashi, K., Kerman, K., Takamura, Y., Matsumoto, K., Tamiya, E. (2007) Label-free immunosensor for prostate-specific antigen based on single-walled carbon nanotube array-modified microelectrodes. Biosensors and Bioelectronics, 22, 2377-2381.

Pacia, S. V., Doyle, W. K., Broderick, P. A. (2001) Biogenic amines in the human neocortex in patients with neocortical and mesial temporal lobe epilepsy: identification with in situ microvoltammetry. Brain research, 899, 106-111.

Padeste, C., Grubelnik, A. \& Tiefenauer, L. (2000) Ferrocene-avidin conjugates for bioelectrochemical applications. Biosensors and Bioelectronics, 15, 431-438.

Pantano, P., Kuhr, W.G. (1991) Characterization of the chemical architecture of carbonfiber microelectrodes. 1. Carboxylates. Analytical Chemistry, 63, 1413-1418. 
Pantano, P., Morton, T. H. \& Kuhr, W. G. (1991) Enzyme-modified carbon-fiber microelectrodes with millisecond response times. Journal of the American Chemical Society, 113, 1832-1833.

Ponchon, J. L., Cespuglio R., Gonon, F., Jouvet, M., Pujol J. F. (1979) Normal pulse polarography with carbon fiber electrodes for in vitro and in vivo determination of catecholamines. Analytical chemistry, 51, 1483-1486.

Ponchon, J. L., Cespuglio, R., Gonon, F., Jouvet, M., Pujol, J. F. (1979). Normal pulse polarography with carbon fiber electrodes for in vitro and in vivo determination of catecholamines. Analytical Chemistry, 51, 1483-1486.

Prabhulkar, S., Li, C.Z. (2010) Assessment of oxidative DNA damage and repair at single cellular level via real-time monitoring of $8-\mathrm{OHdG}$ biomarker. Biosensors and Bioelectronics, 26, 1743-1749.

Prabhulkar, S., Alwarappan, S., Liu, G., Li, C. Z., (2009). Amperometric microimmunosensor for the detection of tumor biomarker. Biosensors and Bioelectronics, 24, 3524-3530.

Privett, B. J., Shin, J. H. \& Schoenfisch, M. H. (2008) Electrochemical Sensors. Analytical Chemistry, 80, 4499-4517.

Qu, B., Chu, X., Shen, G. \& Yu, R. (2008) A novel electrochemical immunosensor based on colabeled silica nanoparticles for determination of total prostate specific antigen in human serum. Talanta, 76, 785-790.

Qureshi, A., Kang, W. P., Davidson, J. L., Gurbuz, Y. (2009) Review on carbon-derived, solid-state, micro and nano sensors for electrochemical sensing applications. Diamond \& Related Materials, 8, 1401-1420.

Reynaud, J. A., Malfoy, B. \& Bere, A. (1980) The electrochemical oxidation of three proteins: RNAase A, bovine serum albumin and concanavalin A at solid electrodes. Journal of Electroanalytical Chemistry, 116, 595-606. 
Rossner, P., Rossnerova, A., Sram, R. J. (2011) Oxidative stress and chromosomal aberrations in an environmentally exposed population. Mutation Research, 707, 34-41.

Ruohola, J. K., Valve, E. M., Karkkainen, M. J., Joukov, V., Alitalo, K. \& Härkönen, P. L. (1999) Vascular endothelial growth factors are differentially regulated by steroid hormones and antiestrogens in breast cancer cells. Molecular and Cellular Endocrinology, $149,29-40$.

Sayre, L. M., Smith, M. A., Perry, G., (2001). Chemistry and biochemistry of oxidative stress in neurodegenerative disease. Current Medicinal Chemistry, 8, 721-738.

Schneider, N.G., Olmstaed, R.E., Franzon, M.A., Lunell, E. (2001) The nicotine inhaler clinical pharmacokinetics and comparison with other nicotine treatments. Clinical Pharmacokinetics, 40, 661-684.

Schulte, A., Schuhmann W. (2007) Single-cell microelectrochemistry. Angewandte Chemie-International Edition In English, 46, 8760.

Sharma, A., Rogers, K. R. (1994) Biosensors. Measurement Science and Technology, 5, 461.

Shigenaga, M.K., Gimeno, C.J., Ames, B.N. (1989) Urinary 8-hydroxy-2'deoxyguanosine as a biological marker of in vivo oxidative DNA damage. Proceedings of Natural Academy of Science. U. S. A., 86, 9697-9701.

Sidló, Z., Reggio, P. H., Rice, M. E. (2008) Inhibition of striatal dopamine release by $\mathrm{CB} 1$ receptor activation requires nonsynaptic communication involving GABA, H2O2, and KATP channels. Neurochemistry International, 52, 80-88.

Spencer, J. P. E., Jenner, A., Chimel, K., Aruoma, O. I., Cross, C. E., Wu, R., Halliwell, B., (1995). DNA strand breakage and base modification induced by hydrogen peroxide treatment of human respiratory tract epithelial cells. FEBS letters 374, 233-236. 
Strein, T. G. \& Ewing, A. G. (1992) Characterization of submicron-sized carbon electrodes insulated with a phenol-allylphenol copolymer. Analytical Chemistry, 64, 1368-1373.

Sunde, R.A. (2010) mRNA transcripts as molecular biomarkers in medicine and nutrition. The Journal of Nutritional Biochemistry, 21, 665-670.

Tampellini, D., Gouras, G.K. (2010) Synapses, Synaptic Activity and Intraneuronal A in Alzheimer's Disease. Front Aging Neuroscience, 2, 13.

Tanaka, T., Tsukube, S., Izawa, K., Okochi, M., Lim, T. K., Watanabe, S., Harada, M. \& Matsunaga, T. (2007) Electrochemical detection of HbA1c, a maker for diabetes, using a flow immunoassay system. Biosensors and Bioelectronics, 22, 2051-2056.

Taniguchi,I., Li, C.-Z., Ishida, M., Yao, Q. (1999) Electrochemical and spectroelectrochemical properties of manganese reconstituted myoglobin. J. Electroanalytical Chemistry, 460, 245-250.

Tansil, N. C., Xie, F., Xie, H., Zhiqiang, G. (2005) An ultrasensitive nucleic acid biosensor based on the catalytic oxidation of guanine by a novel redox threading intercalator. Chemical Communications, 8, 1064-1066.

Teixeira, A. J. R., Gommersampt, J. H., Vandewerken, G., Westra, J. G., Stavenuiter, J. F. C., Dejong, A. (1993) Method for the analysis of oxidized nucleosides by gas chromatography/mass spectrometry. Analytical Biochemistry, 214, 474-483.

Teneggi, V., Squassante, L., Iavarone, L., Milleri, S., Bye, A., Gomeni, R. (2002) Correlation and predictive performances of saliva and plasma nicotine concentration on tobacco withdrawal-induced craving. British Journal of Clinical Pharmacology. 54, 407414.

Timur, S., Telefoncu, A. (2004) Acetylcholinesterase (AChE) electrodes based on gelatin and chitosan matrices for the pesticide detection. Artificial Cells, Blood Substitutes and Immobilization Biotechnology, 32, 427-442. 
Toi, M., Hoshina, S., Takayanagi, T., Tominaga, T. (1994) Association of Vascular Endothelial Growth Factor Expression with Tumor Angiogenesis and with Early Relapse in Primary Breast Cancer. Cancer Science, 85, 1045-1049.

Tosoian. J, Loeb, S. (2010) PSA and beyond: the past, present, and future of investigative biomarkers for prostate cancer. Scientific World Journal, 10, 1919-1931.

Toyokuni, S., Tanaka, T., Hattori, Y., Nishiyama, Y., Yoshida, A., Uchida, K., Hiai, H., Ochi, H., Osawa, T., (1997). Quantitative immunohistochemical determination of 8hydroxy-2'- deoxyguanosine by a monoclonal antibody N45.1: Its application to ferric nitrilotriacetate-induced renal carcinogenesis model. Laboratory Investigation, 76, 365374.

Trivedi, A. H., Dave, B. J., Adhvaryu, S. G. (1990) Assessment of genotoxicity of nicotine employing in vitro mammalian test system. Cancer Letters, 54, 89-94.

Troyer, K. P., Heien, M., Venton J. M., Wightman, R. M. (2002) Neurochemistry and electroanalytical probes. Current opinion in chemical biology, 6, 696-703.

Vestergaard M, Kerman K, Saito M, Nagatani N, Takamura Y, Tamiya E (2005) A rapid label-free electrochemical detection and kinetic study of Alzheimer's amyloid beta aggregation. Journal of American Chemical Society, 127, 11892-11893.

Wan, C., Liu, T., Wei, S., Zhang, S. (2008) Electrochemical determination of 8hydroxydeoxyguanosine using a carbon nanotube modified electrode. Russian Journal of Electrochemistry, 44, 327-331.

Wang, S., Wu, Z., Qu, F., Zhang, S., Shen, G., Yu, R. (2008) A novel electrochemical immunosensor based on ordered Au nano-prickle clusters. Biosensors and Bioelectronics.

Wei, F., Patel, P., Liao, W., Chaudhry, K., Zhang, L., Arellano-Garcia, M., Hu, S., Elashoff, D., Zhou, H., Shukla, S. (2009) Electrochemical sensor for multiplex biomarkers detection. Clinical Cancer Research, 15, 4446-4452. 
Wetscher, G. J., Bagchi, D., Perdikis, G., Bagchi, M., Redmond, E. J., Hinder, P. R., Glaser, K., Hinder, R. A. (1995) In vitro free radical production in rat esophageal mucosa induced by nicotine. Digestive Disease and Sciences, 40, 853-858.

Wetscher, G. J., Bagchi, M., Bagchi, D., Perdikis, G., Hinder, P. R., Glaser, K., Hinder, R. A. (1995) Free radical production in nicotine treated pancreatic tissue. Free Radical Biology and Medicine, 18, 877-882.

Wightman, R. M., Jankowski, J. A., Kennedy, R. T., Kawagoe, K. T., Schroeder, T. J., Leszczyszyn, D. J., Near, J. A., Diliberto, E. J., Viveros, O. H. (1991) Temporally resolved catecholamine spikes correspond to single vesicle release from individual chromaffin cells. Proceedings of the National Academy of Sciences, 88, 10754-10758.

Wu, H. J., Chi, C. W., Liu, T. Y., (2005). Effects of pH on nicotine-induced DNA damage and oxidative stress. Journal of Toxicology and Environmental Health A. 68, 1511-1523.

Wu, J., Yan, F., Zhang, X., Yan, Y., Tang, J. \& Ju, H. (2008) Disposable Reagentless Electrochemical Immunosensor Array Based on a Biopolymer/Sol-Gel Membrane for Simultaneous Measurement of Several Tumor Markers. Clinical Chemistry. 54:14811488.

Wu, L. L., Chiou, C. C., Chang, P. Y., Wu, J. T. (2004) Urinary 8-OHdG: A marker of oxidative stress to DNA and a risk factor for cancer, atherosclerosis and diabetics. Clinical Chimica Acta, 339, 1-9.

Wyss-Coray, T., Loike, J.D., Brionne, T.C., Lu, E., Anankov, R., Yan, F., Silverstein, S.C., Husemann, J. (2003) Adult mouse astrocytes degrade amyloid- in vitro and in situ. Nature Medicine, 9, 453-457.

Yildiz, D., (2004) Comparison of pure nicotine and smokeless tobacco extract induced formation of 8-OH-dG. Toxicology Mechanisms and Methods, 14, 253-256.

Yoshinobu, T., Iwasaki, H., Ui, Y., Furuichi, K., Ermolenko, Y., Mourzina, Y., Wagner, T., Nather, N., Schoning, M. J. (2005) The light-addressable potentiometric sensor for multi-ion sensing and imaging. Methods, 37, 94-102. 
Yuqing, M., Jianquo, G., Jianrong, C. (2003) Ion sensitive field effect transducer-based biosensors. Biotechnology Advances, 21, 527-534.

Yuqing, M., Jianrong, C., Keming, F. (2005) New technology for the detection of $\mathrm{pH}$. Journal of Biochemistry and Biophysics Methods, 63, 1-9.

Zhai, Y., Yu, J., Iruela-Arispe, L., Huang, W. Q., Wang, Z., Hayes, A. J., Lu, J., Jiang, G., Rojas, L. \& Lippman, M. E. (1999) Inhibition of angiogenesis and breast cancer xenograft tumor growth by vegi, a novel cytokine of the tnf superfamily. International Journal of Cancer, 82, 131-136.

Zhang S, Yang J, Lin J (2008) 3, 3'-diaminobenzidine (DAB)-H2O2-HRP voltammetric enzyme-linked immunoassay for the detection of carcionembryonic antigen. Bioelectrochemistry 72, 47-52.

Zhang, H., Xu, J.-J. \& Chen, H.-Y. (2007) Electrochemically Deposited 2D Nanowalls of Calcium Phosphate-PDDA on a Glassy Carbon Electrode and Their Applications in Biosensing. The Journal of Physical Chemistry C, 111, 16564-16570.

Zhang, S., Zheng, F., Wu, Z., Shen, G. \& Yu, R. (2008) Highly sensitive electrochemical detection of immunospecies based on combination of Fc label and PPD film/gold nanoparticle amplification. Biosensors and Bioelectronics, 24, 129-135.

Zhang, X., Ogorevc, B., Rupnik, M., Kreft, M. \& Zorec, R. (1999) Cathophoresis paint insulated carbon fibre ultramicro disc electrode and its application to in vivo amperometric monitoring of quantal secretion from single rat melanotrophs. Analytica Chimica Acta, 378, 135-143.

Zhang, Y., Newcomb, P. A., Egan, K. M., Titus-Ernstoff, L., Chanock, S., Welch, R., Brinton, L. A., Lissowska J., Bardin-Mikolajczak, A., Peplonska, B. (2006) Genetic polymorphisms in base-excision repair pathway genes and risk of breast cancer. Cancer Epidemiology, Biomarkers and Prevention, 15, 353-358. 


\section{SHRADHA PRABHULKAR}

Bachelor of Engineering, Biomedical, 2002-2006, University of Mumbai, India

Ph.D. Candidate, Biomedical Engineering, 2006-present (GPA 3.78/4.00) Florida International University, Miami, FL (Expected Graduation: August 2011)

\section{PUBLICATIONS AND PRESENTATIONS}

1. Alwarappan, S., Prabhulkar, S., Durygin, A., Li, C-Z., The Effect of Electrochemical Pretreatment on the Sensing Performance of Single Walled Carbon Nanotubes, Journal of Nanoscience and Nanotechnology, 9,5, 2991-2996, (2009).

2. Li, C-Z., Liu, G., Prabhulkar, S., Comparison of Kinetics of Hemoglobin Electron Transfer in Solution and Immobilized on Electrode Surface, American Journal of Biomedical Sciences, 1, 4, $303-311$, (2009).

3. Li, C-Z.; Vandenberg, K.; Prabhulkar, S.; Medina, D.; Schneper, L.; Methee, K.; Almeide, E. "Paper Based Point-of-Care Testing Disc for Multiplex Whole Cell Bacteria Detection". Biosensors and Bioelectronics, (2011), article in press, http://dx.doi.org/10.1016/j.bios.2011.04.035.

4. Prabhulkar, S.; Piatyszek, R.; Cirrito, J.; Li, C-Z. "Electrochemical Sensor for Multiplex detection of Amyloid Beta 40 and 42 for Alzheimer's Disease Diagnostics" Journal of Neuroscience, In Preparation.

5. Prabhulkar, S.; Tian, H.; Li, C-Z. "Engineered Proteins: Redox properties and their applications". Antioxidants and redox signaling, Under Revision, Invited comprehensive review.

6. Prabhulkar, S., Li, C-Z., Assessment of oxidative DNA damage and repair at single cellular level via real-time monitoring of 8-OHdG biomarker, Biosensors and Bioelectronics, 26, 4, 1743-1749, (2010).

7. Prabhulkar, S., Alwarappan, S., Liu, G., Li, C-Z., Amperometric microimmunosensor for the detection of tumor biomarker, Biosensors and Bioelectronics, 24, 12, 3524-3530, (2009).

8. Prabhulkar, S., Alwarapan, S., Naja, G.M., Li, C-Z., Electrochemical Immunosensor for the Direct, Reagentless Detection of Tumor Biomarkers, IFMBE Proceedings: Springer, 195-197, (2009). 
9. Prabhulkar, S., Li, C-Z., Electrical Immuno Nanosensor for Breast Cancer Biomarker Assay, iCBBE (International Conference on Bioinformatics and Biomedical Engineering), IEEE Xplore, (2009).

10. Prabhulkar, S., Alwarappan, S., Li, C-Z., Needle-like implantable nanosensors for the detection of tumor biomarkers, Biomedical Engineering Recent Developments (2008). ISBN: 978-1-930636-06-4. 